Heterogeneity in an RBC Model with Durable Goods and Energy

\author{
Philip Bergmann
}




\title{
Heterogeneity in an RBC Model with Durable Goods and Energy
}

Philip Bergmann*

Bielefeld University

\begin{abstract}
This paper investigates the effects of total factor productivity and energy price shocks in a real business cycle (RBC) model with heterogeneous agents. It extends standard RBC models by including the distinction between durable goods and non-durable goods but also including energy in production of non-durable goods. Furthermore, we combine two sources of heterogeneity using idiosyncratic shocks in labor supply and limited asset market participation by a fixed proportion of agents. We study to what degree the empirically observed inequality in income and wealth can be explained by the provided framework. The model can predict the evolution of inequality in income and wealth, unlike traditional homogeneous macroeconomic models with a representative agent. We show that the distinction between nondurable and durable goods leads to a significant improvement in predicting most of the moments close to the one in observational data from Germany. Furthermore, we find that energy price shocks lead to decreasing inequalities, with respect to both income and wealth. In a brief policy analysis, we give an outlook about the effects of redistribution of income between classes of agents.
\end{abstract}

JEL Codes: D52, E32, Q43

*Department of Business Administration and Economics, Bielefeld University, Universitätstrasse 25, 33615 Bielefeld, Germany; e-mail: pbergmann@uni-bielefeld.de 


\section{Introduction}

This paper investigates the effects of total factor productivity and energy price shocks in a real business cycle (RBC) model with heterogeneous agents. It extends the model by Dhawan \& Jeske (2008), including the distinction between durable goods and nondurable goods, by an incomplete market similar to Preston \& Roca (2007). Furthermore, in our model a fixed proportion of agents has limited asset market participation as in Gali et al. (2003). As a result, this model can predict the evolution of inequality in income and wealth, unlike traditional homogeneous macroeconomic models with a representative agent.

Basic dynamic general equilibrium models with a single consumption good produced by a production sector predict a consumption volatility that is significantly lower than the one in observational data. Dhawan \& Jeske (2008) have extended the RBC model by I.-M. Kim \& Loungani (1992) which includes energy, with the opportunity to gain utility from the consumption of accumulated durable goods. Although energy has smaller effects on output fluctuations compared to I.-M. Kim \& Loungani, enlarging the flexibility to re-balance an agent's portfolio improves the prediction of consumption volatility. By impacting consumption of durable goods and improving the prediction of consumption volatility significantly, the factor energy shows that it is not negligible in analyzing economic activities. Huynh (2016) goes beyond this by endogenizing the production process of durable goods and energy, bringing energy volatility closer to its empirical target values. Representative for other, but similar, homogeneous frameworks, both models ignore the existence of heterogeneity in human beings and their decision making. As a result, they are neither able to describe how inequality arises nor how it affects economic activity. However, such explanations become important, in particular when considering the role of government intervention to effectively correct market imperfections.

In this paper, we provide a theoretical framework to demonstrate the consequences of agents' heterogeneous labor supply and limited market participation. The framework explicitly models the consumption of durable and non-durable goods. Just as in Dhawan \& Jeske (2008), we assume complementarity between energy and the usage of durable goods (in the utility function) and capital (in the goods production function). We use explicit aggregation as done by Den Haan \& Rendahl (2010) in order to solve the crosssection capital distribution among Ricardian households and, consequently, the policy function for capital on the macro level of the model.

The aim of this work is to investigate the transmission mechanisms and characteristics of total-factor productivity (TFP) and energy price shocks, but also of external shocks of heterogeneity though labor supply. Moreover, we study to what degree the empirically observed inequality in income and wealth can be explained by the provided framework. Therefore, we calibrate the model to match the German economy. Furthermore, we con- 
sider not only how policy intervention through redistribution affects individuals' income and wealth, but also the inequality on the macro level of the economy.

We show that the distinction between non-durable and durable goods leads to a significant improvement in predicting most of the moments close to the one in observational data from Germany. Here, energy price shocks have a contractionary effect on economic activity, as they cause disruptions in particular in durable goods, as is similarly shown in Dhawan \& Jeske (2008). Nevertheless, TFP is still the driving force of output volatility. The provided framework is able to match income inequality indices quite well, whereas inequality of wealth remains underestimated. This is justified given that we assume homogeneity in individuals' productivity as well as the exogenous process of labor supply. Furthermore, we find that energy price shocks lead to decreasing inequalities, with respect to both income and wealth. This happens due to the complementary relationship between durable goods and energy and sunk costs, which arise along with adjustments in the durable goods stock. We conclude that it is not the low-income agent who benefits from volatility in energy prices, but the high-income agent who looses in income and wealth due to higher absolute sunk costs.

Policy intervention in the form of redistribution of income decreases income inequality on the macro level, between both classes of agents, and within the class of rule-of-thumb agents, but leads to a slight increase among Ricardian agents. For wealth inequality, we notice a slight increase in overall inequality. This is due to decreasing saving rates, which widen the gap between savers. Accordingly, we conclude that policy instruments have to be evaluated carefully in order to successfully combat inequality.

The remainder of this paper is structured as follows: After a brief discussion of several sources of heterogeneity in Section 2, Section 3 describes the model economy. Section 4 specifies the market equilibrium and examines theoretical literature in order to solve the aggregate capital stock. Section 5 presents the calibrated and estimated parameters. Section 6 presents the results of the model. In Sections 7 and 8, we conduct accuracy checks and a sensitivity analysis. Section 9 discusses the policy implication of redistribution through income taxation. Section 10 concludes.

\section{Theoretical Literature on Inequality}

Many traditional neoclassical economic models often assume an economy populated by a representative consumer who operates in a perfectly competitive good, factor, and asset market. Aggregated shocks, e.g. in TFP, can cause uncertainty in the market, which affects the behavior of consumers in maximizing their utility. Even in models in which heterogeneous agents face idiosyncratic shocks, such as in labor supply or income, the assumption of a representative household can hold through aggregation of heterogeneous agents, when complete markets are present (e.g. in standard Arrow-Debreu economies). 
The reason is that idiosyncratic risk can fully be diversified away (e.g. by borrowing and saving) and hence become irrelevant for equilibrium outcomes. The market is selfregulating and volatility in aggregate economic activity in an efficient response to shocks (Christiano et al., 2018), while government interference is inefficient and worsen the state of the economy. However, when agents cannot fully insure against idiosyncratic risk, e.g. due to incomplete capital markets, inequality in the evolution of wealth occurs. Incomplete capital markets may for example exist when there is a borrowing constraint, preventing agents from holding debt, so that they cannot borrow against their future earnings. When markets fail, government intervention can be efficient for correcting market failures.

To understand how inequality occurs and evolves in macroeconomic models, we briefly focus on several sources of heterogeneity and how they are mapped in economic models. For an extended discussion of approaches on modeling heterogeneity, we refer to Heathcote et al. (2009) and Guvenen (2011). It is common to distinguish between fundamental inequality or inequality of opportunity and inequality of outcome, when analyzing inequality in general. The latter is usually the result of the former, economically often resulting in inequality in income, wealth, consumption, utility, or leisure time. While individual utility is the ultimate object of interest, this is difficult to measure and quantify. Therefore, attraction is mostly turned to the remaining variables that play an intermediate role, particularly income and wealth.

Fundamental inequality describes the heterogeneous nature of individuals such as health, education, social status, gender, preference or age. When considering these types of inequality from the economic modeling perspective, fundamental inequality influences the model selection, the formation of assumption about the model, and its ingredients such as variables or functions. The model just acts as an intermediate transmission system. Consequently, a model without fundamental inequality cannot explain inequality on the output side. There are several sources of heterogeneity that cause fundamental inequality within a society. In the following, we look at three of them: namely, capabilities, external shocks, and preferences.

The assumption of different capabilities among human beings has a significant impact on inequality. In traditional models including homogeneous agents, individuals do not differ in their decision making. However, in real life this homogeneity is not very likely, because human beings differ in their behavior or their individual skills and abilities. This has an influence on their levels of productivity, and hence also on earnings, which in turn impacts income and wealth. In models that include education, agents can increase their productivity by choosing different amounts of schooling. However, that decision depends on several factors, such as the ability to learn, the starting level of human capital, access to educational institutions, or simply the choice of studying or entering the labor market (e.g. Huggett et al., 2011). 
A further variation in capability comes from the restricted access to further key institutions, such as financial markets. Under "limited asset market participation", there is a distinction between two classes of agents: Ricardian agents who have free access to the capital market, and rule-of-thumb agents who are excluded from this market. Economically, this means that the latter cannot insure against income disruption to smooth their consumption. Other models describe heterogeneity in capability by including choice of occupation, in which an individual decides about becoming an entrepreneur or a worker because of its individual risk aversion (e.g. Lucas Jr, 1978; Kanbur, 1979; Clemens, 2006).

Considering heterogeneity in external shocks has become popular with standard incomplete market models (SIM), also called Bewley models (Bewley, 1976). In the SIM approach, individuals are identical ex-ante but differ ex-post due to idiosyncratic shocks which are uninsurable. These shocks are unexpected or unpredictable events and follow a stochastic process. In contrast to aggregate shocks in traditional RBC models, which generally affect the entire economy including several sectors, these idiosyncratic shocks affect households individually. Initial models incorporate uninsurable idiosyncratic earning shocks (e.g. Imrohoroğlu, 1989; Huggett, 1993; Aiyagari, 1994) which translate into inequality of income and wealth through different saving decisions. Storesletten et al. (2004) and Shimer (2010) model heterogeneity in the labor market by including idiosyncratic shocks in labor supply to replicate job fluctuation. Next to a job loss, further idiosyncratic shocks can affect health and family (e.g. Hubbard et al., 1995; Greenwood \& Guner, 2008). An individual's health status can become dramatically worse through a sudden disease. The family composition can change through marriage, divorce, the birth of a child, or death. Although these types of heterogeneity can involve some decision making and can be modeled endogenously, they also incorporate an exogenous component (risk).

Heterogeneity in preferences is closely connected to heterogeneity in capabilities, as various abilities, such as learning abilities and human capital, might subsequently influence individual behavior. Many models assume that once set, preferences remain constant throughout the entire lifetime. Alternatively, in models that feature discrete groups of agents, such as overlapping generation models, different preferences can be assigned to different stages of life (e.g. Persson \& Tabellini, 1994; Benabou, 2000). Furthermore, preferences may vary at the individual level after introducing a statistical distribution over parameters such as time preference, risk aversion, or elasticity of substitution.

In this paper, we combine two sources of heterogeneity. We first introduce heterogeneity by using idiosyncratic shocks in labor supply that allow for income fluctuation among all agents and result in an incomplete market model. However, this type of model would not allow for dichotomy in the access to selected institutions. Consequently, households at the extreme ends of income and wealth distribution would not yet be different in any 
relevant way. Moreover, taxation policy would become complicated, as there would be no groups that can individually be taxed progressively, as is evident from real-life observations. Therefore, we also introduce limited asset market participation, by excluding a fixed proportion of agents from the capital market. We acknowledge that this may violate the permanent income hypothesis by Friedman (2018), stating that agents save in anticipation of possible future declines. However, the violation would only be partial, thanks to the presence of a further (durable) consumption goods that can be accumulated over time.

\section{Model}

The model consists of two sectors: a household sector and a sector with goods-producing firms. Moreover, the model is characterized by incomplete markets, aggregate uncertainty, as well as an infinite number of agents. The specific structure of heterogeneity comes from the household sector which faces a partly uninsurable idiosyncratic labor supply and hence labor shocks similar to Aiyagari (1994). Since employers cannot discriminate between agents by assumption, a shock on the demand side would not affect agents individually, but aggregately. As a result, the introduction of idiosyncratic shocks on the supply side allows introducing heterogeneity among agents.

In addition, we distinguish between two types of households which differ by their access to the capital market. Ricardian households can intertemporally allocate capital while rule-of-thumb households are excluded from this activity. ${ }^{1}$ Besides that, both classes do not differ; hence, they face the same elasticities of substitution in the utility function, the same time discount rate, and the same depreciation rate for durable goods.

As a result, we combine two approaches of inequality described before, namely 'incomplete market models' and 'limited asset market participation models'. By this, we create inequality within and between different groups which offers possibilities to model inequality more realistically. The infinity-lived households, indexed by $i$, are defined over an interval $i \in[0,1]$ while Ricardian and rule-of-thumb households account for $[0, \lambda]$ and $(\lambda, 1]$ respectively. For a better differentiation, households are further indexed with their respective type, namely, Ricardian households $\{R\}$ and rule-of-thumb households $\{N\}$. Figure A.1 in the Appendix depicts a graphical description of the model. Hereafter, the model is described in more detail.

\footnotetext{
${ }^{1}$ In fact, rule-of-thumb households can use durable goods to slightly intertemporally smooth consumption. However, using the durable goods stock is not as efficient as using the capital stock, due to additional adjustment costs, and hence it can be described as partly-illiquid wealth. Therefore, these household are considered as a light version of non-Ricardian households as we elaborate later.
} 


\subsection{Ricardian households}

In the model, all households maximize their utility by choosing the optimal demand for consumption goods and energy given the budget constraints. Households can consume three type of goods: non-durable goods $C N$ which are provided by the goods production sector, durable goods $C D$ in which agents can invest and which is accumulated over time, and energy $E_{\mathrm{H}}$ which is provided exogenously. ${ }^{2}$ The utility function is assumed to have constant elasticity of substitution (CES) between durable goods and energy which are nested within a Cobb-Douglas function with non-durable goods. ${ }^{3}$ Furthermore, it includes a separate additive penalty function to fulfill the transversality condition which otherwise might be violated due to occasionally-binding inequality constraints. Ricardian households consider the following utility function:

$$
\begin{array}{r}
U_{R, i, t}=\ln \left[C N_{R, i, t}^{\gamma}\left(\theta C D_{R, i, t-1}^{\zeta}+(1-\theta)\left(E_{\mathrm{H}}\right)_{R, i, t}^{\zeta}\right)^{\frac{1-\gamma}{\zeta}}\right]-\phi P\left(S_{R, i, t}\right) \\
\text { where } \quad P\left(S_{R, i, t}\right)=\frac{1}{\left(S_{R, i, t}+b\right)^{2}} \quad \text { with } S_{R, i, t} \geq b
\end{array}
$$

where $\theta \in(0,1)$ determines the consumption share of the durable goods. Furthermore, to fulfill a complementary relationship between durable goods and energy, the inverse of the elasticity of substitution $\zeta<0$ must hold while the substitutionary relationship between this consumption bundle and non-durable goods imply $\gamma \in(0,1) . \phi>0$ is a penalty parameter.

The asset market is incomplete because of having a heterogeneous agent model with idiosyncratic shocks. Hence, employment risks are only partially insurable and the budget constraint includes occasionally-binding inequality. By adding the penalty function (2) to agent's utility, this allows us to deal with the problem of non-negative constraints by formulating the optimization problem as an unconstrained one. Here, we take the penalty specification suggested by Preston \& Roca (2007). ${ }^{4}$ The idea is that any amount of consumption and asset holding is feasible but the objective function faces undesired outcome when the constraint is violated. When individual asset holding $S_{i, t}$ approaches the borrowing limit $b$, the penalty function approaches infinity. For small $\phi$, the borrowing constraint becomes similar to $S_{i, t}+b \geq 0$ as in Aiyagari (1994). $b \geq 0$ describes the natural borrowing limit which avoids Ponzi-schemes.

\footnotetext{
${ }^{2}$ Hereafter, we omit the time index when describing variables.

${ }^{3}$ The elasticity of substitution between durable and non-durable goods is often set close to unity in empirical literature (e.g. Ogaki \& Reinhart, 1998).

${ }^{4}$ For further penalty approaches, see Den Haan \& Ocaktan (2009).
} 
Lemma 1. Strict concavity of utility

The partial derivatives for the utility function $U_{R}$ are:

$$
\begin{gathered}
U_{C N}^{\prime}>0, U_{C D}^{\prime}>0, U_{E_{\mathrm{H}}}^{\prime}>0, U_{S_{R}}^{\prime}>0 \\
U_{C N C N}^{\prime \prime}<0, U_{C D C D}^{\prime \prime}<0, U_{E_{\mathrm{H}} E_{\mathrm{H}}}^{\prime \prime}<0, U_{S_{R}, S_{R}}^{\prime \prime}<0 \\
U_{C N C D}^{\prime \prime}=U_{C D C N}^{\prime \prime}>0, U_{C D E_{\mathrm{H}}}^{\prime \prime}=U_{E_{\mathrm{H} C D} C 0, U_{C N E_{\mathrm{H}}}^{\prime \prime}=U_{E_{\mathrm{H}} C N}^{\prime \prime}>0 .}
\end{gathered}
$$

Utility function $U_{t}$ is overall strictly concave in $C N, C D, E_{\mathrm{H}}$ iff all the following conditions hold:

$$
\begin{gathered}
\phi>0 \\
0<\gamma<1 \\
\zeta, \theta<1 .
\end{gathered}
$$

Proof: Analogously to H.1.1 in Bergmann (2018).

According to Lemma 1, a rise in consumption of all three consumption goods increases utility but with a diminishing rate. The complementary relationship between durable goods and energy implies the expenses for a certain amount of energy which is require to consume the accumulated durable goods. Hence, energy can be considered to be consumed to enhance the consumption of durable goods in a non-perfect substitutable manner. Alternatively, the presence of energy is required to consume durable goods. Overall concavity of utility function $U$ is guaranteed if Proposition 1 holds.

The maximization problem of Ricardian households is restricted by the budget constraint below.

$$
C N_{R, i, t}+\left(p_{\mathrm{H}}\right)_{t}\left(E_{\mathrm{H}}\right)_{R, i, t}+\left(I_{C D}\right)_{R, i, t}+\left(I_{\mathrm{Y}}\right)_{R, i, t}=w_{t} L_{R, i, t}+r_{t} S_{R, i, t-1}+\pi_{t}
$$

According to that, Ricardian households gain wage income $w_{t}$ from the supply of labor and capital rents $r_{t}$ from their accumulated savings. ${ }^{5}$ On the expenditure side are non-durable consumption goods and energy as well as investments in the capital stock and durable goods described by the following equations:

$$
\left(I_{\mathrm{Y}}\right)_{R, i, t}=S_{R, i, t}-\left(1-\delta^{Y}\right) S_{R, i, t-1}
$$

\footnotetext{
${ }^{5}$ Under the assumption of perfect competition in the goods market, goods-producing firms gain zero profits, hence $\pi=0$.
} 


$$
\begin{aligned}
\left(I_{C D}\right)_{R, i, t}= & C D_{R, i, t}-\left(1-\delta^{C D}\right) C D_{R, i, t-1}+I C\left(C D_{R, i, t}, C D_{R, i, t-1}\right) \\
& \text { where } \quad I C\left(C D_{R, i, t}, C D_{R, i, t-1}\right)=\frac{\omega_{1 c d}}{1+\omega_{2 c d}}\left(\frac{C D_{R, i, t}-C D_{R, i, t-1}}{C D_{R, i, t-1}}\right)^{1+\omega_{2 c d}}
\end{aligned}
$$

Both investments are each diminished by a fixed depreciation rate while durable goods investments also contain adjustment costs $(I C){ }^{6}$ These costs are assumed to be quadratic in nature, hence, investment in durable goods goes along with an increasing and convex cost of net investment. In other words, the costs of adjusting investments increase proportionally faster than the amount of durable goods which is adjusted. On the one side, adjustment costs help to lower the correlation between investments and economic activity (Hayashi, 1982). On the other side, it captures the fact that building up or changing durable goods is costly and takes time. So, it avoids excessive changes in investments in the short run. In the long run, households do not face much of adjustment cost when they keep investments infinity small. As a result, households will respond by adjusting their investment decision continuously and smoothly.

In this model, labor supply is determined exogenously by an idiosyncratic component following an autoregressive process proposed by Preston \& Roca (2007). This is in contrast to Dhawan \& Jeske (2008) and Bergmann (2018) who assume labor to be endogenously determined. Hence, individual agents cannot choose the amount of work they are likely to provide. Because the supply of labor is set exogenously, it does not depend on the wage rate. This might describe a situation where an employee is demanded to work short-time or over-time which is not compensated. The stochastic autoregressive term for individual $i$ follows:

$$
L_{R, i, t}=\left(1-\rho_{L}\right) \bar{L}_{R}+\rho_{L} L_{R, i, t-1}+\varepsilon_{L, R, i, t}
$$

comprising the steady state $\bar{L}$, adjustment coefficient $\rho_{L}$, labor opportunity of the previous period, and a normally distributed variable $\varepsilon_{L, R, i} \stackrel{\text { iid }}{\sim} N\left(0, \sigma_{L, R}^{2}\right)$ describing a bounded i.i.d. disturbance. This shock is not insurable and hence, it leads to a variation in the income of the individuals, which has an impact on consumption. However, by accumulating primary capital but also durable goods, the effect of disturbances can be mitigated. Under the assumption of $\rho_{L}<1$, (6) describing labor supply is stationary distributed.

Opposite to traditional neoclassical models with homogeneous agents, the heterogeneous structure of the model allows us to examine the evolution of inequality of outcomes such as income or wealth. As explained before, Ricardian households can gain income

\footnotetext{
${ }^{6} \mathrm{By}$ reason of the cross-sectional distribution of capital and the way to deal with it through approximate aggregation, we do not consider adjustment costs along with investments in the capital stock which holds the model simple.
} 
from labor and capital supply. The (net-)income equation corresponds to the income approach of an agent's budget constraint (3) after depreciation and is described by:

$$
I N C_{R, i, t}=w_{t} L_{R, i, t}+r_{t} S_{R, i, t-1}+r_{t} S_{R, i, t-1}+\pi_{t}
$$

Agent's wealth consists of income in the current period, equal to equation 13 and the stock of accumulated assets. A further share of wealth is the stock of accumulated durable goods, in contrast to Gali et al. (2003); H. Kim et al. (2005); Preston \& Roca (2007); Den Haan \& Ocaktan (2009). Both net-portfolios (after depreciation) increase wealth which is denoted by:

$$
W L T H_{R, i, t}=w_{t} L_{R, i, t}+r_{t} S_{R, i, t-1}+\left(1-\delta^{Y}\right) S_{R, i, t-1}+\left(1-\delta^{C D}\right) C D_{R, i, t-1}+\pi_{t} .
$$

\subsection{Rule-of-thumb households}

Rule-of-thumb households share the same utility function like Ricardian households by maximizing their consumption of non-durable goods, durable goods, and energy, denoted by the following equation:

$$
U_{N, i, t}=\ln \left[C N_{N, i, t}^{\gamma}\left(\theta C D_{N, i, t-1}^{\zeta}+(1-\theta)\left(E_{\mathrm{H}}\right)_{N, i, t}^{\zeta}\right)^{\frac{1-\gamma}{\zeta}}\right]
$$

The definitions and properties of all parameters comply with those from (1). Consequently, overall strict concavity is satisfied as in Lemma 1. Theoretically, the utility function also includes the penalty function (2) as described before. However, because rule-of-thumb agents are excluded from the financial asset market, their asset holding is zero. Hence, they are not affected by it. The maximization problem is confronted with the budget constraint:

$$
C N_{N, i, t}+\left(p_{\mathrm{H}}\right)_{t}\left(E_{\mathrm{H}}\right)_{N, i, t}+\left(I_{C D}\right)_{R, i, t}=w_{t} L_{N, i, t}
$$

where rule-of-thumb households solely gain income from their labor supply. They are barred from any access to the capital market and hence the possibility of intertemporal substitution. However, in contrast to Krusell \& Smith (1998); Gali et al. (2003); Den Haan \& Ocaktan (2009); Troch (2014), the possibility to invest in durable goods yields in an opportunity to smooth their consumption behavior according to

$$
\begin{aligned}
\left(I_{C D}\right)_{N, i, t}= & C D_{N, i, t}-\left(1-\delta^{C D}\right) C D_{N, i, t-1}+I C\left(C D_{N, i, t}, C D_{N, i, t-1}\right) \\
& \text { where } \quad I C\left(C D_{N, i, t}, C D_{N, i, t-1}\right)=\frac{\omega_{1 c d}}{1+\omega_{2 c d}}\left(\frac{C D_{N, i, t}-C D_{N, i, t-1}}{C D_{N, i, t-1}}\right)^{1+\omega_{2 c d}}
\end{aligned}
$$


Concerning rule-of-thumb agents, adjustment costs in durable investments also fulfill a further role. By construction, these households can use the durable goods stock to intertemporally smooth consumption despite the exclusion from the financial asset market. This is not only natural and legitimate but also reflects conditions from reality. However, in this theoretical framework, the lack of access to the capital market will cause excess volatility in durable goods investments. Hence, additional costs makes it less efficient to use this investment possibility. ${ }^{7}$ In addition, because rule-of-thumb agents can accumulated durable goods over time, this also means that they are not equal to non-Ricardian agents which by definition consume their current disposable income and are not able to smooth consumption. As a result, rule-of-thumb agents are assumed to be a light version of non-Ricardian agents because their smoothing capability is clearly limited, having no access to the asset market and facing adjustment costs when using the durable goods stock.

There is a further difference between Ricardian and rule-of-thumb households in the determination of the idiosyncratic employment opportunity equation following Preston \& Roca (2007) and Troch (2014). Unlike Ricardian households, the latter do not only responds to the employment opportunity from the previous period but also on variation in the productivity of the goods-producing sector.

$$
L_{N, i, t}=\left(1-\rho_{L}\right) \bar{L}_{N}+\rho_{L} L_{N, i, t-1}+\rho_{L, A}\left(A_{t}-\bar{A}\right)+\varepsilon_{L, N, i, t}
$$

Steady-state labor supply $\bar{L}_{N}$ is equal to its counterpart of Ricardian households, $\rho_{L}$ indicates the variation coefficients, $\bar{A}$ is steady state productivity and $\varepsilon_{L, N, i, t}$ a bounded i.i.d. disturbance with mean and variance $\left(0, \sigma_{L, N}^{2}\right)$. From the specification of the idiosyncratic employment opportunity, it holds that $\operatorname{Cov}\left(\varepsilon_{L, N, i, t}, A_{t}\right)>0$ although the disturbances of this idiosyncratic shock and the productivity equation are uncorrelated, such that $\operatorname{Cov}\left(\varepsilon_{L, N, i, t}, \varepsilon_{A, t}\right)=0$. Hence, opposite to Preston \& Roca (2007) and Troch (2014), ruleof-thumb households' income shocks are only partly uninsurable due to the existence of durable goods. But variation in their income stream are still more volatile than those of Ricardian households.

Rule-of-thumb households gain income from labor supply only according to:

$$
I N C_{N, i, t}=w_{t} L_{N, i, t} .
$$

In contrast to pure non-Ricardian households, who consume all their current disposable income and do not hold any wealth, in this model, rule-of-thumb agents can hold wealth by accumulating a durable goods stock. However, adjustments of this stock go along

\footnotetext{
${ }^{7}$ Alternatively, durable goods can be described to be a less-liquid factor stock.
} 
with additional costs, which is why it can also be described as partly-illiquid. The wealth equation follows:

$$
W L T H_{N, i, t}=\left(1-\delta^{C D}\right) C D_{N, i, t-1}
$$

\subsection{Production sector}

The production sector produces goods that are consumed by all households as non-durable goods $C N$. Following I.-M. Kim \& Loungani (1992) and Dhawan \& Jeske (2008), the production function in a perfect competitive market is given by:

$$
Y_{t}=A_{t}\left[\eta K_{t-1}^{\nu}+(1-\eta)\left(E_{\mathrm{Y}}\right)_{t}^{\nu}\right]^{\frac{\alpha}{\nu}} L_{t}^{1-\alpha}
$$

where $A$ defines Hicks-neutral productivity, $\eta \in(0,1)$ measures the share of capital in terms of energy and $\nu$ the elasticity of the substitution between capital and energy. As $\nu<0$, there is a complementary relationship between both input factors similar to (Dhawan \& Jeske, 2008). Thus, the efficient use of capital $K$ to produce output requires some energy $E_{\mathrm{Y}}$. In addition, the company employs people supplied by households $L$. $\alpha \in(0,1)$ indicates the elasticity of substitution of the capital-energy bundle. As the elasticity of substitution between labor and the composition of physical capital and energy is one, non-durable goods are produced with constant returns to scale, characterizing a Cobb-Douglas production function.

Lemma 2. Concavity of final production

The partial derivatives for the final production function are:

$$
\begin{gathered}
Y_{K}^{\prime}>0, Y_{E_{\mathrm{Y}}}^{\prime}>0, Y_{L}^{\prime}>0, \\
Y_{K K}^{\prime \prime}<0, Y_{E_{\mathrm{Y}} E_{\mathrm{Y}}}^{\prime \prime}<0, Y_{L L}^{\prime \prime}<0, \\
Y_{K E_{\mathrm{Y}}}^{\prime \prime}=Y_{E_{\mathrm{Y}} K}^{\prime \prime}>0, Y_{K L}^{\prime \prime}=Y_{L K}^{\prime \prime}>0, Y_{E_{\mathrm{Y}} L}^{\prime \prime}=Y_{L E_{\mathrm{Y}}}^{\prime \prime}>0 .
\end{gathered}
$$

The production function $Y_{t}$ is overall concave in $A^{Y}, K, E_{\mathrm{Y}}, L>0$ iff all the following conditions hold:

$$
\begin{aligned}
& \nu, \eta \leq 1 \text { or } \nu>1, \eta \geq 1 \text { or } \nu=1, \eta>1 \\
& \alpha<1
\end{aligned}
$$

Proof: See H.1.1 in Bergmann (2018)

According to Lemma 2, final output increases with installed physical capital, energy and labor but at a decreasing rate. Moreover, overall concavity of the production function is satisfied. Actual alteration of investments in real capital takes place with a one-period 
delay, which is analogous to fixed investment. However, capital is only supplied by Ricardian households.

Firms producing non-durable goods face the following profit function:

$$
\pi_{t}=Y_{t}-r_{t} K_{t-1}-w_{t} L_{t}-\left(p_{\mathrm{Y}}\right)_{t}\left(E_{\mathrm{Y}}\right)_{t}
$$

The price of non-durable goods is normalized to one. Hence, revenues of firms are equal to $Y$. On the expenditure side, the input factors capital, labor, and energy are paid off with their respective marginal products $w, r_{Y}$, and $p_{E}$. As the production sector is modeled by consisting of infinitely small firms, the market participants act under perfect competition. Rents of the input factors labor and capital (wage and interest rate) are determined by the labor and capital market, while energy prices are determined by an exogenous process. Hence, the profit of the production sector is $\pi=0$.

\subsection{Market clearing}

The model is in equilibrium when all markets clear. For the goods market, this means that production equals the aggregated demand of households for non-durable consumption, investment as well as exogenous expenditures that are made for energy consumption. Hence, the aggregate resource constraint follows:

$$
Y_{t}-\left(p_{\mathrm{Y}}\right)_{t}\left(E_{\mathrm{Y}}\right)_{t}=C N_{t}+\left(p_{\mathrm{H}}\right)_{t}\left(E_{\mathrm{H}}\right)_{t}+\left(I_{C D}\right)_{t}+\left(I_{\mathrm{Y}}\right)_{t}
$$

By assumption, energy prices, which are exogeneously determined, are the same for households and firms. Hence, $\left(p_{\mathrm{E}}\right)_{t}=\left(p_{\mathrm{H}}\right)_{t}=\left(p_{\mathrm{Y}}\right)_{t}$ holds. Furthermore, the simplification of the exogenous setting of energy prices is based on the assumption that Germany is a small country in terms of energy consumption. ${ }^{8}$ Hence, it has little market power to affect the world price of energy.

Next to the goods market, all factor markets have to clear. Consequently, the labor market is in equilibrium when demand for labor by goods-producing firms equals the labor supplied by households at the market wage rate. In the presence of Ricardian and rule-of-thumb households, aggregate labor supplied is described by the weighted sum of labor supply of both types which is exogenously determined by idiosyncratic labor opportunity:

$$
L_{t}=\int_{0}^{\lambda} L_{R, i, t}+\int_{\lambda}^{1} L_{N, i, t} .
$$

To ensure an equal wage rate for Ricardian and rule-of-thumb households and consequently the same labor productivity, labor market equilibrium is characterized by

\footnotetext{
${ }^{8}$ According to BP (2017), Germany's share of total primary energy consumption is $2.4 \%$.
} 
$L_{t}=L_{R, t}=L_{N, t}$. Coenen \& Straub (2005) illustrate this as a consequence of unions which pool the wage income of both groups of households.

Similarly, the aggregate demand for non-durable and durable goods is determined by their weighted sum of consumption:

$$
\begin{gathered}
C N_{t}=\int_{0}^{\lambda} C N_{R, i, t}+\int_{\lambda}^{1} C N_{N, i, t} \\
C D_{t}=\int_{0}^{\lambda} C D_{R, i, t}+\int_{\lambda}^{1} C D_{N, i, t} .
\end{gathered}
$$

The market clearing condition for energy is satisfied when the sum of energy demand by the goods-producing sector and weighted sum of the household sector equal energy supply where the latter is determined by an exogenous price formation:

$$
E_{t}=\int_{0}^{\lambda}\left(E_{\mathrm{H}}\right)_{R, i, t}+\int_{\lambda}^{1}\left(E_{\mathrm{H}}\right)_{N, i, t}+\left(E_{\mathrm{Y}}\right)_{t}
$$

The physical capital market is in equilibrium when Ricardian households' supply of capital equals the demand of capital by goods-producing firms at the market rental rate:

$$
K_{t}=\int_{0}^{\lambda} S_{R, i, t} .
$$

Next to idiosyncratic labor supply shocks, there are two further shocks affecting aggregate TFP in a firm's production function and energy prices for all energy consuming entities. Both, Hicks-neutral TFP and the price of energy are assumed to be exogenous and follow stochastic AR(1) processes. The laws of motion are described by the following log-functions:

$$
\begin{gathered}
\ln A_{t}=\rho_{\mathrm{A}} \ln A_{t-1}+\varepsilon_{\mathrm{A}, t} \\
\ln \left(p_{\mathrm{E}}\right)_{t}=\rho_{\mathrm{P}} \ln \left(p_{\mathrm{E}}\right)_{t-1}+\varepsilon_{\mathrm{P}, t}
\end{gathered}
$$

where $\rho_{A}, \rho_{P} \in(0,1)$ measures the sensitivity coefficients of persistence and $\varepsilon_{A}, \varepsilon_{P}$ the disturbance which is independent and identically distributed with zero mean and variance $\sigma_{i}^{2}, i \in(A, P)$. 


\section{Competitive Equilibrium}

\subsection{Households}

In the following, the dynamic optimization problem is solved by maximizing each actor's maximization problem. The equations are derived in detail in Appendix C.1. All households decide about their consumption of non-durable goods, durable goods, and energy to optimize their expected lifetime utility. In contrast to Dhawan \& Jeske (2008) and Bergmann (2018), households cannot choose their supply of labor in this model as it is fixed and only affected by an exogenously determined variation of labor opportunity. Furthermore, this economy contains a continuum of individuals who are ex-ante identical but ex-post different in their asset holding $S_{i, t}$ and employment opportunity $L_{R, i, t}$ and $L_{N, i, t}$. This leads to heterogeneity due to incomplete insurance markets.

From this, the Ricardian households face the following optimization problem:

$$
\begin{array}{r}
\max _{\substack{C N_{R, i, t}, C D_{R, i, t} \\
\left(E_{\mathrm{H}}\right)_{R, i, t}, S_{R, i, t}}} U_{R, i, 0}=\mathbb{E}_{0} \sum_{t=0}^{\infty} \beta^{t}\left\{\ln \left[C N_{R, i, t}^{\gamma}\left(\theta C D_{R, i, t-1}^{\zeta}+(1-\theta)\left(E_{\mathrm{H}}\right)_{R, i, t}^{\zeta}\right)^{\frac{1-\gamma}{\zeta}}\right]-\phi \frac{1}{\left(S_{R, i, t}+b\right)^{2}}\right. \\
\left.+\lambda_{t}^{H}\left\{C N_{R, i, t}+p_{t}^{H}\left(E_{\mathrm{H}}\right)_{R, i, t}+I_{R, i, t}^{C D}+I_{R, i, t}^{Y}-w_{t} L_{R, i, t}-r_{t} S_{R, i, t-1}-\pi_{t}\right\}\right\}
\end{array}
$$

while the rule-of-thumb households' optimization problem is given by:

$$
\begin{aligned}
\underset{C N_{N, i, t}, C D_{N, i, t},\left(E_{\mathrm{H}}\right)_{N, i, t}}{\max } U_{N, i=0} \sum_{t=0}^{\infty} \beta^{t}\{ & \ln \left[C N_{N, i, t}^{\gamma}\left(\theta C D_{N, i, t-1}^{\zeta}+(1-\theta)\left(E_{\mathrm{H}}\right)_{N, i, t}^{\zeta}\right)^{\frac{1-\gamma}{\zeta}}\right] \\
& \left.+\lambda_{t}^{H}\left\{C N_{N, i, t}+p_{t}^{H}\left(E_{\mathrm{H}}\right)_{N, i, t}+I_{N, i, t}^{C D}-w_{t} L_{N, i, t}\right\}\right\} .
\end{aligned}
$$

According to this, the corresponding first order conditions are written as:

$$
\begin{gathered}
1=\beta \frac{\theta(1-\gamma)}{\gamma} \mathbb{E}\left\{\frac{C D_{R, i, t}^{\zeta-1} C N_{R, i, t}}{\theta C D_{R, i, t}^{\zeta}+(1-\theta)\left(E_{\mathrm{H}}\right)_{R, i, t+1}^{\zeta}}\right\}+\beta \mathbb{E}\left\{\frac{C N_{R, i, t}}{C N_{R, i, t+1}}\left(1-\delta^{C D}\right)\right\} \\
\text { for } c \in(R, N) \\
\left(p_{\mathrm{H}}\right)_{t}=\frac{(1-\gamma)(1-\theta)}{\gamma} \frac{C N_{R, i, t}\left(E_{\mathrm{H}}\right)_{R, i, t}^{\zeta-1}}{\left(\theta C D_{R, i, t}^{\zeta}+(1-\theta)\left(E_{\mathrm{H}}\right)_{R, i, t}^{\zeta}\right)} \\
\quad \text { for } c \in(R, N) \\
1=\beta \mathbb{E}\left\{\frac{C N_{R, i, t}}{C N_{R, i, t+1}}\left(1+r_{R, i, t+1}-\delta^{Y}\right)\right\}
\end{gathered}
$$


Equation (27) describes the intertemporal substitution of durable goods. Due to its complementary relationship, it depends positively on energy consumption while it is negatively affected by an increase in non-durable consumption. Equation (28) determines the demand for energy and (29) equals the Euler equation describing the intertemporal substitution of non-durable goods. The latter implies that current marginal utility of nondurable goods is equal to the discounted utility of future consumption. While (27) and (28) are the same for both types of households, rule-of-thumb households are excluded from the possibility to use the capital market for intertemporal substitution of nondurable goods. Hence, (29) is only valid for Ricardian households.

Aggregate supply of labor by the household sector can be derived with (74) in combination with equations (6) and (12). As a result, it is determined by

$$
L_{t}=\bar{L}+\frac{(1-\lambda) \rho_{L, A}}{1-\rho_{L}}\left(A_{t}-\bar{A}\right)
$$

Due to the properties of the variances $\sigma_{L, i}, i \in(R, N)$ of zero mean, idiosyncratic employment opportunity shocks are canceled out according to the law of large numbers. ${ }^{9}$ This leaves aggregate labor supply to the steady state of labor supply plus the adjusted business cycle fluctuation of productivity. As a result, labor supply behaves pro-cyclically.

\subsection{Production sector}

Goods production is maximized by optimizing over the employment of input factors physical capital, labor, and energy whose prices equal their respective marginal productivities. As the price of the aggregated (non-durable) goods is normalized to one, all prices in the economy are real prices.

$$
\begin{gathered}
r_{t}=\alpha \eta A_{t}\left[\eta K_{t-1}^{\nu}+(1-\eta)\left(E_{\mathrm{Y}}\right)_{t}^{\nu}\right]^{\frac{\alpha}{\nu}-1} L_{t}^{1-\alpha} K_{t-1}^{\nu-1} \\
\left(p_{\mathrm{Y}}\right)_{t}=\alpha \eta A_{t}\left[\eta K_{t-1}^{\nu}+(1-\eta)\left(E_{\mathrm{Y}}\right)_{t}^{\nu}\right]^{\frac{\alpha}{\nu}-1} L_{t}^{1-\alpha}\left(E_{\mathrm{Y}}\right)_{t}^{\nu-1} \\
w_{t}=(1-\alpha) A_{t}\left[\eta K_{t-1}^{\nu}+(1-\eta)\left(E_{\mathrm{Y}}\right)_{t}^{\nu}\right]^{\frac{\alpha}{\nu}} L_{t}^{-\alpha}
\end{gathered}
$$

While the prices for capital and labor are regulated by the market to match demand and supply, energy prices are exogenously determined by (24). As commonly assumed, all

\footnotetext{
${ }^{9}$ Observing a large number of agents, the average of $\varepsilon$ obtained from a large number of trials should be close to the expected value, which is the mean of the variance.
} 
factor rents are putting negative pressure on the respective demand.

To derive the equilibrium of the model, agents must forecast future prices of capital and labor to solve the optimization problem. Labor $L_{t}$, productivity $A_{t}$, and energy prices $P_{t}$, are exogenous stochastic processes, while demand for durable goods depends on the difference of households' incomes, consumption of non-durable goods, and energy. In contrast to that, the process that describes the evolution of capital still has to be determined. Additionally, due to heterogeneity among households, the stochastic properties of the stock of capital also depend on the distribution of capital wealth. As a result, the cross-sectional capital distribution becomes a state variable by its own which is described by:

$$
\Gamma_{t+1}=H\left(\Gamma_{t}, C D_{t}, A_{t},\left(p_{\mathrm{E}}\right)_{t}\right)
$$

where $H(\cdot)$ is the law of motion, including all state variables except labor. According to (30), the latter is excluded, as aggregate labor supply is only dependent on productivity fluctuations while all idiosyncratic labor shocks for households, as well as lagged labor supply, are canceled out. Opposite to Den Haan \& Ocaktan (2009), in this model, capital distribution only concerns Ricardian households, as the remaining agents do not intertemporally transfer physical capital.

In equilibrium, the economy is determined by a set of allocation and price paths that satisfy the following conditions, where $i \in(R, N)$ :

i) solving the households' problems $\left\{C N_{i}, C D_{i}, S_{i},\left(E_{\mathrm{H}}\right)_{i}\right\}$ given the prices $\left\{r, w,\left(p_{\mathrm{E}}\right)\right\}$.

ii) solving the firm's demand of $\left\{K, L, E_{\mathrm{Y}}\right\}$ maximizing the profit given the prices $\left\{r, w,\left(p_{\mathrm{E}}\right)\right\}$.

iii) rents of input factors are equal to marginal productivity $\left\{r, w,\left(p_{\mathrm{E}}\right)\right\}$ of each factor, determined by (31),(33),(32).

iv) all markets clear according to $(17),(74),(71),(72),(21)$. This includes the aggregation of input factors for all agents j with $K=\int S_{R, j} d j$ and $L=\int L_{j} d j$.

v) the distribution of $\left(S_{t-1}, C D_{t}, A_{t},\left(p_{\mathrm{E}}\right)_{t}\right)$ and hence, the probability distribution function (34) as well as the aggregated and idiosyncratic shock processes (23), (24), (6), and (12) are stationary.

Next to uncertainty, this model includes non-linear and stochastic properties, which is why it is not possible to obtain analytical solutions. The equilibrium can alternatively be obtained using numerical methods. Unfortunately, the law of motion for the capital distribution (equation 34) is a high-dimensional object, and leads to a large state space. 


\subsection{Solution methods for capital stock}

To deal with non-linear and stochastic properties of capital distribution, Krusell \& Smith (1998) propose a simplification by relying on a finite and discrete set, as described in the following. Under the assumption of bounded rational agents, they show that the distribution can also be summarized by a few moments only. As described before, solving a macroeconomic model for an equilibrium is more difficult since heterogeneous agents have to be taken into account. In a simple framework, considering heterogeneity in the accumulation of capital, Krusell \& Smith (1998) notice that approximate aggregation is a helpful tool to determine all aggregated variables, such as consumption and wealth. In their work, they notice that higher-order moments of wealth distribution do not affect the evaluation of total capital. The authors argue that the correlation between the marginal propensity to consume out of wealth and levels of households' wealth is close to zero. Only for very poor households does this not hold. But as the fraction of wealth stemming from very poor households is relatively small, a higher order of moments describing the wealth distribution does not significantly improve the determination of the accumulation of capital. In equilibrium, the agents' decisions of how to accumulate capital is almost independent of the distribution of aggregated wealth. With respect to the model at hand, future prices only depend on the moments of the physical capital stock but not on its distribution. As a result, it is sufficient to know the evolution of the total capital stock to forecast its price.

Accordingly, the corresponding general transition law of aggregate capital can also be described as:

$$
K_{t}=\varrho_{0}(s)+\sum_{i=0}^{I} \varrho_{i}(s) M(i)+\varrho_{2} A_{t-1}+\varrho_{3}\left(p_{\mathrm{E}}\right)_{t-1}+\varrho_{4} C D_{R, t-1}
$$

where $M(i)$ describes the cross-sectional average of assets of individual i, while $s$ represents a vector of aggregate state variables. In this paper, there are two more state variables, in comparison to the general models by Den Haan \& Rendahl (2010). These variables are durable goods and energy prices which enter the law of motion.

Given this extended and more precise law of motion, each individual household can compute its optimal choice of consumption. There are several approaches to solve for aggregate capital, of which we will present simplified summaries. For a detailed description, we refer to Algan et al. (2014). But besides these approaches, the remaining procedure is always similar and consists of the following five steps: (1) selecting the order of moments by determining the approximation methodology, (2) choosing the functional form of law of motion of aggregate capital, (3) calculating individual policy functions by solving the decision problem, (4) updating the law of motion of aggregate capital, (5) iterating steps (2)-(5) until convergence. 
The order of moments is closely linked to the selection of algorithm to obtain the aggregate law of motion. Above, it was pointed out that a few moments are sufficient to numerically approximate the equilibrium of a macroeconomic model with heterogeneous agents. Even the first moment of the wealth distribution (mean), along with the aggregated productivity shock, can be sufficient to describe all aggregated variables very accurately, as first shown by Krusell \& Smith (1998). According to them, it is disputable that the model's approximate equilibrium is significantly less accurate in comparison to the true theoretical equilibrium given agents' irrationality.

Alternatively, Preston \& Roca (2007) investigate the approximation using the second order of moments. They confirm the accurate determination of endogenous variables by using first-order dynamics only. Furthermore, they show that aggregate variation is less affected by second order moments compared to first order moments because of the virtually linear saving decision of agents. Nevertheless, the second order moments can contribute to the determination of individual mean consumption and saving when considering non-linear properties in the solution. In Preston \& Roca (2007)'s work, a comparison improves accuracy by $2 \%$. On the downside, when using second order moments in combination with the perturbation method, we need auxiliary policy rules and new aggregate state variables, which complicates the model by increasing its dimensionality. Therefore, because in our model the propensity to save out of wealth is almost equal across all agents, first order moments will be used in the model at hand.

As the law of motion of aggregate capital is derived from the individual policy function, we will first focus on the determination of the latter. Numerically, there are two methods to solve the policy functions: using the projection technique or the perturbation technique. The first generally consists of three steps: defining a grid in the state variables, calculating the conditional expectation of the optimized decision equations such as the Euler equation by applying quadratic methods, followed by solving the equation to find the coefficients of the approximating function for which the errors on the grid are minimized. This procedure has a few advantages, especially with respect to heterogeneous agents, because it captures the distributional aspect. Furthermore, it can be applied to non-linear equations. However, the more state variables there are in the model, the more difficult it becomes to solve the policy function. The main difference between the projection and perturbation methods is that the projection method is designed to derive a global approximation, while perturbation techniques are designed to be a local method. Still the latter can also give very close global approximations.

Perturbation techniques approximate policy functions around their steady state values. Concurrent with that, there can be only one steady state, limiting the result to a local optimum. Furthermore, it can only be applied to sufficiently linear equations, otherwise the results may be less robust and explosive. Technically, perturbation methods use the Taylor expansion, whose order is also determined by the number of moments. 
In general, a higher-order approximation reduces the error of a Taylor series, bringing it closer to the analytic function. First order perturbation methods are widely used in economics as they are fast to compute and simple to apply. While the order is primarily a technical issue for calculating the Taylor approximation, the number of moments also describes the degree of rationality of an agent. In the present paper, the first order perturbation approach will be used, similar as in Troch (2014), and based on the findings of Krusell \& Smith (1998). On the one side, there is only a low contribution by an extension to second order. On the other side, although using second moments increases the agents' degree of rationality, it also goes along with considering the evolution of cross-products, increasing the complexity of determining the aggregate capital stock. Hence, it is questionable whether agents consider such higher moments in their decision making about optimizing their asset accumulation.

Given the individual policy functions, we can derive the aggregate law of motion of capital (35). Next to limiting the set of moments, Krusell \& Smith (1998) were also among the first to develop an approach to obtain the aggregate policy function from a simulation procedure. After each step they solve for the individual policy rule, they construct a time series of the cross-sectional moments. By applying least squares, new coefficients for the law of motion $\Xi$ can be estimated from it. This process is iterated until convergence. On the downside, this approach is very computational and introduces sampling noise due to the long-run simulations. Subsequent to the approaches described so far, further ones have been developed by Den Haan (1996), Den Haan (1997), and Algan et al. (2008, 2010), all building on Krusell \& Smith (1998). The former Den Haan (1996) simulates the individual and aggregated policy function of capital, using parameterization of the conditional expectation to avoid the approximation of law of motion of the finite set of moments. The other two, instead of using simulations, use projection techniques. However, this requires knowledge of either the aggregate capital stock $K_{t+1}$ or the actual distribution, which again increases the number of state variables and the complexity.

In this paper, we apply the approach of explicit aggregation by Den Haan \& Rendahl (2010). Compared to the simulation and projecting approaches, this approach is less computational. Moreover, with respect to the model at hand, it is much simpler, as we use first order moments only. In general, the idea is to derive the aggregated law of motion by integrating the individual policy functions. Along with that, further information on the cross-sectional distribution does not have to be considered.

The parameterized individual policy function of agent $i$ is given by:

$$
\begin{aligned}
S_{R, i, t}=\varpi_{0}+\varpi_{1} S_{R, i, t-1}+\varpi_{2} K_{t-1} & +\varpi_{3} A_{t-1}+\varpi_{4}\left(p_{\mathrm{E}}\right)_{t-1} \\
& +\varpi_{5} L_{R, i, t-1}+\varpi_{6} C D_{R, i, t-1}+\varpi_{7} \varepsilon_{P, t-1} .
\end{aligned}
$$


This function expresses the policy function of the individual capital stock (and hence, its physical capital wealth) at the end of period t, after any realization of shocks through labor participation, technological progress, and energy prices. Furthermore, the function holds for both types of households, whereby the state variable for all rule-of-thumb households is $S_{t}=0$. With respect to the market clearing, we can transcribe the heterogeneous law of motion to the law of motion of aggregated capital by integrating (36):

$$
\begin{aligned}
\int S_{R, i, t}=\varpi_{0}+\int \varpi_{1} S_{R, i, t-1}+ & \varpi_{2} K_{t-1}+\varpi_{3} A_{t-1}+\varpi_{4}\left(p_{\mathrm{E}}\right)_{t-1} \\
& +\int \varpi_{5} L_{R, i, t-1}+\int \varpi_{6} C D_{R, i, t-1}+\varpi_{7} \varepsilon_{P, t-1} .
\end{aligned}
$$

Subsequently, the integrated terms can be substituted by the market clearing conditions (73), (72), and (30). Solving the equation for aggregated capital $K_{t}$ leads to:

$$
K_{t}=\underbrace{\lambda\left(\varpi_{0}+\varpi_{5} \bar{L}_{R}\right)}_{\Xi_{0}}+\underbrace{\left(\varpi_{1}+\lambda \varpi_{2}\right)}_{\Xi_{1}} K_{t-1}+\underbrace{\lambda \varpi_{3}}_{\Xi_{2}} A_{t-1}+\underbrace{\lambda \varpi_{4}}_{\Xi_{3}}\left(p_{\mathrm{E}}\right)_{t-1}+\underbrace{\lambda \varpi_{6}}_{\Xi_{4}} C D_{R, i, t-1}+\underbrace{\lambda \varpi_{7} \varepsilon}_{\Xi_{5}} \varepsilon_{P, t-1} .
$$

Since physical capital can only be accumulated by Ricardian households and considering the fact that idiosyncratic employment opportunity shocks are canceled out in equilibrium according to the law of large numbers, it holds that $\int L_{R, i, t-1}=\bar{L}$. By suppressing the constant coefficients, we derive the aggregated policy function for capital in a straightforward manner.

$$
K_{t}=\Xi_{0}+\Xi_{1} K_{t-1}+\Xi_{2} A_{t-1}+\Xi_{3}\left(p_{\mathrm{E}}\right)_{t-1}+\Xi_{4} C D_{R, t-1}+\Xi_{5} \varepsilon_{P, t-1}
$$

Hereby, we have taken advantage of being faced with a linear policy function including first moments only. Considering higher order moments, further laws of motion, who determines those variables, needs to be added as pointed out by Den Haan \& Rendahl (2010). Concurrent, this means that without any modification of the approximation process, an infinite set of moments is required to find a solution for those policy functions.

In accordance with the procedure to compute the optimal choice of consumers with respect to the correct aggregated in equilibrium, the previous steps are iterated until there is convergence within the coefficients of (39) (see Section 5.2).

\section{Calibration \& Determination of Law of Motion of Aggregated Capital}

In the following, we determine the parameters for the model. To do so, we either calibrate the values by calculating the values from the model in steady state condition, by using empirical data to fit the model with plausible real data, or by obtaining the values from 
existing literature. A derivation from the steady states can be found in Appendix C.1. The respective structural parameters which characterize the properties of the model are summarized in Table ??, while Table ?? summarizes the shock-related parameters.

The steady state condition of the model corresponds to the model with respect to its long run historical averages from data. Only for labor supply do we set its long-run steady state value to $\bar{L}=0.3$ as it is also standard in the literature. This follows from the assumption that $30 \%$ of the available time of an agent is used for working. Although this goes along with Dhawan \& Jeske (2008), it is also similar to the value assumed for Germany (see Hristov, 2016).

According to Dhawan \& Jeske (2008), we set the time discount factor and the elasticity of substitution of the durable good/energy consumption bundle and non-durable goods in the utility function of households equal to $\beta=0.99$ and $\zeta=-2.8748$. For the elasticity of substitution within the non-durable goods production function, we choose $\nu=-0.15$ as in Kemfert \& Welsch (2000). While Dhawan \& Jeske (2008) follow I.-M. Kim \& Loungani (1992) by choosing $\nu=-0.7$ and performing a sensitivity analysis for other values, Kemfert \& Welsch (2000) estimate the elasticity of substitution specifically for Germany using alternative nesting structures. As $\zeta, \nu<0$, this leads to a complementary relationship between these factors in the household and firm sectors. The capital income share in goods production is set to $\alpha=0.36$, similar to Kydland \& Prescott (1982); Hansen (1985); Maußner (1994). Inversely, this corresponds to a labor income share of $64 \%$ and accounts for the average of the capital income parameter set by Marto (2014) and Flor (2014) for Germany. Compared to lower values in earlier literature, the reduction of labor income shares considers a more capital-intensive production which goes along with Schmalwasser \& Schidlowski (2006) who argue that capital shock grows faster than production as labor is increasingly replaced with capital in recent time. The elasticity of substitution between the energy-durable bundle and non-durable goods is equal (unity), similar to Fernandez-Villaverde \& Krueger (2011). According to the derivation of the model in steady state using targeted ratios from empirical data (see Appendix C.1), $\gamma$ is set to 0.781 which puts a higher weight on non-durable goods. In comparison to Dhawan \& Jeske (2008) who use target moments of the US for calibration, the value is slightly lower for Germany.

Due to an initial value problem, the parameters $\zeta$ and $\theta$ in the utility function and the production function cannot be simultaneously calibrated. Hence, either of those must be predetermined, in our case the elasticities in these functions. Subsequently, the particular share parameters are calculated to match empirical data. Furthermore, we take the same depreciation rate of durable goods from Dhawan \& Jeske (2008) due to the assumption that the behavior of US households with respect to durable goods does not distinguish from German consumers significantly. Accordingly, $\delta^{C D}$ is set to 0.0683 . 
The cost function of accumulation of durable goods is assumed to be quadratic according to Bruno \& Portier (1995) and Dhawan \& Jeske (2008). As the proportional part of the adjustment costs $\omega_{2 d}$ does not affect the steady state condition of the model, it is calibrated in order to closely match volatility of total fixed investment to that from data. The benchmark model does not involve any taxes, hence $\tau=0$ holds.

Regarding the motion of the capital stock, used in the production sector, its depreciation rate is calculated from the time preference rate and the steady state interest rate while the latter is calculated from the long-run first order condition of the production function. The sensitivity parameter of the borrowing constraint is set to $\phi=0.5$. According to Preston \& Roca (2007), theory does not restrict the setting of this parameter with respect to its magnitude. Hence, it is chosen to ensure no essential violation of the borrowing constraint. By setting the natural borrowing limit to $b=0$, a household's utility is negatively affected by any negative asset holding.

Considering the fraction of rule-of-thumb consumers, Mayer \& Stähler (2013) assume its share to be 0.33 which satisfies a moderate crowding out of private consumption for Germany in 2011. ${ }^{10}$ Stähler \& Thomas (2012) surmise a higher share of 0.4 in Germany for the post-financial crisis period after 2008. For models covering the EU area as a whole, Coenen \& Straub (2005) set the fraction of liquidity-constraint agents to 0.25 which is in line with Coenen et al. (2008) while others assume a significant higher fraction of 0.37 (Forni et al., 2009). In our model, the fraction of rule-of-thumb consumers is set to $1-\lambda=0.35$ which is between these two ranges. Such a sizable fraction of rule-of-thumb consumers helps to reconcile the model with empirical evidence, in particular with respect to inequality measurements. It is worth to mention that existing literature often assumes a balanced weight between Ricardian and rule-of-thumb households, frequently referred to the models by Gali et al. (2003) and Campbell \& Mankiw (1989), while the latter mainly relate this share to the pre-1990 period in the USA. An equal weight distribution is usually taken as an initial value for further estimations. Hereby, the USA is often observed as the underlying economy which reasonably differs from the German economy in terms of capital and income distribution. For instance, Colciago (2011) reports a higher fraction of 0.5 which is also consistent with Mankiw (2000); Bilbiie \& Straub (2013); Callegari (2007); Muscatelli et al. (2004); and Amato \& Laubach (2003). Considering the estimates based on Markov-chain Monte Carlo methods by Di Bartolomeo et al. (2011), the fraction of rule-of-thumb consumers in the USA indeed are at the higher end of the G7 countries, only surpassed by France and the UK. Overall, as Gali et al. (2003) notify that the introduction of liquidity constraint consumers can alter the equilibrium dynamics of the model, we further do some sensitivity checks for several values of $\lambda$ in Section 7.

\footnotetext{
${ }^{10}$ Di Bartolomeo et al. (2011) estimate a fraction of rule-of-thumb consumers which is at the lower end with 0.075 . Finding similar results for Japan, they explain these findings with psychological and cultural factors of the countries as well as higher saving rates compared to other G7 countries. However, they also do not rule out measuring errors.
} 
Table 1: Parameter values

\begin{tabular}{ccc}
\hline Parameter & Value & Description \\
\hline$\beta$ & 0.990 & discount factor \\
$\zeta$ & -2.875 & elas. of substitution between durable goods and energy in households \\
$\theta$ & 0.999 & share of durable goods in consumption good bundle \\
$\gamma$ & 0.781 & elas. of substitution of consumption \\
$\lambda$ & 0.650 & Ricardian household share \\
$\phi$ & 0.050 & sensitivity of penalty constraint \\
$\alpha$ & 0.365 & final output elas. of VA \\
$\eta$ & 0.949 & share of capital in capital-energy bundle \\
$\nu$ & -0.150 & elas. of substitution between capital and energy in production \\
$\delta_{C D}$ & 0.068 & depreciation rate of durable goods \\
$\delta_{Y}$ & 0.018 & parameter adjustment costs \\
$\omega_{1 d}$ & 2.410 & parameter adjustment costs (proportional part) \\
$\omega_{2 d}$ & 1.000 & tax rate \\
$\tau$ & 0.000 & coefficient of constant in aggregate capital accumulation \\
$\Xi_{0}$ & -0.664 & coefficient of $K_{t-1}$ in aggregate capital accumulation \\
$\Xi_{1}$ & 0.963 & coefficient of $P_{t-1}$ constant in aggregate capital accumulation \\
$\Xi_{2}$ & 0.988 & coefficient of $C D_{R, t-1}$ constant in aggregate capital accumulation \\
$\Xi_{3}$ & 0.007 & coefficient of $\epsilon_{P, t-1}$ constant in aggregate capital accumulation \\
$\Xi_{4}$ & 0.084 & \\
$\Xi_{5}$ & 0.003 & \\
\hline \hline
\end{tabular}

\subsection{Calibration of shocks}

The parameters for the shock process are summarized in Table ??. Technological progress follows an $\mathrm{AR}(1)$ process. It is a common practice to assume a persistent parameter of 0.95 as considered by Kydland \& Prescott (1982) and Hansen (1985). With respect to that, Kydland \& Prescott (1982) suggest a standard deviation of 0.007 for the growth rate of the Solow residual. But there is little formal analysis of that specific derivation. Gomme \& Rupert (2007) re-estimate the Solow residual process using three different regressions with varying numbers of capital stocks, by also taking durable goods into account. The results are fairly similar, amongst others, to those of Kydland \& Prescott (1982) or Hansen (1985) and confirm that a first order process provides a good rendering of the data. Furthermore, Gomme \& Rupert (2007) argue that the results are not sensitive to the number of capital stocks. ${ }^{11}$ Their autoregressive coefficient of 0.9641 and volatility of the shock of 0.0082 are somewhat larger than the usual values. For the present model, we choose a persistent coefficient of $\rho_{A}=0.964$ for the technological process and a shock volatility of $\sigma_{A}=0.0086$ which is in line with Flor (2014) for the German economy and only slightly differs from Gomme \& Rupert (2007) who based their analysis on US data.

\footnotetext{
${ }^{11}$ In fact, when calculating the Solow residual, Kydland \& Prescott (1982) omit the capital stock completely. They justify that capital series has a smooth process and hence less effect on the Solow residuals.
} 
The structure of energy market and hence the price formation processes differ significantly among countries. Therefore, we cannot use the estimates from studies like Dhawan \& Jeske (2008) who consider the US economy. Alternatively, we do a separate estimation to derive the energy price function based on German data. Since the mid-1990s, Germany has imported more than $60 \%$ of its energy use (The World Bank, 2019). To trace energy prices, we consider the evolution of monthly import prices of energy between 2005 and 2018. Next to a conservative $\operatorname{AR}(1)$ process, we estimate an $\operatorname{ARMA}(1,1)$ process such as Dhawan \& Jeske (2008) and I.-M. Kim \& Loungani (1992). The results are summarized in Table 2 together with the log-likelihood and Bayesian information criterion.

Table 2: Estimation of energy price function

\begin{tabular}{ccc}
\hline & $\mathrm{AR}(1)$ & $\mathrm{ARMA}(1,1)$ \\
\hline constant & $110.300^{* * *}$ & $112.8^{* * *}$ \\
& $(6.40)$ & $(7.68)$ \\
$\mathrm{AR}(1)$ & $0.984^{* * *}$ & $0.974^{* * *}$ \\
& $(73.09)$ & $(54.52)$ \\
$\mathrm{MA}(1)$ & & $0.355^{* * *}$ \\
& & $(5.00)$ \\
sigma & $5.340^{* * *}$ & $4.905^{* * *}$ \\
& $(24.07)$ & $(22.69)$ \\
\hline $\mathrm{LL}^{\mathrm{a}}$ & -512.2475 & -498.3773 \\
$\mathrm{BIC}$ & 1039.813 & 1017.178 \\
\hline${ }^{\mathrm{a}}$ Log-likelihood (LL) and Bayesian Information Criterion (BIC) are \\
used as estimators of the relative quality of the statistical model-based. \\
level of significance: ${ }^{*} p<0.1,{ }^{* *} p<0.05,{ }^{* * *} p<0.01$.
\end{tabular}

According to the two-quality estimators, $\operatorname{ARMA}(1,1)$ is preferred over $\operatorname{AR}(1)$, although the dominance is only weak. Nevertheless, we continue with an $\operatorname{ARMA}(1,1)$ energy price function despite the increase of complexity, due to an additional state variable (in form of the moving average of the variance of energy prices). It is thoroughly reasonable to assume that agents consider the price fluctuation of energy as one of their essential products in their utility function to predict future prices and consequently make a decision about their saving behavior.

Similar to TFP, labor supply or more precisely the employment shock follows an AR(1) process. While Preston \& Roca (2007) set a employment persistence of 0.93 and for thumb-to-rule agents a persistence rate of current aggregate market conditions of 0.7 , most literature assume a higher persistence rate of individual employment between 0.95 and 0.97 (e.g. Storesletten et al., 2004; Den Haan \& Ocaktan, 2009; Lopez, 2010; Lee \& Mukoyama, 2015). In our model, we set $\rho_{\mathrm{L}}=0.96$ for both groups of agents. For the variance, we follow general literature with a variance of $\sigma_{\mathrm{EMP}}=0.05$ as in Den Haan \& Ocaktan (2009) and Preston \& Roca (2007). Lopez assumes a significantly higher variance of 0.12 in the base state and during recession an even greater variance to include a cyclical 
variation of the risk-premium. In our model, this fact is covered by the aggregate market condition term which has a persistence of $\rho_{\mathrm{L}, \mathrm{A}}=0.04$ for rule-of-thumb households. ${ }^{12}$

Table 3: Parameter values of shocks

\begin{tabular}{ccc}
\hline Parameter & Value & Description \\
\hline$\rho_{\mathrm{A}}$ & 0.964 & persistence technology shock of $A$ \\
$\rho_{\mathrm{P}}$ & 0.974 & persistence energy price shock of $P$ \\
$\rho_{\mathrm{P}_{\sigma}}$ & 0.355 & persistence energy price shock of $\sigma_{P}$ \\
$\rho_{\mathrm{L}}$ & 0.960 & persistence labor opportunity shock of $L$ \\
$\rho_{\mathrm{L}, \mathrm{A}}$ & 0.040 & persistence technology shock in labor opportunity $L$ \\
$\sigma_{\mathrm{A}}$ & 0.0086 & volatility shock of technological progress \\
$\sigma_{\mathrm{P}}$ & 0.049 & volatility shock of energy prices \\
$\sigma_{\mathrm{L}, \mathrm{R}}$ & 0.050 & volatility shock of labor (Ricardian agents) \\
$\sigma_{\mathrm{L}, \mathrm{N}}$ & 0.050 & volatility shock of labor (rule-of-thumb agents) \\
\hline \hline
\end{tabular}

\subsection{Law of motion of aggregated capital}

The law of motion of aggregated capital is derived by the iteration algorithm described in Section 4.3. The initial function contains arbitrary values which respects the steady state values of capital and ensures a stable condition of the model. In principle, the initial distribution should not influence the convergence of coefficients. This is because the stationary density of the probability distribution function (34) should be independent of the starting state variables as long as the steady state values are respected. After each optimization process, the law of motion and its coefficients are updated according to (38). We set the convergence speed of the updating process of $10 \%$ to avoid explosive structures and instability. This means that the former aggregated policy function of capital is updated by only $10 \%$ of the new estimated coefficients. The number of simulations should be sufficiently large to guarantee convergence to the stationary distribution. Altogether, the iteration process is run over 150 periods. Figure 1 depicts the convergence of each coefficient in the policy function of aggregate capital

Clearly, convergence is reached after half of the iteration process. The same value is approached regardless of the selected initial starting points. As a result, the final law of motion of aggregate capital in consideration of the individual optimization behavior of households is given by:

$$
K_{t}=-0.6549+0.9630 K_{t-1}+0.9782 A_{t-1}+0.0067\left(p_{\mathrm{E}}\right)_{t-1}+0.0833 C D_{R, t-1}+0.0024 \epsilon_{P, t-1}
$$

\footnotetext{
${ }^{12}$ It seems reasonable to assume a slightly higher persistence and lower cyclical behavior due to higher restrictions in the German labor market than in the USA.
} 
Figure 1: Coefficients of law of motion of aggregated capital

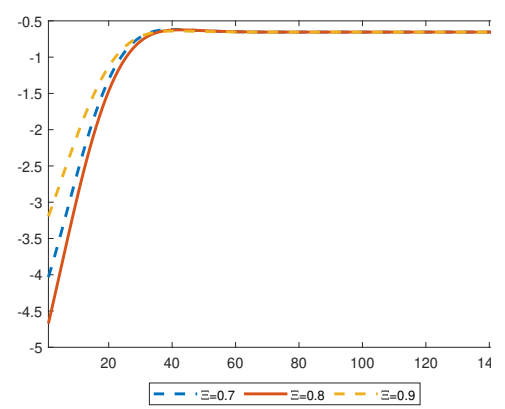

(a) Coefficient $\Xi_{0}$

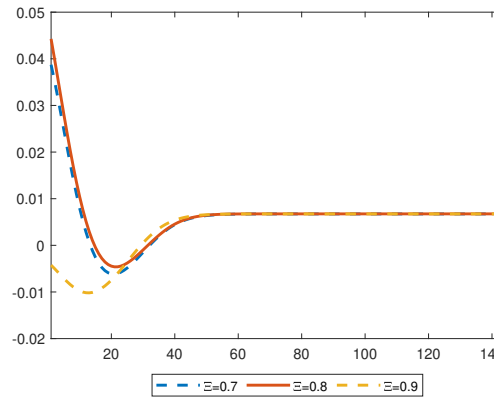

(d) Coefficient $\Xi_{3}$

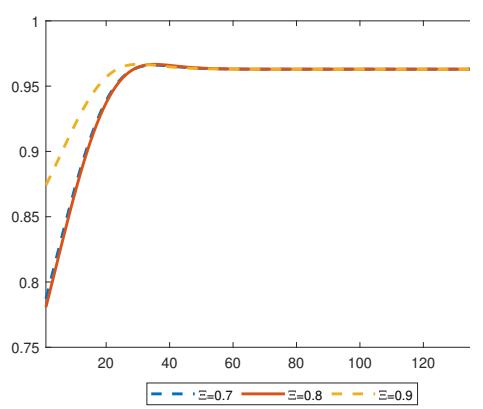

(b) Coefficient $\Xi_{1}$

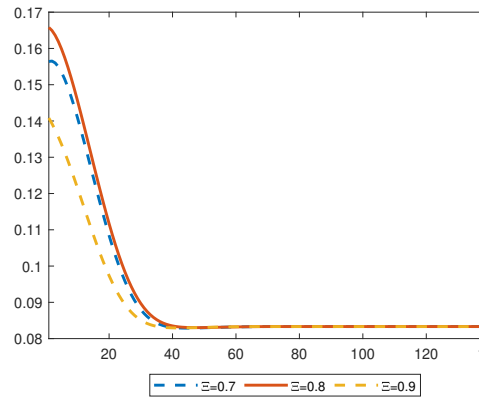

(e) Coefficient $\Xi_{4}$

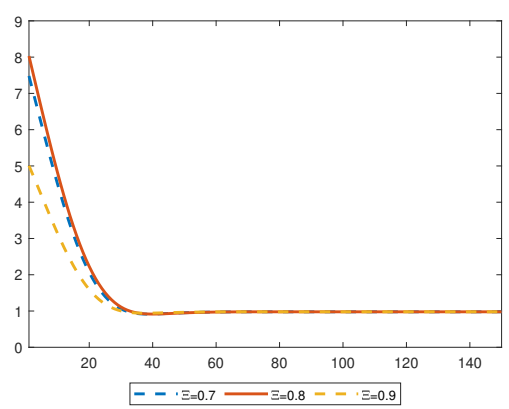

(c) Coefficient $\Xi_{2}$

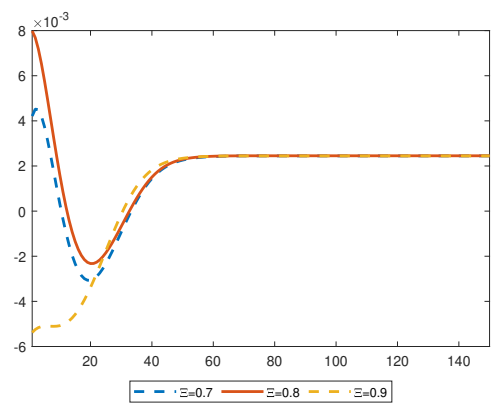

(f) Coefficient $\Xi_{5}$

The derivation of the coefficient of the final law of motion of aggregate capital is based on an iteration process about the decision making of agents. As long as the initial starting points respect the steady state value of capital, $\Xi_{i}$ converge to stable values.

\section{Results}

The analysis of results is separated into three parts. First, we look at the simulated moments of selected endogenous variables after running the model for several times. By comparing the results with observations from the German economy, we are able to validate and analyze the predictive power of the model. Because the relevant statistics for capturing business cycles is the standard deviation, we focus on $2^{\text {nd }}$ moments to cover the volatility of variables. Second, we present some impulse response functions (IRFs) that show the expected propagated path of standard deviation of the endogenous variables, conditional on a one-time shock in the initial period. We focus on both aggregate shocks, namely a temporary increase in TFP and energy prices, and the direction and shape of the response of selected model variables. Studying IRFs is a handy tool to evaluate the responses to aggregate exogenous shocks, which means that we can check the coherency with respect to economic theory. However, studying IRFs to evaluate consequences of idiosyncratic labor supply shocks does not work because of heterogeneous responses of agents. Hence, the third part concentrates on the analysis of the evolution of the income and wealth distributions, by inspecting several inequality metrics. 


\subsection{Simulated moments}

Table 4: Volatility of simulated variables $\left(2^{\text {nd }}\right.$ moments $)$

\begin{tabular}{|c|c|c|c|c|c|c|c|c|}
\hline & & $(1)$ & $(2)$ & $(3)$ & (4) & $(5)$ & (6) & (7) \\
\hline Variable & data & simple & baseline & no IC & diff wages & only $\varepsilon_{A}$ & only $\varepsilon_{P}$ & only $\varepsilon_{L}$ \\
\hline Output & 1.62 & 0.97 & 1.58 & 1.59 & 1.24 & 1.57 & 0.16 & 0.02 \\
\hline Non-durable goods & $\overline{0.8 \overline{1}}$ & 4.05 & $2 \overline{82}$ & 3.20 & $\overline{2} . \overline{2} 8$ & $0 . \overline{12}$ & $\overline{0} \overline{0} \overline{3}$ & $2 . \overline{77}$ \\
\hline$C N_{R}$ & & & 2.40 & 3.76 & 2.35 & 0.05 & 0.03 & 2.44 \\
\hline$C N_{N_{-}} \ldots$ & & & 6.45 & 5.36 & 4.54 & 0.33 & 0.06 & 6.26 \\
\hline Durāble goods & $\overline{3.0 \overline{1}}$ & $3 . \overline{28}$ & $3 . \overline{33}$ & $\overline{7.53}$ & $\overline{2} . \overline{6} 0^{-}$ & $0 . \overline{1} 6$ & $\overline{0} . \overline{7} \overline{7}$ & $3 . \overline{07}$ \\
\hline$C D_{R}$ & & & 2.90 & 10.24 & 2.99 & 0.20 & 0.90 & 2.74 \\
\hline$C D_{N}$ & & & 7.38 & 9.48 & 4.46 & 0.20 & 0.55 & 6.80 \\
\hline Total energy & $\overline{1.7 \overline{6}}$ & $3 . \overline{00}$ & $2 . \overline{95}$ & $2 . \overline{97}$ & $\overline{2} . \overline{6} 0^{-}$ & $\overline{0} \overline{7} \overline{4}$ & $\overline{3} . \overline{0} \overline{8}$ & 0.09 \\
\hline$E_{y}$ & & 2.92 & 2.86 & 2.86 & 2.52 & 0.74 & 2.98 & 0.01 \\
\hline$E_{h, R}$ & & 0.14 & 0.13 & 0.28 & 0.14 & 0.00 & 0.10 & 0.08 \\
\hline$E_{h, N}$ & & & 0.23 & 0.26 & 0.15 & 0.01 & 0.08 & 0.20 \\
\hline Labor supply & $\overline{1 .} \overline{3} \overline{1}$ & $\overline{4.52}$ & $3 . \overline{46}$ & $3 . \overline{46}$ & $\overline{3} . \overline{4} 6$ & $\overline{0} . \overline{0} 2$ & $\overline{0} . \overline{0} \overline{0}$ & $3 . \overline{48}$ \\
\hline$L_{R}$ & & & 4.61 & 4.61 & 4.61 & 0.00 & 0.00 & 4.70 \\
\hline$L_{N}$ & & & 4.44 & 4.44 & 4.44 & 0.06 & 0.00 & 4.33 \\
\hline Labor demand & $\overline{1.3 \overline{1}}$ & $\overline{4.52}$ & $0 . \overline{28}$ & $\overline{0.2 \overline{8}}$ & $0 . \overline{19}$ & $0 . \overline{2} 8$ & $\overline{0} \overline{0} \overline{0}$ & 0.00 \\
\hline Wage & 1.07 & 2.06 & 1.15 & 1.28 & 1.32 & 1.13 & 0.33 & 0.04 \\
\hline Fix capital formation & 4.01 & 4.68 & 4.54 & 5.04 & 4.59 & 0.83 & 0.15 & 4.53 \\
\hline Energy price & 5.28 & 5.42 & 5.30 & 5.30 & 5.30 & 0.00 & 5.56 & 0.00 \\
\hline
\end{tabular}

Data is based on observations from Germany between 1991-2012 using an HP-filter to detrend.

All simulation results denote the percentage standard deviation (2nd moment) over 1000 periods using an HP-filter.

(1) includes Ricardian agents only (all agents have access to the asset market)

(2) shows results of baseline model

(3) shows results of model without adjustment costs in durable goods investments

(4) shows results under the assumption of different productivities for both classes of agents

(5-7) shows results of the baseline model with one specific shock only

Table ?? displays the simulated percent standard deviation of selected variables of various simulations of the model and the corresponding observations from Germany between 1991-2012 using an HP-filter to detrend the data. Next to the baseline model discussed so far, which includes all shocks (column 2), we show the moments of a simplified version of the model including Ricardian agents only (column 1) as well as the moments of the model without adjustment costs in durable goods investments (column 3). In addition, we look at the volatility or variables when the model is affected by each shock separately (column 5-7).

The model with one class of agents, namely Ricardian agents (column 1), corresponds to the baseline model with adjustment costs and durable goods by Dhawan \& Jeske (2008), but with one exception. In contrast to Dhawan \& Jeske (2008), labor supply is based on an idiosyncratic process and is determined exogenously in this model. While output volatility explains $60 \%$ of its empirical target, agents fail to smooth consumption because volatility of durable above all non-durable goods are higher than the data values. This is due to the high volatility in the supply of labor, which leads to fluctuation in 
income. All households have to choose between consumption and asset allocation in order to smooth consumption expenditures which are otherwise volatile due to the inconsistency of income because of the presence of shocks in TFP and energy prices. However, agents cannot fully insure against employment shocks, due to incomplete capital markets. This leads to income variations and affects those expenditures from which they can directly get utility, namely non-durable consumption goods.

Investigating the baseline model (column 2), the volatility of output is in line with historical values from Germany. The same applies to the standard deviation of aggregated durable goods which is only slightly higher. Here, fluctuations are significantly reduced due to the presence of adjustment costs. This is apparent in comparison with the model without those costs on doing investments in durable goods (column 3) in which volatility is more than twice as high. In contrast to that, volatility of total non-durable goods is far above their empirical targets which is mainly driven by the consumption fluctuation of rule-to-thumb agents. Similarly, volatility of durable goods of rule-of-thumb households is clearly above those of Ricardian households. However, its effect on the volatility of total durable goods is relatively low.

The reason for the high volatility of total non-durable goods is the missing possibility of intertemporal asset allocation to smooth consumption because rule-of-thumb households are hindered to postpone income to later periods considering their budget constraint (equation 10). The alternative of intertemporal income allocation via durable goods is constrained by adjustment costs but has also a lower attractiveness as it is linked to higher energy expenditures due to its complementary relationship. In cases where adjustments in durable goods are not constrained, fluctuations are significantly higher for durable goods whose consumption is easier to be experienced by households as it is only constrained with additional energy expenditures. But opposite to non-durable consumption goods, there is no production process that might limit the supply of durable goods. This is in line with Dhawan \& Jeske (2008) who also find excess volatility for durable goods without the presence of adjustment costs. However, this does not apply to nondurable goods, due to endogenous labor supply in their model. Although volatility in idiosyncratic and exogenous labor supply is significantly lower in the present baseline model in comparison to the model without rule-of-thumb agents, volatility is still above its empirical target. As a result, the higher fluctuation of labor income is transmitted to consumption expenditures and physical capital investments (Ricardian agents). In sum, matching the fluctuation of durable goods comes at the expense of overestimating the fluctuation of non-durable goods similar to Alvarez-Parra et al. (2012).

The standard deviation of total (fixed) investment is close to that of the data as we choose $\omega_{1 c d}$ to target the moments of durable goods and physical capital investments. Similarly, the volatility of energy prices matches its empirical target as we have estimated the energy price function by an $\operatorname{ARMA}(1,1)$ process. Similar to Dhawan \& Jeske (2008), 
labor demand volatility is well below the empirical value, accounting for only $22 \%$ of its fluctuation.

Although we do not distinguish between Ricardian and rule-of-thumb agents in terms of wages, it is visible that the volatility of consumption goods differs significantly due to the missing possibility to smooth expenditures by the latter group. Therefore, we also check how the moments are affected by changing the labor productivity of rule-ofthumb agents and hence the labor income relative to wages of Ricardian households. The standard deviation of lowering wages of rule-of-thumb households by $1 / 3$ are displayed in column 4. Of particular interest are the values of those variables that directly affect the agent's utility. Volatility of both the total durable and non-durable consumption goods, are far below those of the baseline model. The available income of rule-of-thumb agents decreases and hence leads to lower fluctuation values to impact the volatility of consumption goods. Hence, it is apparent that a different productiveness of labor improves the performance of the model to match empirical targets.

Next, we look at the degree of influence of the variables due to different shocks (columns 5-7). Unexpected shocks in TFP account for the origin of output volatility as energy price shocks can explain only $10 \%$ of fluctuation in GDP (see column 5). This is in line with the literature claiming that TFP is the main driver for business cycle fluctuation despite the presence of energy price or more specifically oil price shocks (I.M. Kim \& Loungani, 1992; Rotemberg \& Woodford, 1996; Finn, 2000; Dhawan \& Jeske, 2008). Opposed to that, consumption is hardly affected by TFP shocks. Here, volatility in the supply of labor is the main driving force for durable goods which can almost fully explain volatility in comparison to $24 \%$ by energy price shocks. It is worth mentioning that the influence of TFP on consumption goods is also held down due to an exogenous labor supply. According to Dhawan \& Jeske (2008), productivity shocks can attribute almost half to the volatility of non-durable goods by fully endogenizing the labor stock.

The energy price shock (column 6) plays a prevailing indirect role in influencing the utility function as well as the production process by increasing their costs. Furthermore, the energy share in producing output and generating utility for households is relatively small compared to capital, labor or consumption goods. But unsurprisingly, energy has a larger effect on durable goods in the utility function in comparison to capital investment in the production function as energy consumption has a larger share in the former. This is in line with Dhawan \& Jeske (2008) who find the same results in a fully homogeneous economy model. In total, our results confirm the limited direct role of energy price fluctuation to output volatility. TFP is still the main driver of business cycles. However, they are not negligible in particular by explaining volatility in the consumption behavior of durable goods. Hence, as proposed by Hamilton (2008), energy price shocks affect the 
economy through other transmission channels such as postponing the purchase of durable goods.

\subsection{Impulse response functions}

In the following, we analyze the impulse response function to changes in the productivity process $A$ and changes in the price of energy $P$. Responses are shown by their deviation from the balanced growth paths. As we use log-differences, fluctuations are mapped in percentages. The dynamic results are based on the calibrated values, hence the shocks are not normalized but correspond to the individual standard deviations of positive shocks $\sigma_{A}$ and $\sigma_{P}$ as described in Table ??. The graphs aim to explain two questions: Firstly, how do the endogenous variables respond to each shock. Secondly, to what extent do the responses differ with respect to different types of agents. For better comparability, we partly include the dynamics of both agents in the same graphs. Ricardian agents are marked by a dashed line, rule-of-thumb agents are marked by a dotted line, the production sector is marked by a dot-dashed line, while a solid line represents the overall dynamics of a respective variable.

\subsubsection{Shock to TFP in the (non-durable) goods production sector}

In this section, we investigate a positive productivity shock to the (non-durable) goods production sector as depicted in Figure ??. Higher TFP lowers the marginal costs of goods producers and shifts up the supply of output. Along with a more productive production sector, marginal productivity of input factors increases as the same unit of all input factors becomes more productive, other things equal. For Ricardian agents, this has a positive income effect as wages increase in combination with a stable supply of labor. As the latter is exogenous, there is no substitution effect leading to a net increase in income. For rule-of-thumb agents, income also rises. However, labor supply positively responds to boom phases in business cycles, which additionally has a positive effect on their incomes. This stimulation is lagged progressively expanding, hence the persistent effects lead to an inverse u-shaped dynamic of labor supply. But opposite to Ricardian agents, they do not have access to the capital market. Hence, all income is split into expenditures in durable goods, in non-durable goods, and due to the complementary link in energy, which all share the same expanding dynamics as income.

Next to consumption expenditures, Ricardian households use the additional channel to enhance their asset investments because of the increase demand in capital due to lower marginal costs and an increase in the factor price. As an immediate response, a higher return on assets makes durable goods less attractive than capital. Consequently, Ricardian agents shift more of their investment portfolio towards capital investments, causing crowding out of durable goods investment in the short-term. Along with decaying 

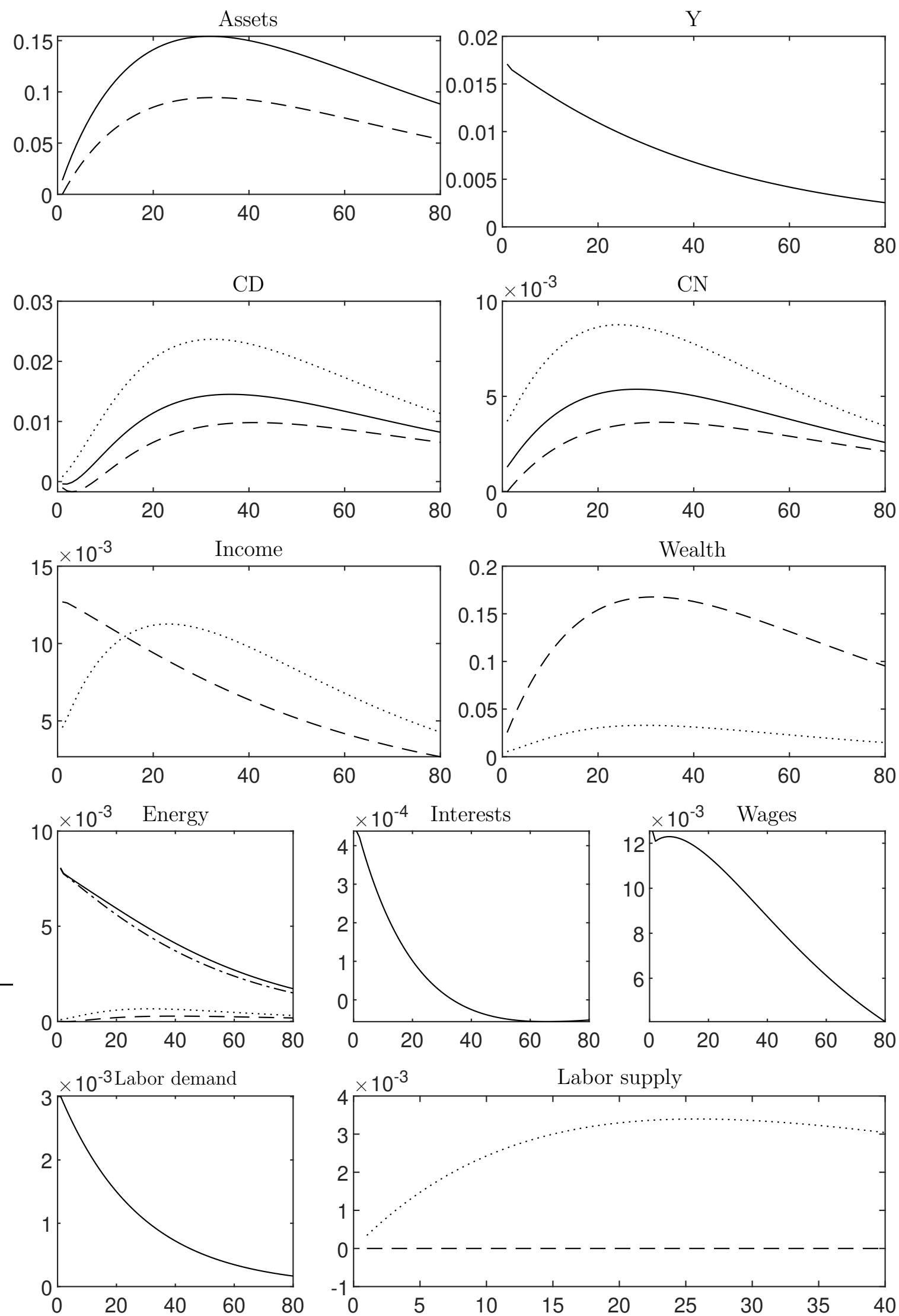

All subfigures depict the deviations for each respective variable from the deterministic steady state in percentage. The solid lines display the respective aggregate variables, the dashed lines display the respective variables for Ricardian agents, the dotted lines display the respective variables for rule-of-thumb agents, and the dotted-dashed lines display the variables for firms (in the energy graph only). 
productivity, the increase in capital stock eventually puts downwards pressure on the interest rate in the midterm, which diminishes the advantage of capital investments. Hence, durable purchases increase. After 30 periods, the capital market is saturated and households reduce their saving efforts. By reason of asset savings, the volatility of expenditures for consumption goods and energy for Ricardian households are relatively lower with respect to those of rule-to-thumb agents. Furthermore, as the former do not face increases in labor supply and positive income volatility declines until it returns to its balanced growth path.

As producers and households use more physical capital and durable goods, the overall demand for energy increases which is mainly traced back to the production sector due to their lower marginal costs. The price of energy which is equivalent to the world market price is inelastic and hence stays constant over the time. In total, we notice a significantly positive business cycle in the economy where all actors are positively affected. By reason of different earning channels, the income of Ricardian and rule-of-thumb agents evolves differently.

\subsubsection{Shock to energy prices}

Energy prices react inelastically to a change in the demand of energy as we have seen in the previous scenario in Section 6.2.1. Hence, they behave like world market prices which do not vary significantly with changes in the demand of a small country. As a result, a positive energy price shock acts as an energy supply crunch in this framework. Similarly, this goes along with a decline in productivity in the energy generation process as in Bergmann (2018) or the traditional oil price setting by the OPEC. ${ }^{13}$

Figure ?? shows the responses to a temporary exogenous increase in the energy price. The instantaneous response of all economic entities leads to a reduction of the demand for energy, which leads to a drop in the quantity of energy used by households and producers. Note that according to the structure of the exogenous process of price determination, the same stochastic shock affects the energy price for two periods. Hence, in the second period, the quantity of energy continues to drop before converging back to its balanced growth path in the long term.

The producer faces higher marginal costs in energy leading to a reduction of output and consequently a fall in capital returns and wages. Due to the complementarity of capital and energy, there is less demand for assets. But opposite to Dhawan \& Jeske (2008) and Huynh (2016), labor supply is exogenously determined (whose price formation process is not affected by energy price changes), whereas labor demand stays constant and wages clearly fall relative to interests to balance the market equilibrium. However,

\footnotetext{
${ }^{13}$ The Organization of the Petroleum Exporting Countries (OPEC) includes 15 countries accounting for $44 \%$ of global oil extraction and owning more than $80 \%$ of oil reserves.
} 

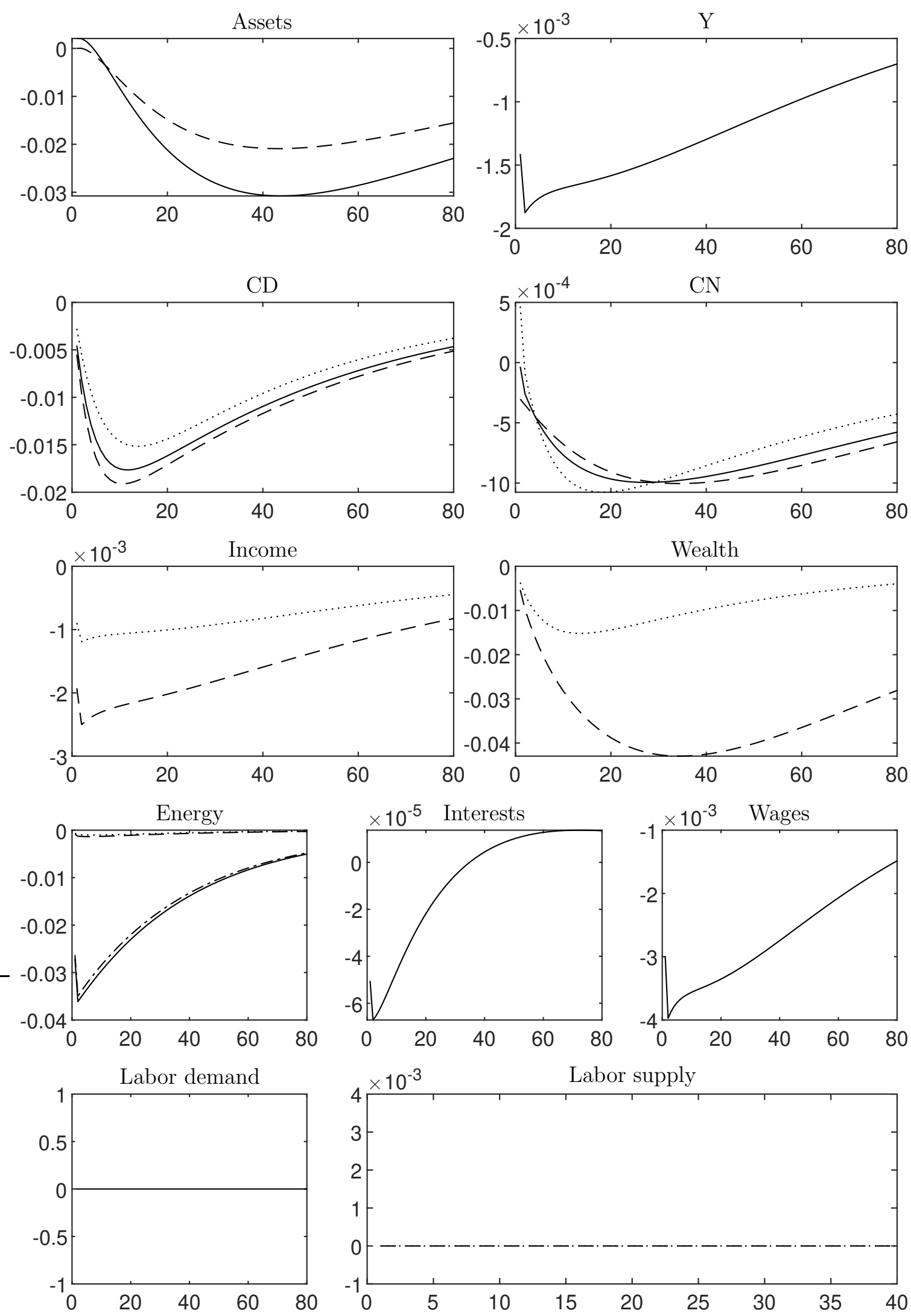

All subfigures depict the deviations for each respective variable from the deterministic steady state in percentage. The solid lines display the respective aggregate variables, the dashed lines display the respective variables for Ricardian agents, the dotted lines display the respective variables for rule-of-thumb agents, and the dotted-dashed lines display the variables for firms (in the energy graph only). 
this also means that labor cannot be substituted for the loss in the capital-energy bundle which puts additional downward pressure on production.

For both groups of households, an increase in energy prices has impacts on both, the expense and the income sides of the budget constraint. On the one side, purchases of energy become more expensive which increase costs. On the other side, lower returns for production factors decrease the income. However, the negative income effect distinguishes between both types of agents. While rule-of-thumb households only suffer from lower wages, Ricardian households also face a decline in capital income, leading to income losses, which are about twice as large. As a consequence, consumption of durable and non-durable goods is cut by all agents which happens with a delay due to the lagged structure of durables within the utility function. Furthermore, the decline of the former is significantly higher given the high complementarity of energy and durables. Moreover, non-durable consumption goods can partly substitute the energy-consumption bundle which further increases the differences. Concerning Ricardian households, the combination of a lower interest rate and lower income budget also results in a reduction in its alternative investment, namely financial assets. This contraction is persistent which leads to a decline in the negative impact of the interest rate. When the rental rate of capital exceeds its steady state values, which happens after 40 periods, the change in the reduction of physical capital investments turns around.

Figure ?? also depicts the various impacts on the demand of energy when comparing the household and the production sectors. Although both sectors use energy in their utility or production process and hence, are directly affected by price changes, the latter has the predominant share in the decline of total energy demand. This is essentially due to the weight of energy in the capital-energy bundle, which is clearly higher in comparison to the equivalent bundle in the utility function.

In sum, the response dynamics after a positive energy price shock confirm the results from Section 6.1 as output is significantly less influenced in comparison to its response following a change in productivity as in Section 6.2.1. However, both groups of agents clearly respond by dropping their investments in durable goods to optimize their utilities. Fluctuations are particularly faced by Ricardian households whose effective budget is stronger reduced due to the loss of capital returns.

\subsection{Inequality}

In the previous section, we have investigated the dynamic responses of the economy, by looking at the impacts of each shock in isolation. Moreover, the exogenous stimuli have been temporary and occurred only once. Now, we simulate the economy by impacting the model with all shock simultaneously and continuously. We run the simulation for 1000 periods considering 1000 different agents which are split up into Ricardian and rule-of- 
thumb households and whose proportion is fix over the whole time sequence. Furthermore, we launch the simulation by endowing each agent with the same amount of labor, durable goods, and financial assets whereby the latter only holds for Ricardian agents. Next to the TFP and energy price shocks, each agent is additionally affected by an individual employment shock. The latter leads individuals' decisions to significantly differ from each other. The whole procedure gives insight about the development of the distribution of all endowment factors. Here, we are in particularly interested in the income and wealth distribution as they are the main factors from which utility is gained. Therefore, in the following, we focus the analysis by considering some inequality metrics which are often used in relevant literature but also in the public perception.

\subsubsection{Distribution}

Figure 4: Distribution of income and wealth

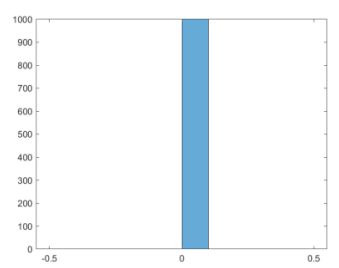

(a) Income $t=1$

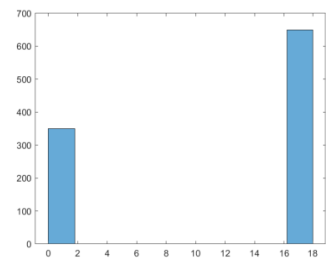

(e) Wealth $\mathrm{t}=1$

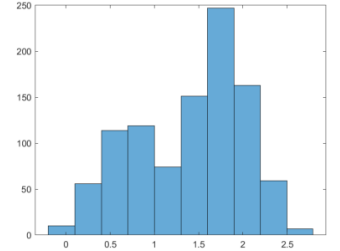

(b) Income $t=10$

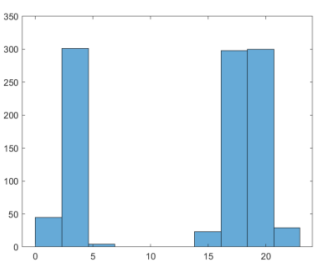

(f) Wealth $\mathrm{t}=10$

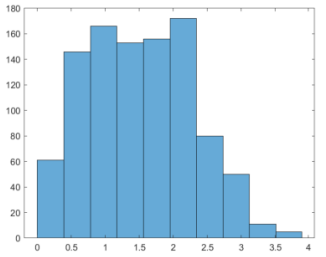

(c) Income $t=100$

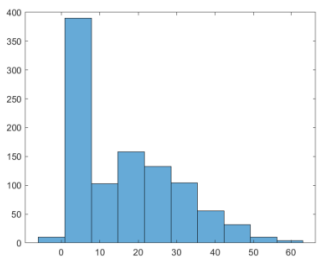

(g) Wealth $\mathrm{t}=100$

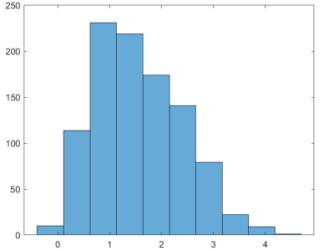

(d) Income $t=1000$

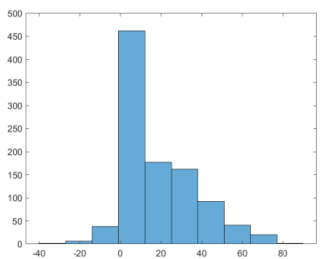

(h) Wealth $\mathrm{t}=1000$

Figures show distribution of income or wealth after t periods. Each bin-width is 10 .

Figure 4 depicts the evolution of the income and wealth distribution after the $1^{\text {st }}, 10^{\text {th }}$, $100^{\text {th }}$, and $1000^{\text {th }}$ period. By assuming that all shocks act on the model from the second period and capital returns are payed out with a lag of one period, all agents receive the same wage earnings which also account for total income in the initial period (see Figure $5(\mathrm{a})$ ). Hence, the income is equally distributed. In contrast, agents' wealth consists of labor income, the stock of durable goods, and possible assets. As only Ricardian agents are endowed with the latter, we can notice an imbalance in its distribution, but only between both groups. From the second period onwards, this does change as each agent is differently affected by employment stimuli. Furthermore, productivity shocks influence the response of both groups of households differently as rule-of-thumb employment is pos- 
itively correlated with TFP. Even energy price shocks have different consequences for the decision making of agents as they affect the composition of utility by directly changing the price of one consumption good. The direct consequence of this is an alternation of the income distribution within both groups of agents, and thus also for wealth in subsequent periods as each agent is using the intertemporal smoothing channels differently. Particularly in the initial periods, income and wealth reflect the property of normal distribution from the idiosyncratic labor supply shocks within both groups. Households, which can invest in productive financial assets, can accumulated more capital in the long term due to positive capital returns. Hence, considering wealth, the distribution dispersion is larger among Ricardian households as we see clearly in Figure 5(f). In sum, we find convergence of the income and wealth distribution over the long run which is also reflected in the evolution of inequality indices as we will see later. Both, income and wealth distribution are right skewed which corresponds to reality whereby the size of skewness of the latter is explicitly larger in the long term.

Moreover, the wealth distribution of Figure $5(\mathrm{~h})$ clearly shows the existence of agents who are indebted in the long term despite the borrowing constraint in the utility function, similar to Troch (2014). However, the share of those who have accumulated negative wealth is low with only $5 \%$ and relatively stable. Consequently, the economy does not collapse by a Ponzi scheme. Furthermore, we can identify agents who are indebted to be Ricardian households. Because individual households' policy functions are linear by construction, the same holds for the capital accumulation equation of households, ${ }^{14}$ which is almost linear in their own holdings of assets. Consequently, the propensity to save out of wealth is the same for all Ricardian households as we discussed before in Section 4 and the saving behavior of agents does not differ at both ends of the wealth distribution (for very rich and very poor agents). However, this does hold for the poorest agents in real life. Nevertheless, capital aggregation still holds because the share of these agents and the fraction of wealth they hold are very small and have no significant implications on the qualitative outcome of the simulation.

\subsubsection{Inequality ratios}

Inequality metrics are useful to determine the performance of the model to replicate the income and wealth distribution of Germany. Opposite to the whole distribution, ratios reflect the parts of the distribution with respect to each other and are a good measurement of between-class inequality. Hence, it is a relative measure and easier to interpret. Table ?? reports the $90 / 10,90 / 50$, and 50/10 percentile income ratios, comparing the income of the 90th, 50th, and 10th income group. According to the results, the model findings are only slightly above the income distribution of Germany but otherwise the

\footnotetext{
${ }^{14}$ We use linear policy functions to numerically solve for the decision making of all agents on the basis of all state variables in the simulation.
} 
model does a good job in predicting the income distribution. As the deviations are mostly visible in the $\mathrm{P} 90 / \mathrm{P} 50$ and $\mathrm{P} 50 / \mathrm{P} 10$ ratios, this means that the baseline model lightly overestimates the income inequality within the lower half. By looking at the income shares which show the income share of a sub-population relative to its size, we can see that for the bottom $20 \%$ and next $20 \%$ earners, the results are somewhat lower but still close the the empirical targets. Hence, the dispersion of income can attributed to the lower income groups or the low income tail. Nevertheless, the finding can be assessed as good, in particular with respect to the simplification of the model.

Table 5: Inequality metrics

\begin{tabular}{|c|c|c|c|c|}
\hline & & Baseline & Data $^{a}$ & Source \\
\hline \multirow{3}{*}{ Income ratios } & $\overline{\mathrm{P} 90 / \mathrm{P} 10}$ & 5.93 & 3.58 & OECD (2019a) \\
\hline & P90/P50 & 1.95 & 1.87 & OECD (2019a) \\
\hline & $\mathrm{P} 50 / \mathrm{P} 10$ & 3.04 & 1.93 & OECD (2019a) \\
\hline \multirow{3}{*}{ Income shares } & buttom $20 \%$ & $\overline{5} . \overline{3} \overline{5}$ & $8.52^{-}$ & The World Bank (2019) \\
\hline & 2nd $20 \%$ & 10.67 & 13.2 & The World Bank (2019) \\
\hline & buttom $20 \overline{\%}$ & $-\overline{0.5}$ & 0.0 & $\overline{O E C D}(2 \overline{19 a})$ \\
\hline \multirow{3}{*}{ Wealth shares } & buttom $40 \%$ & 4.8 & 0.5 & OECD (2019a) \\
\hline & top $10 \%$ & 31.1 & 59.8 & OECD (2019a) \\
\hline & top $5 \%$ & 17.6 & 46.3 & OECD (2019a) \\
\hline \multirow{3}{*}{ Gini } & top $1 \%$ & 4.5 & 23.7 & OECD (2019a) \\
\hline & Income & $0 . \overline{3} \overline{7}$ & $0 . \overline{3} 30^{-}$ & The World Bank (2019) \\
\hline & Wealth & 0.553 & $0.667^{\mathrm{b}}$ & The World Bank (2019) \\
\hline
\end{tabular}

a We use the average of the data from 1991 to 2013 to match the steady state moments of the calibrated model.

$\mathrm{b}$ This data refers to the value from 2000 which lies in the middle of the observed time period. More recent data indicate a significantly higher Gini index for wealth (77.5) in 2015.

Furthermore, we consider the distribution of wealth by reporting the wealth shares of three sub-population groups (see Table ??). Here, we can see a significant deviation between the model predictions and the metrics reported by the OECD (2019b). While the results for the bottom $20 \%$ are similar to the data, the baseline model underestimates the actual inequality for the further sub-population groups. This become apparent by looking at the richest households. For instance, the top $5 \%$ of wealthiest agents own $46 \%$ of total wealth while the model predicts a share of only $18 \%$. As a result, although the model's prediction of income distribution comes close to the empirical target and indicates a more unequal distribution for wealth, which goes along with properties of the German economy, the model fails to predict the targeted metrics for wealth inequality. In particular, the assumption of equal productivity among agents but also the equal individual initial endowments among and within both groups of agents seems to be too simplistic. $^{15}$

\footnotetext{
${ }^{15}$ By simulating the model with lower productivity for rule-of-thumb agents, income inequality indeed increases significantly.
} 


\subsubsection{Gini index}

A further metrics to capture economy-wide dispersion of income and wealth is the Gini index. This synthetic measure is the most widely used single indicator of inequality because of its simplicity of calculation and interpretation (The World Bank, 2014). The index which is generally scaled between 0 and 1 where a value of zero expresses perfect equality and 1 shows maximal inequality. ${ }^{16}$ It reflects half of the relative mean absolute difference or alternatively, the mean of the difference between every possible pair of agents, divided by the mean size, hence, the relative inequality within the economy:

$$
G=\frac{1}{2 n^{2} \mu_{y}} \sum_{i=1}^{n} \sum_{j=1}^{n}\left|y_{i}-y_{j}\right| \quad \text { with } \quad \mu_{y}=\frac{1}{n} \sum_{i=1}^{n} y_{i}
$$

Figure 5: Lorenz curves

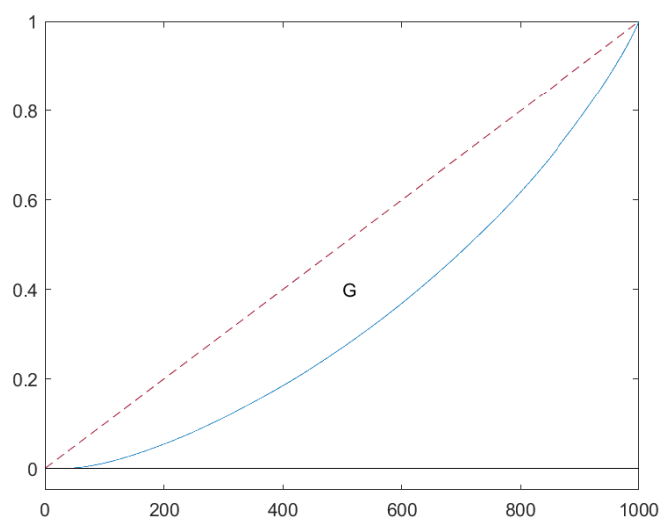

(a) Income

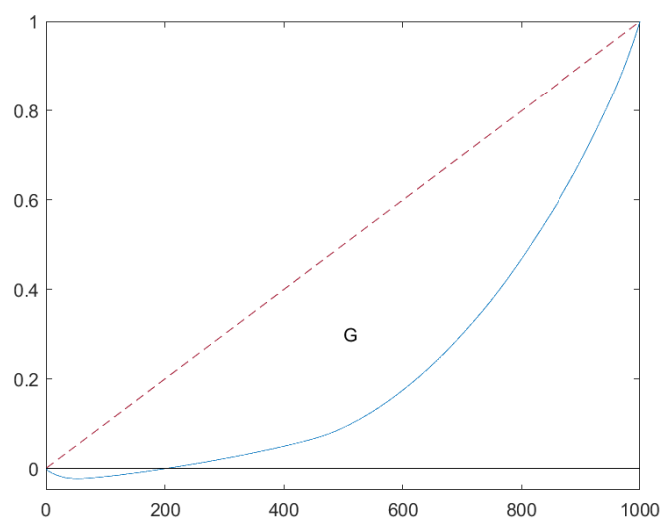

(b) Wealth

The dashed (dotted) curve denotes the $45^{\circ}$-line description line of equity while solid blue line depicts the Lorenz curve. The area between both curves amounts to the Gini coefficient G.

where $y_{x}$ denotes the income/wealth of agent $x$ and $n$ the total number of agents (in our model $n=1000$ ). The Gini index and the Lorenz curve are closely related. The latter depicts the cumulative proportion of ordered individuals plotted onto the corresponding cumulative proportion of their size while the former describes the area between the Lorenz curve and its corresponding function with no inequality (see Figure 5). In case of no idiosyncratic shocks and a single class of households only, the Lorenz curve for income and wealth is described by a $45^{\circ}$-line (see red curve in Figures 3(a) and 3(b)). Consequently, there is no inequality. In the baseline model, the income Gini index corresponds to the empirical target which confirms the good performance of the model in this regard.

\footnotetext{
${ }^{16}$ When allowing for negative values in the distribution (such as debt in case of wealth distribution), the Gini index can also theoretically become larger than 1.
} 
However, the wealth Gini index is significantly lower in comparison to the German data, which is in line with the finding from before.

\subsubsection{Theil index}

The Gini index is handy to compare several distributions as it meets many axioms according to Cowell (1985). These include anonymity, scale of independence, population independence, and the transfer principle (Pigou-Dalton transfer principle). However, by not complying with the principle of decomposability, it can only describe the overall degree of inequality. Hence, it does provide any information about the distribution within the economy. This also means that it is possible to have two societies with the same Gini index but different distributions. Therefore, we also consider the income and wealth distribution of the baseline model with respect to the Theil index which allows to decompose inequality.

Applied to our model, the Theil coefficient describes inequality as the sum of inequality between groups (Ricardian vs. rule-of-thumb households) and inequality within these groups:

$$
\begin{array}{r}
T_{T}=\sum_{i=1}^{n}\left[\frac{y_{i}}{n \bar{y}} \ln \left(\frac{y_{i}}{\bar{y}}\right)\right]=\underbrace{S_{R} T_{R}}_{\begin{array}{c}
\text { within Ricardian } \\
\text { agents inequality }
\end{array}}+\underbrace{S_{N} T_{N}}_{\begin{array}{c}
\text { within rule-of-thumb } \\
\text { agents inequality }
\end{array}}+\underbrace{S_{R} \ln \frac{\bar{y}_{R}}{\mu}+S_{N} \ln \frac{\bar{y}_{N}}{\mu}}_{\begin{array}{c}
\text { between group } \\
\text { inequality }
\end{array}} \\
\text { with } \quad S_{m}=\frac{n_{m}}{n} \frac{\bar{y}_{m}}{\mu}, \quad m \in(R, N) \quad \text { and } \quad \mu_{y}=\frac{1}{n} \sum_{i=1}^{n} y_{i}
\end{array}
$$

where $T_{R}$ and $T_{N}$ are the decomposed Theil indices of both groups. This allows us to make up for the main factor contributing to overall inequality as we can associate the sources of inequality to the different parts of the decomposed Theil index. Table 6 includes the results for each component of the index. For the income distribution, within groups inequality mainly contributes to total inequality. They are at the same level as agents within both classes each share the same dispersion impacts through idiosyncratic shocks which significantly affect the individual income. These shocks have the same properties for both classes, so between groups inequality is hardly visible. On the contrary, within groups inequality significantly differs as Ricardian agents can accumulate assets by having access to the financial capital market. Income varies within this class whereby wealth accumulation evolves unequally. Rule-of-thumb households can only accumulate wealth through investments in durable goods. Hence, the possibility of different wealth evaluation is limited. By reason of the different market accesses, between groups inequality is naturally higher in comparison with its respective index of income inequality. The same hold for the total Theil index. 
Table 6: Decomposition of Theil index

\begin{tabular}{|c|c|c|c|c|}
\hline & \multicolumn{2}{|c|}{ Theil index within } & \multirow{2}{*}{$\begin{array}{l}\text { between group } \\
\text { inequality }\left(T_{B}\right)\end{array}$} & \multirow{2}{*}{$\begin{array}{c}\text { total } \\
\text { Theil }\left(T_{T}\right)\end{array}$} \\
\hline & Ricardian agents $\left(T_{R}\right)$ & rule-of-thumb agents $\left(T_{N}\right)$ & & \\
\hline Income & 0.1486 & 0.1483 & 0.0300 & 0.1761 \\
\hline Wealth $^{\mathrm{a}}$ & 0.2686 & 0.0410 & 0.2023 & 0.4528 \\
\hline \multicolumn{3}{|c|}{ share of } & & total \\
\hline & Ricardian agents $\left(S_{R}\right)$ & rule-of-thumb agents $\left(S_{N}\right)$ & & share \\
\hline Income & $76.30 \%$ & $23.70 \%$ & - & $100 \%$ \\
\hline Wealth & $92.04 \%$ & $7.96 \%$ & - & $100 \%$ \\
\hline
\end{tabular}

Furthermore, we can point out a significant difference in the shares of income and wealth held by both classes. Here, the latter is significantly shifted in favor for Ricardian households due to the exclusive access to the financial asset market. In the long term, the Theil indices even out at a constant level (see Figure 6). In sum, income and wealth inequality are closely related while the latter is usually at a higher level due to its higher persistency.

Figure 6: Theil indices

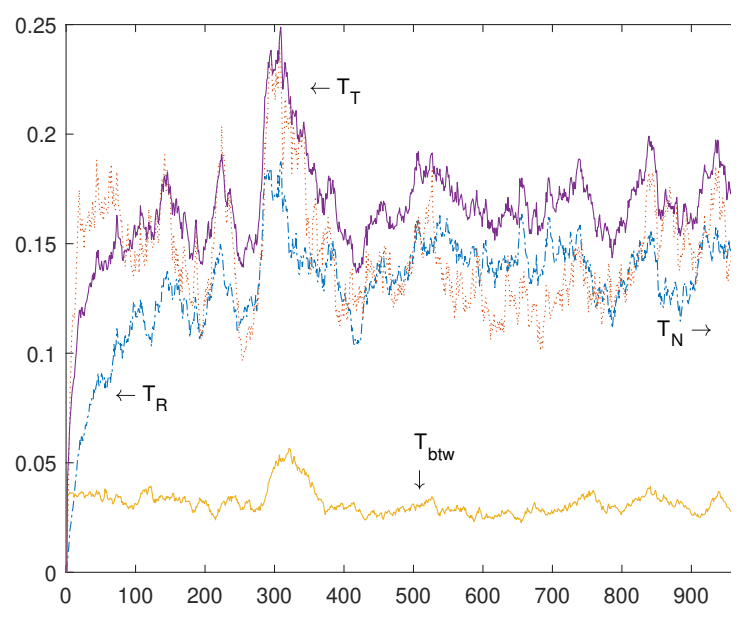

(a) Income

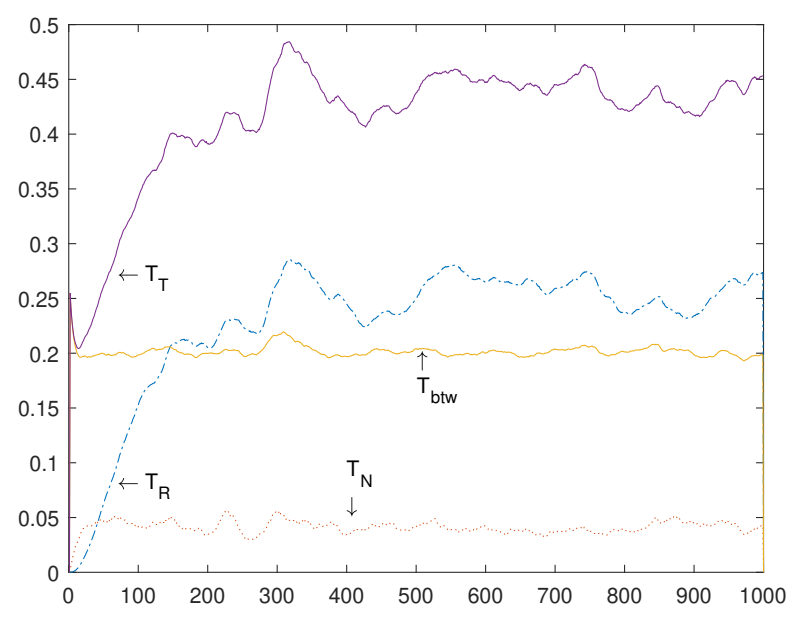

(b) Wealth

As the Theil index cannot be calculated with data containing negative values, we have neutralized the debt (hold by $5 \%$ of population). Hence, the wealth Theil index of Ricardian agents and consequently, the total Theil index, do not reflect the proper values which are slightly higher.

\section{Sensitivity Analysis}

In this study, we have set up a model that has been meant to present how inequality develops in an RBC framework by using two heterogeneous classes of agents. As such, we 
have particularly stylized the model i.e. by distinguishing between Ricardian and rule-ofthumb agents, while holding the share of the different classes of agents constant. This also means that the ability of intertemporal decision making of an agent cannot be altered, as switching to the other class is not possible.

Hence, we examine a sensitivity analysis to shed a further light on the general ability of this model to reproduce business cycles caused by exogenous stimuli. By using alternative specification of some parameters, we cannot only look at the dynamic responses but also on their effects on inequality measurements. Here, we focus on those parameters which are most likely to have an impact on an agent's decision making and which are not calibrated according to the equilibrium condition of the economy. These include the share of Ricardian households $\lambda,{ }^{17}$ the presence of adjustment costs in making an investment in durable goods $\omega_{2 c d}$, as well as the presence of each shock in isolation. The latter particularly allows us to find out the notable source of impact on inequality measurements originating from exogenous stimuli.

Figure 7: IRFs of income with various $\lambda$ 's

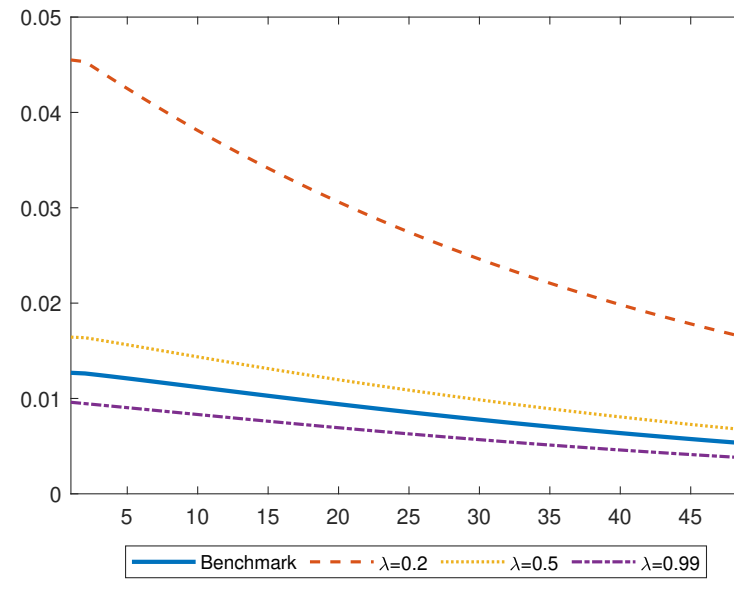

(a) Ricardian agents

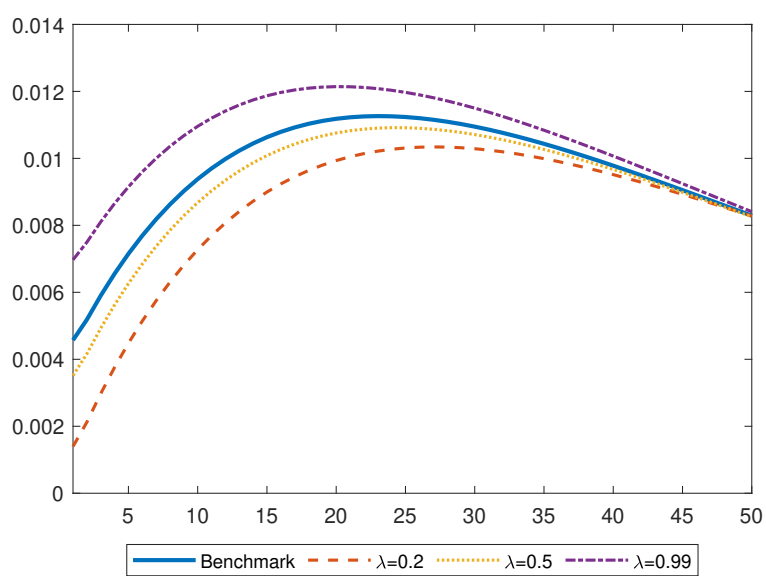

(b) Rule-of-thumb agents

Because TFP is the main driver for business cycle fluctuation despite the presence of the energy price as we have previously confirmed in Sections 6.1 and 6.2.1, we consider the IRFs of a temporary exogenous increase in productivity to the production sector. Investigating the responses of income and wealth with various shares of Ricardian agents and rule-of-thumb agents after a positive impact through TFP, we can see that for the former, income is higher the less agents have access to the capital asset market (see Figure 7a). In particular, having a Ricardian household share of only $20 \%$ boosts earnings by 3.7 times larger in comparison to a household share of $99 \%$, while the increase

\footnotetext{
${ }^{17}$ Gali et al. (2003) point out that the distinction between Ricardian and rule-of-thumb households can alter the equilibrium dynamics of the model. In our model, we restrict the sensitivity analysis to $0.2 \leq \lambda<1$ as we find indeterminacy when $\lambda<0.2$ and $\lambda=1$. Other models find different indeterminacy regions such as $\lambda<0.36$ (Marto, 2014).
} 
Figure 8: IRFs of wealth with various $\lambda$ 's

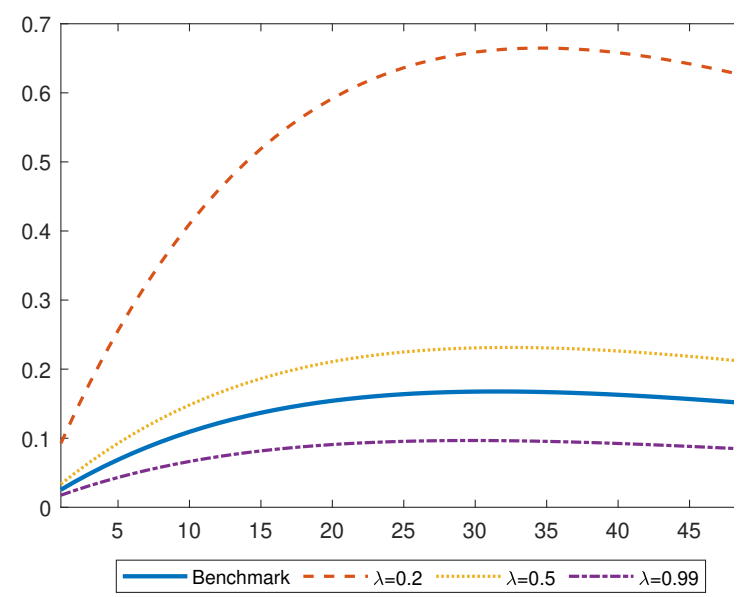

(a) Ricardian agents

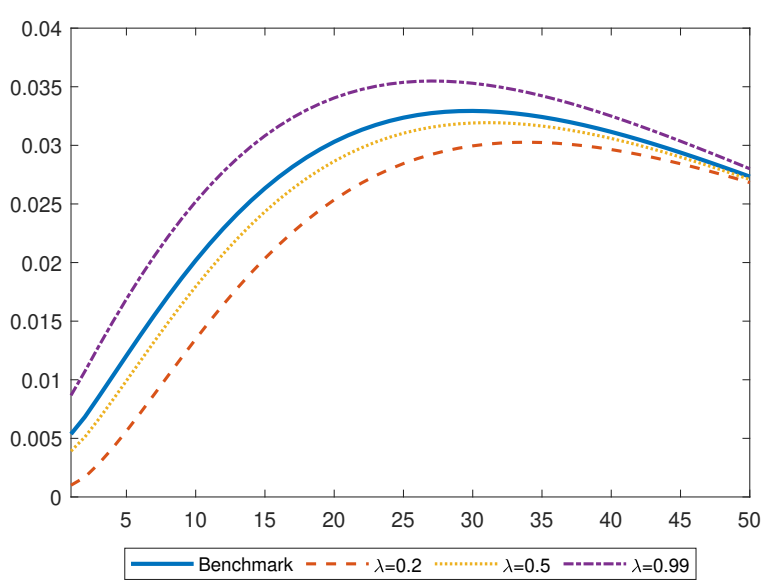

(b) Rule-of-thumb agents

is disproportionate. On the opposite, the rule-of-thumb agents' income proportionally increases the higher the share of Ricardian households. By reason of the correlation of labor employment and productivity, income diverges from its steady state value for several periods until it converges back. The dynamics can be explained as the more households can access the asset market, the more capital will be invested because it works as an additional channel of intertemporal consumption smoothing. Simultaneously, productivity of capital decreases and productivity of labor, hence wages, increases. The difference of both groups are intensified with respect to the development of wealth. At its peak, the dynamic of a Ricardian agent's wealth at $\lambda=0.2$ is 5.9 times as large as at $\lambda=0.99$ (see Figure 8).

Table 7: Sensitivity

\begin{tabular}{|c|c|c|c|c|c|c|}
\hline & \multicolumn{4}{|c|}{ Income } & & \multirow{2}{*}{$\begin{array}{c}\text { Wealth } \\
\text { Gini }\end{array}$} \\
\hline & Gini & share bottom $20 \%$ & $\mathrm{P} 90 / \mathrm{P} 10$ & $\mathrm{P} 90 / \mathrm{P} 50$ & & \\
\hline baseline model & 0.3265 & 0.0535 & 5.9317 & 1.9499 & i & 0.5526 \\
\hline$\lambda=0.99$ & 0.3067 & 0.0526 & 5.6150 & 1.7491 & I & 0.4828 \\
\hline$\lambda=0.5$ & 0.3401 & 0.0538 & 6.2699 & 2.1069 & । & 0.5862 \\
\hline$\lambda=0.2$ & 0.4076 & 0.0500 & 8.5594 & 3.0293 & 1 & 0.6959 \\
\hline$\omega=1$ & 0.2692 & 0.0747 & 4.0821 & 1.7057 & I & 0.3912 \\
\hline only $\sigma_{A}$ & 0.1246 & 0.1288 & 1.8538 & 1 & । & 0.2694 \\
\hline only $\sigma_{P}$ & 0.1211 & 0.1308 & 1.8135 & 1 & 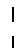 & 0.2693 \\
\hline only $\sigma_{L}$ & 0.3371 & 0.0490 & 6.4927 & 1.9869 & । & 0.5671 \\
\hline$\overline{\text { no energy price shocks }}$ & $\overline{0} . \overline{3} \overline{3} 2 \overline{3}$ & $\overline{0} . \overline{0} 5 \overline{10}$ & $6 . \overline{24} \overline{8} 7$ & $\overline{1.9} \overline{6} \overline{97}$ & | & $0 . \overline{56} \overline{1} 1$ \\
\hline
\end{tabular}

Values correspond to the respective equivalent from Table 5.

Table ?? depicts an overview of the results of the sensitivity analysis by showing the outcome for some inequality measurements. In particular, we look at the Gini coefficient of income and wealth, the income share of the bottom $10 \%$ of population, and two income ratios. By comparing the these results, we get an impression of what influences inequality 
Figure 9: Gini coefficients with various $\lambda$ 's

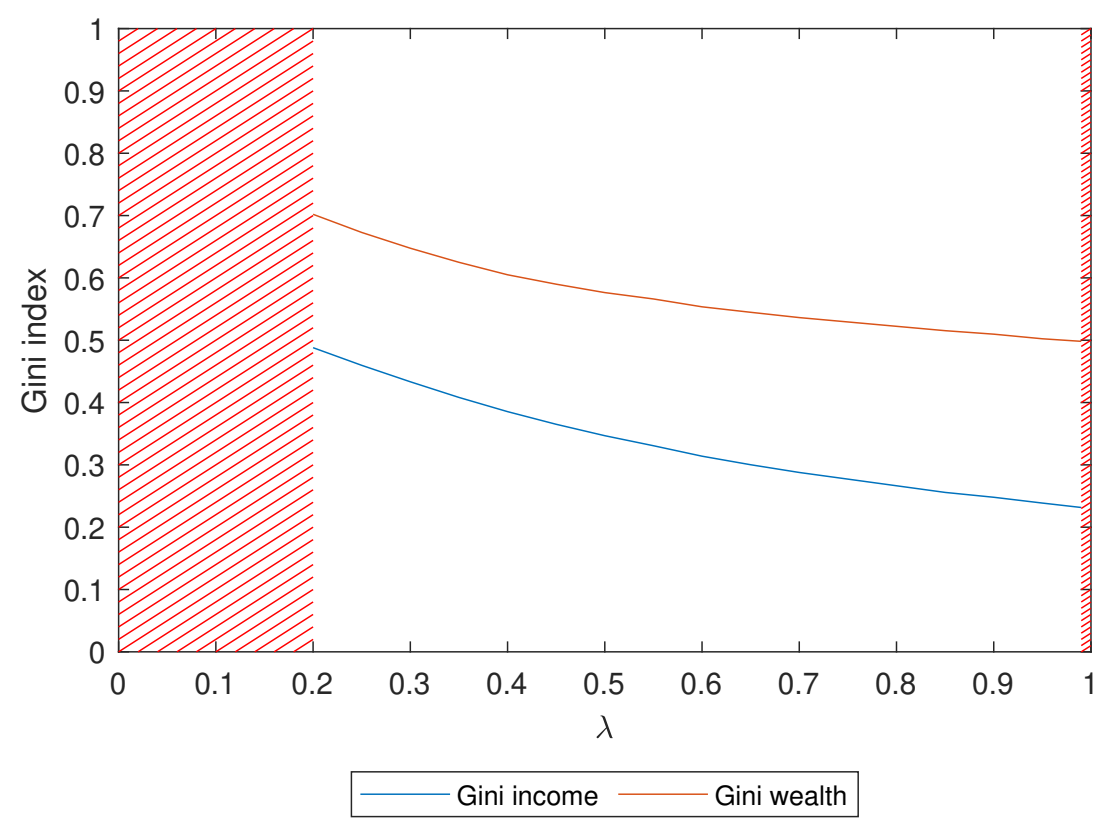

Shaded area mark indeterminacy when $\lambda<0.2$ and $\lambda=1$.

and to what degree these changes appear. The results from the IRF analysis are confirmed by these inequality measurements. The lower the share of Ricardian households, the larger inequality in income according to the Gini index which is also reflected by the income share and income ratios (see also Figure 9 ). This is consistent for the value set $\lambda \in[0.2,1)$. Furthermore, inequality in wealth rises even more strongly.

Moreover, inequality declines significantly when eliminating costs in doing investment adjustments in durable goods. This is mainly due to the fact that the omission of costs enables rule-of-thumb households to use this channel to smooth their consumption intertemporally more effectively. In contrast, Ricardian households can also continuously use the financial asset market for intertemporal consumption smoothing.

By looking at the impact of each shock on the distribution of income and wealth, presented in the last three column of Table ??, we cannot recognize a significant difference between the results for a shock in TFP and energy prices. The Gini coefficients for income and wealth are 0.12 and 0.27 respectively and apparently deviate from the baseline model. These are the pure effects of distinguishing between Ricardian and rule-of-thumb households as individual employment variations are omitted. In contrast, by looking at the presence of a temporary exogenous increase in employment only, the inequality parameters are significantly higher and closer to the baseline model. Hence, we can identify these shocks as the main source of producing inequality in the distribution of income and wealth. 
Since this model focuses on the presence of energy price shocks, we also look at the impact of volatility of energy prices on inequality metrics. The analysis of IRFs in Section 6.2.2 shows that the qualitative responses of both classes of agents are qualitatively similar, because in both cases there is an aggregated shock that does not differ between the entities. This particularly holds for responses to impacts from energy prices, because both classes are energy purchasers and both receive payments from the production sector (whose output is also affected by the quantity of energy and its prices). Consequently, it does not come as a surprise that differences in the income and wealth distribution in the scenario of no energy price fluctuations are relatively small in comparison to the baseline model with energy price shocks. The last row of Table ?? describes both distributions by their respective inequality indices. All measurements are slightly above those of the baseline model. This means that the presence of volatility in energy prices has a positive impact on income and wealth inequality, which means that both decrease marginally. The reason for these dynamics is the complementary relationship between durable goods and energy. The richer the agent, the higher the consumption of this consumption bundle. The presence of volatility in energy prices leads to adjustments in the durable goods stock, re-optimizing the agents' maximization problems (25) and (26). This goes along with additional expenditures due to the investment cost function (see equations (5) and (11)), which are sunk costs. As a result, the wealthier the agent and the larger the durable goods stock, the higher these sunk costs.

Based on this complementary relationship between durable goods and energy, and the consequences as described above, we conclude that it is not the low-income agent who benefits from volatility in energy prices, but instead it is the high-income agent who looses due to higher absolute sunk costs. However, this claim only holds when the proportionality coefficient of the complementary factors durable goods and energy increases when consumption of this bundle increases. ${ }^{18}$

\section{Policy Implication Through Taxation}

So far, existing RBC frameworks, which implement energy consumption through their main economic entities, are mainly based on the assumption of homogeneous agents. This model is predominantly designed to extend this field of literature by heterogeneity in the capability and endowments of agents. As we have seen in the results of this model, different forms of heterogeneity can lead to inequality in income or wealth which each have implications on the current utility and intertemporal choice of agents. It is likely to avoid unequal distributions as they can lead to negative impacts for the society which can be transferred to many spheres in public life. For instance, inequality can enhance

\footnotetext{
${ }^{18}$ The income effect is larger for durable goods than for energy. Hence, the ratio $C D / E_{\mathrm{H}}$ increases.
} 
polarization, alienation and social friction but it can also encourage crime with negative consequences for the rest of society. As a result, all members of society would lose out. A free-market system does not necessarily respond to the wants and needs of individuals who are socially and economically worse off, especially not if they have insufficient economic votes to have any impact on market demand.

It should be the responsibility of policy makers of a country using its exceptional position by having organized control over a human community to meet these challenges. Hereby, various policy-making tools are available which have different effects but also a varying degree of support from miscellaneous community groups. However, we do not discuss the feasibility of a specific policy intervention with respect to its acceptance in society. There is a particular field in literature that is dealing not only with the electoral behavior of voters but also the decision making of policy makers with respect to upcoming elections (e.g. Nordhaus, 1975).

One of the government's most powerful tools to tackle inequality is fiscal policy. On the one hand, this directly affects households' decision making about consumption though taxes or transfers. On the other hand, this can not only indirectly influence agents by the provision of public goods and services but also promote the incentive to work. In particular, the role of tax policy plays an important role in times of increasing pre-tax inequality according to OECD (2019b). Therefore, we discuss the impacts of one possible instrument to induce a redistribution channel of income in a simplified form. By assuming that rule-of-thumb households belong to social group which is, by average, worse off in terms of income and wealth, we implement a one-way transmission channel of income from Ricardian households to rule-of-thumb households. This is done by taxing income of former agents whose revenues are directly re-distributed to the latter. We consider a non-progressive, constant tax rate which is put on overall income, hence capital returns plus wage income.

The budget constraints of both groups of agents (3) and (10) are altered accordingly: ${ }^{19}$

Ricardian households:

$$
\begin{aligned}
C N_{R, i, t}+\left(p_{\mathrm{H}}\right)_{t}\left(E_{\mathrm{H}}\right)_{R, i, t} & +\left(I_{C D}\right)_{R, i, t}+\left(I_{\mathrm{Y}}\right)_{R, i, t} \\
& =(1-\tau)\left(w_{t} L_{R, i, t}+r_{t} S_{R, i, t-1}+\pi_{t}\right)
\end{aligned}
$$

Rule-of-thumb households:

$$
\begin{aligned}
C N_{N, i, t}+\left(p_{\mathrm{H}}\right)_{t}\left(E_{\mathrm{H}}\right)_{N, i, t} & +\left(I_{C D}\right)_{N, i, t} \\
& =w_{t} L_{N, i, t}+\tau\left(w_{t} L_{R, i, t}+r_{t} S_{R, i, t-1}+\pi_{t}\right) .
\end{aligned}
$$

\footnotetext{
${ }^{19}$ Obviously, equations (7), (8), (13), and (14), describing the income and wealth of both classes of agents, alter respectively.
} 
The direct responses of the income and wealth of both groups of agents are depicted in Figures 10 and 11. Again, we consider the IRFs after an exogenous impact on TFP. Unsurprisingly, taxation of income leads to a decline of Ricardian households' earnings in comparison to the baseline model. However, the positive impulse from the increase in the marginal productivity of capital and labor still results into a boost of income. A $0.86 \%$ increase in TFP leads to an immediate $1.02 \%$ increase in income at $20 \%$ income tax ( $0.95 \%$ when $\tau=0.25)$ while income increases by $1.27 \%$ with government intervention. The redistribution leads to an instantaneous increase of rule-of-thumb agents' budget by $0.71 \%(\tau=0.2)$ and $0.77 \%(\tau=0.25)$ while without taxes, income rises by only $0.46 \%$. As clarified in Section 6.2.1, the rise of income is persistent for rule-of-thumb households due to the positive correlation of productivity and employment.

Figure 10: IRFs of income after taxation

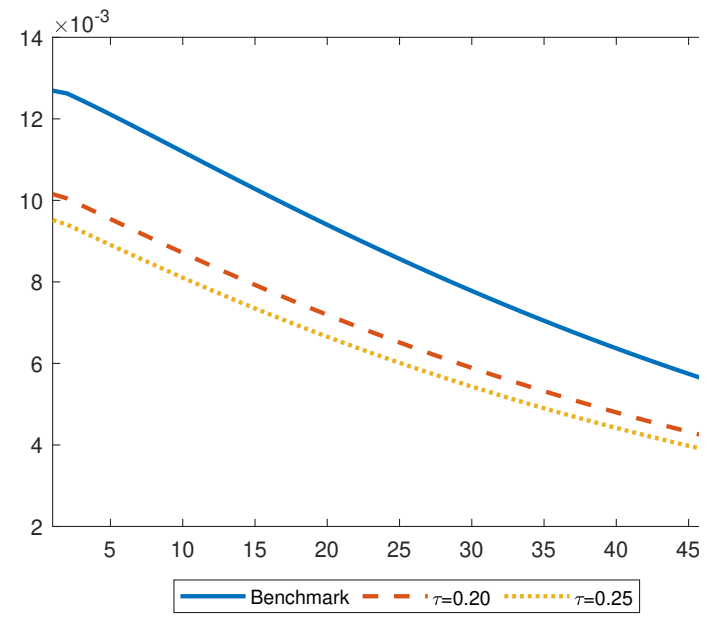

(a) Ricardian agents

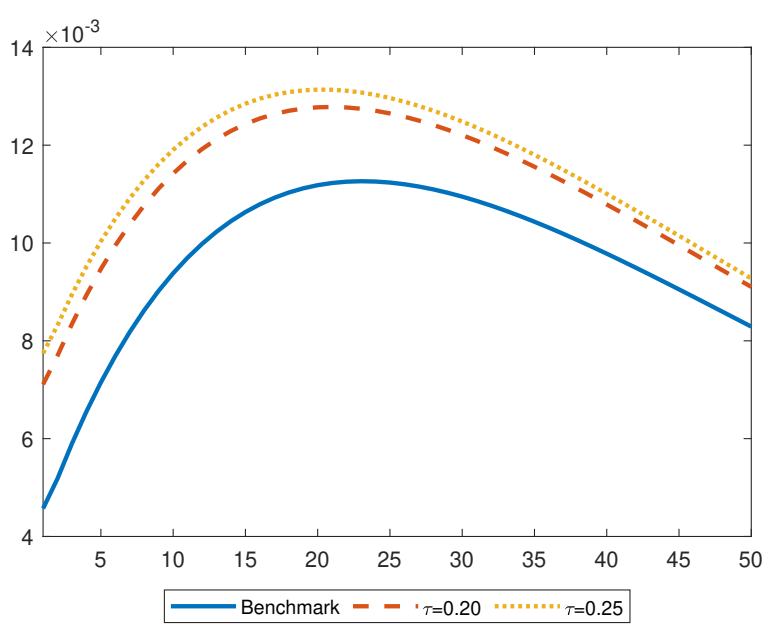

(b) Rule-of-thumb agents

Figure 11: IRFs of wealth after taxation

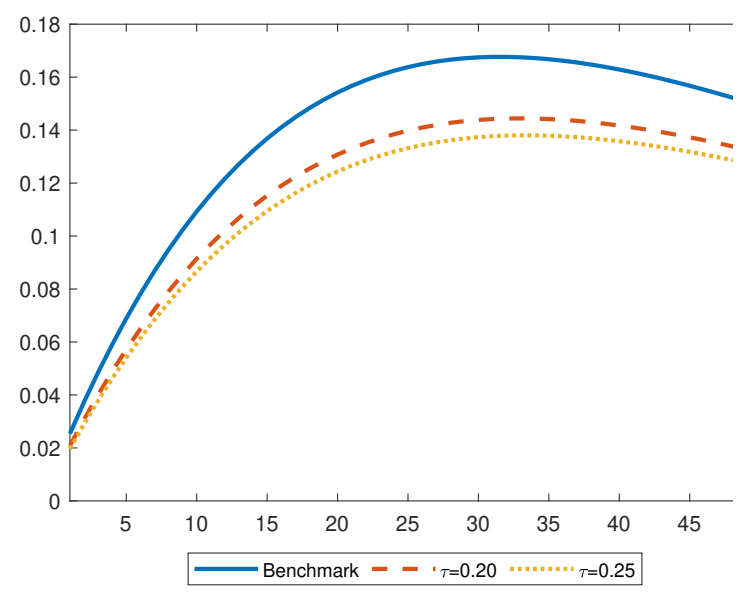

(a) Ricardian agents

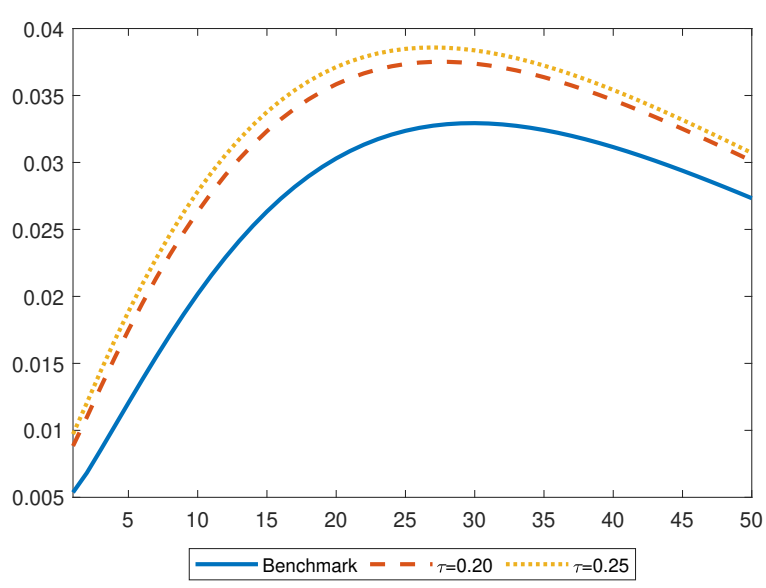

(b) Rule-of-thumb agents 
Table 8: Taxation

\begin{tabular}{|c|c|c|c|c|c|c|c|}
\hline & \multirow[b]{2}{*}{ Gini } & \multicolumn{2}{|c|}{ Income } & \multicolumn{4}{|c|}{ Wealth } \\
\hline & & share bottom $20 \%$ & P90/P10 & $\mathrm{P} 90 / \mathrm{P} 50$ & & Gini & $\Delta$ output \\
\hline baseline & 0.3265 & 0.0535 & 5.9298 & 0.5526 & 1 & 1.9496 & - \\
\hline$\tau=0.20$ & 0.2869 & 0.0636 & 4.5433 & 1.7169 & & 0.5581 & $-0.06 \%$ \\
\hline$\tau=0.25$ & 0.2811 & 0.0644 & 4.3995 & 1.6790 & । & 0.5620 & $-0.08 \%$ \\
\hline
\end{tabular}

Values correspond to the respective equivalent from Table ??.

Similarly, the wealth of Ricardian agents increases over a longer term. The difference between the scenarios with and without taxes are significantly visible in subsequent periods as the retraction of investments results in impacts of wealth only later. At its peak, wealth has reduced from $+16.8 \%$ to $+14.4 \%$ (20\% income tax) and $+13.8 \%$ (25\% income tax) while the increase in the income of rule-of-thumb agents leads more investments in durable goods. As a consequence, wealth increases from $+3.3 \%$ to $+3.8 \%$ (20\% tax) and $+3.9 \%$ ( $25 \%$ tax $)$.

This policy intervention led to redistribution between classes, and not within classes, and was thus aimed at reducing inequality between groups, not within groups. Nevertheless, within inequality is also affected because we consider a linear tax rate. Consequently, each Ricardian agent has to pay the same taxes relative to its income while each ruleof-thumb agent receives the same amount of subsidy. This subsidy is relatively more valuable with respect to its total income for a poor recipient than for richer agent (see Table A.1). Note that we look at average inequality measurements over a longer period. In Table 8, we present the results in accordance to the sensitivity analysis by looking at the same selected inequality parameters as well as at changes in economic performance. According to this, the Gini income index indicates a reduction by 3.96 points in case of a $20 \%$ income tax on Ricardian households (4.54 points for a tax rate of $25 \%$ ).

The income share and both income ratios confirm the developments of lower income inequality. This is not surprising as the redistribution of income is permanent and hence rule-of-thumb households also profit by a positive investment portfolio in assets. As aftertax income decreases for Ricardian households, this also means that durable goods and asset investments declines and hence, personal savings diminish. Figure A.2 depict the corresponding shifts of the Lorenz curve for both income and wealth.

According to Table 8, this goes along with an increase of the Gini wealth index by 0.55 points $(\tau=0.2)$ and 0.94 points $(\tau=0.25)$ stating a light rise in inequality of wealth. Previous literature confirms these findings (i.e. Cagetti \& De Nardi, 2008; Berman et al., 2015). Doing a simulation, Berman et al. (2016) show that a positive average tax rate reduces net income and consequently savings. But simultaneously, the authors find that the saving rate for capital is essential to model wealth inequality. They detect that 
an imperfect correlation between wealth and income leads to the non-trivial effect of a reduction of the relative gap between deciles.

The following modified example by Berman et al. (2016) demonstrates these dynamics: Assuming that Ricardian households' wealth is $W_{R, t+1}=W_{R, t}+s D_{t}+a_{R, t+1} W_{R, t}$ where $W_{R}$ is wealth (capital asset + durables), $s D$ is the share of income that is saved, and $a_{R}$ is the value change rate of wealth (i.e. gains from capital returns). Respectively, ruleof-thumb households' wealth is $W_{N, t}=\omega W_{R, t}$ with $\omega<1$. Opposite to Berman et al. (2016), rule-of-thumb households have a different value change rate of wealth $a_{N}$ which is strictly smaller to the one of Ricardian households $\left(a_{N}<a_{R}\right)$. This is because they are excluded from the asset market, so they cannot gain capital returns. ${ }^{20}$

As a result, the relative wealth is:

$$
\begin{aligned}
\frac{1}{\omega}= & \frac{W_{R, t+1}}{W_{N, t+1}}=\frac{W_{R, t}+s D_{t}+a_{R, t+1} W_{R, t}}{\omega W_{R, t}+s D_{t}+\omega a_{N, t+1} W_{R, t}} \\
& \Leftrightarrow \quad s=\frac{\omega W_{R, t}\left(a_{R, t+1}-a_{N, t+1}\right)}{(1-\omega) D_{t}} \quad \text { with } s<1 .
\end{aligned}
$$

In case of a decrease in the saving rate $s$, we can solve for the relative wealth that increases. Hence, the relative gap between the "rich" (or Ricardian) and the "poor" (or rule-of-thumb) agent becomes wider when personal savings from income are smaller with respect to the remaining terms. In case of an income tax, we can still have an increase in the ratio between individual wealth values despite a shift from the "poor" agents to the "rich" agents, dependent on the difference of $a_{N}$ and $a_{R}$. Of course, this example hold not only for the comparison between classes but also within a class, in particular the Ricardian agent class. However, the tax policy does not redistribute income among agents of the same group. Therefore, a decrease in $s$ always leads to an increase in the wealth ratio when $a_{2}<a_{1}$.

We have seen that the implementation of a constant income tax rate to induce the redistribution of income from the high income group to the low income group indeed has impacts on economic inequality, but with different responses. Inequality in income can be diminished, while inequality in wealth expands, but to a lower extent. As a consequence of this trade-off, it should first be evaluated which of the two outcomes to aim at. In terms of output, the economy is only marginally harmed by $0.06 \%$ ( $20 \%$ tax) or $0.08 \%$ (25\% tax). As reported by Piketty \& Saez (2003), Neckerman \& Torche (2007), and Biewen \& Juhasz (2012), the minor change in wealth inequality is traced back to the fact that since the 1980s, disparate labor income has mainly driven inequality rather than capital gains. But in our model, we assume an equal wage rate for both groups of agents. We leave this investigation for future research.

\footnotetext{
${ }^{20}$ Of course this assumption holds only if the capital returns for Ricardian households are strictly positive.
} 


\section{Conclusion}

In this paper, we have constructed an RBC model with heterogeneous agents with idiosyncratic properties which belong to two sub-classes, namely either Ricardian households or rule-of-thumb households. Agents can consume durable goods, non-durable goods, and energy. Energy, provided endogenously and in unlimited quantity, is needed in order to either gain utility from durable goods, or to be able to produce goods through capital. To handle heterogeneity on the macro level of the model, explicit aggregation as developed by Den Haan \& Rendahl (2010) is applied in order to solve the cross-sectional capital distribution, and hence the aggregate policy function for capital. The model has been calibrated on the basis of data from the German economy. Next to analyzing the model and its aggregated outputs, we have performed a separate simulation to investigate the evolution of individual heterogeneous outputs and their distributions.

We confirm findings from existing literature that TFP is the main driver for output fluctuation even though the presence of energy price shocks and resulting increases have a contractionary effect on output. Moreover, we show that the distinction between nondurable and durable goods leads to a significant improvement in matching most of the moments, with the exception of non-durable goods, because agents receive an additional channel of adjusting their investment decisions. It follows that energy mainly causes disruptions in durable goods investment. Thanks to heterogeneous characteristics of the model, we are able to make predictions of inequality in income that are close to the empirical target while inequality in wealth remains underestimated. This underestimation is mainly attributed to the absence of idiosyncratic productivity differences of agents, but also to the simplification that labor is supplied exogenously. With respect to energy price shocks, inequalities in income and wealth decrease, due to the complementary relationship between durable goods and energy, as well as sunk costs that arise along with adjustments in the durable goods stock. Hence, we conclude that it is not the low-income agent who benefits from volatility in energy prices. Instead, it is the high-income agent who looses in both income and wealth, due to higher absolute sunk costs.

In a brief policy analysis, we have taxed Ricardian agents' incomes with a constant tax rate, with revenues directly redistributed to rule-of-thumb agents, which is a simple possible policy instrument that induces a change in inequality. This has resulted in a reduction of income inequality, with the distribution of wealth becoming more unequal but to a lower extent. Furthermore, only between-inequality is affected because there has been no redistribution within agent classes. Aggregate economic performance in terms of output is only marginally harmed by this form of taxation. Nevertheless, we deduce that it should be evaluated carefully what kind of effect on inequality should be aimed for. Society can be quite sensible to the implementation of policy tools because agents are differently affected given their financial endowments, social standing, or education. 
In future research, it would be worth analyzing the responses in the case that agents can optimize their labor supply, given the simplification of labor supply by agents in this model. In addition to uncertain idiosyncratic shocks, this might decrease the volatility of non-durable goods consumption in order to close the deviation from observational data. Furthermore, endogenizing energy generation such as in Bergmann (2018), while at the same time introducing a separate production of durable goods such as Baxter (1996) and Huynh (2016) can help to improve the description of energy within the economy. Both adaptations can have significant implications on the optimal allocation of labor and capital because agents would have further channels to shift mobile factors. With respect to modeling heterogeneity, robustness can further be verified by increasing the set of moments as done in Preston \& Roca (2007). Additionally, a further subdivision of agents' classes in terms of their access to asset markets, but also a higher degree of differentiation between classes through heterogeneity in preferences, might help to improve the prediction of wealth inequality. 


\section{References}

Aiyagari, S. R. (1994). Uninsured idiosyncratic risk and aggregate saving. The Quarterly Journal of Economics, $109(3), 659-684$.

Algan, Y., Allais, O., \& Den Haan, W. J. (2008). Solving heterogeneous-agent models with parameterized cross-sectional distributions. Journal of Economic Dynamics and Control, 32(3), 875-908.

Algan, Y., Allais, O., \& Den Haan, W. J. (2010). Solving the incomplete markets model with aggregate uncertainty using parameterized cross-sectional distributions. Journal of Economic Dynamics and Control, 34(1), 59-68.

Algan, Y., Allais, O., Den Haan, W. J., \& Rendahl, P. (2014). Solving and simulating models with heterogeneous agents and aggregate uncertainty. In Handbook of computational economics (Vol. 3, pp. 277-324). Elsevier.

Alvarez-Parra, F., Toledo, M., \& Brandao Marques, L. (2012). Business Cycles in Emerging Markets: The Role of Durable Goods and Financial Frictions (Research Department working papers). CAF Development Bank Of Latinamerica. Retrieved from https://EconPapers.repec.org/RePEc:dbl:dblwop: 243

Amato, J. D., \& Laubach, T. (2003). Rule-of-thumb behaviour and monetary policy. European Economic Review, 47(5), 791-831.

Baxter, M. (1996). Are consumer durables important for business cycles? Review of Economics and Statistics, 78(1), 147-155.

Benabou, R. (2000). Unequal societies: Income distribution and the social contract. American Economic Review, 90(1), 96-129.

Bergmann, P. (2018). Durable Goods and Energy in RBC: An Endogenous Multisectoral Model (Bielefeld Working Papers in Economics and Management No. 08-2018 No. 8). Bielefeld University. doi: 10.2139/ssrn.3303759

Berman, Y., Ben-Jacob, E., \& Shapira, Y. (2016). The dynamics of wealth inequality and the effect of income distribution. PloS one, 11(4), e0154196.

Berman, Y., Shapira, Y., \& Ben-Jacob, E. (2015). Modeling the Origin and Possible Control of the Wealth Inequality Surge. PloS one, 10(6), e0130181. doi: 10.1371/ journal.pone.0135548

Bewley, T. (1976). The Permanent Income Hypothesis: A Theoretical Formulation. Journal of Economic Theory, 16(2), 252-292. Retrieved from http://www. 
sciencedirect.com/science/article/pii/0022053177900096 doi: https://doi .org/10.1016/0022-0531(77)90009-6

Biewen, M., \& Juhasz, A. (2012). Understanding rising income inequality in germany, 1999/2000-2005/2006. Review of Income and Wealth, 58(4), 622-647.

Bilbiie, F. O., \& Straub, R. (2013). Asset market participation, monetary policy rules, and the great inflation. Review of Economics and Statistics, 95(2), 377-392.

BP. (2017). BP Statistical Review of World Energy 2017 (Tech. Rep.). London: British Petroleum p.l.c.

Bruno, C., \& Portier, F. (1995). A small open economy RBC model: the French economy case. In Advances in business cycle research (pp. 173-194). Springer.

Cagetti, M., \& De Nardi, M. (2008). Wealth inequality: Data and models. Macroeconomic Dynamics, 12(S2), 285-313. doi: 10.1017/S1365100507070150

Callegari, G. (2007). Fiscal policy and consumption (Unpublished doctoral dissertation). European Univerity Institute.

Campbell, J. Y., \& Mankiw, N. G. (1989). Consumption, income, and interest rates: Reinterpreting the time series evidence [NBER Macroeconomics Annual]. In Nber macroeconomics annual 1989 (Vol. 4, pp. 185-216). MIT Press.

Christiano, L. J., Eichenbaum, M. S., \& Trabandt, M. (2018, Summer). On DSGE models. Journal of Economic Perspectives, 32(3), 113-140. Retrieved from https:// ideas.repec.org/a/aea/jecper/v32y2018i3p113-40.html

Clemens, C. (2006). Status concerns and occupational choice under uncertainty. Advances in Theoretical Economics, 6(1), 1-25.

Coenen, G., McAdam, P., \& Straub, R. (2008). Tax reform and labour-market performance in the euro area: A simulation-based analysis using the new area-wide model. Journal of economic Dynamics and control, 32(8), 2543-2583.

Coenen, G., \& Straub, R. (2005). Does government spending crowd in private consumption? theory and empirical evidence for the euro area. International Finance, 8(3), $435-470$.

Colciago, A. (2011). Rule-of-thumb consumers meet sticky wages. Journal of money, credit and banking, 43(2-3), 325-353.

Cowell, F. A. (1985). Measures of distributional change: An axiomatic approach. The Review of Economic Studies, 52(1), 135-151. 
Den Haan, W. J. (1996). Heterogeneity, aggregate uncertainty, and the short-term interest rate. Journal of Business 86 Economic Statistics, 14 (4), 399-411.

Den Haan, W. J. (1997). Solving dynamic models with aggregate shocks and heterogeneous agents. Macroeconomic dynamics, 1(2), 355-386.

Den Haan, W. J. (2008). Accuracy tests. Dynare Summer School. (Available at: http://www.wouterdenhaan.com/notes.htm)

Den Haan, W. J. (2010). Assessing the accuracy of the aggregate law of motion in models with heterogeneous agents. Journal of Economic Dynamics and Control, 34(1), 79-99.

Den Haan, W. J., \& Marcet, A. (1994). Accuracy in simulations. The Review of Economic Studies, 61(1), 3-17.

Den Haan, W. J., \& Ocaktan, T. S. (2009). Solving Dynamic Models with Heterogeneous Agents and Aggregate Uncertainty with Dynare or Dynare++ [2009 Meeting Papers]. Society for Economic Dynamics, 776. Retrieved from https://ideas.repec.org/p/ red/sed009/776.html

Den Haan, W. J., \& Rendahl, P. (2010). Solving the incomplete markets model with aggregate uncertainty using explicit aggregation. Journal of Economic Dynamics and Control, 34(1), 69-78.

Dhawan, R., \& Jeske, K. (2008). Energy price shocks and the macroeconomy: the role of consumer durables. Journal of Money, Credit and Banking, 40(7), 1357-1377.

Di Bartolomeo, G., Rossi, L., \& Tancioni, M. (2011). Monetary policy, rule-of-thumb consumers and external habits: a G7 comparison. Applied Economics, 43(21), 27212738 .

Fernandez-Villaverde, J., \& Krueger, D. (2011). Consumption and saving over the life cycle: How important are consumer durables? Macroeconomic Dynamics, 15(5), 725770.

Fernández-Villaverde, J., Rubio-Ramírez, J. F., \& Schorfheide, F. (2016). Solution and estimation methods for DSGE models. In Handbook of macroeconomics (Vol. 2, pp. 527-724). Elsevier.

Finn, M. G. (2000). Perfect competition and the effects of energy price increases on economic activity. Journal of Money, Credit and banking, 2000, 400-416.

Flor, M. (2014). Post reunification economic fluctuations in Germany: A real business cycle interpretation. Review of Business and Economics Studies, 2014(4). 
Forni, L., Monteforte, L., \& Sessa, L. (2009). The general equilibrium effects of fiscal policy: Estimates for the euro area. Journal of Public Economics, 93(3-4), 559-585.

Friedman, M. (2018). Theory of the consumption function. Princeton university press.

Gali, J., López-Salido, J. D., \& Vallés, J. (2003, December). Rule-of-thumb consumers and the design of interest rate rules (Working Papers No. 0320). Banco de España. Retrieved from https://ideas.repec.org/p/bde/wpaper/0320.html

Gomme, P., \& Rupert, P. (2007). Theory, measurement and calibration of macroeconomic models. Journal of Monetary Economics, 54(2), 460-497.

Greenwood, J., \& Guner, N. (2008). Marriage and divorce since World War II: Analyzing the role of technological progress on the formation of households. In Nber macroeconomics annual 23 (Vol. 1, pp. 231-276). The University of Chicago Press.

Guvenen, F. (2011, November). Macroeconomics With Heterogeneity: A Practical Guide (NBER Working Papers No. 17622). National Bureau of Economic Research. Retrieved from https://ideas.repec.org/p/nbr/nberwo/17622.html

Hamilton, J. D. (2008). Oil and the Macroeconomy. The new Palgrave dictionary of economics, 2.

Hansen, G. D. (1985). Indivisible labor and the business cycle. Journal of monetary Economics, 16(3), 309-327.

Hayashi, F. (1982). Tobin's marginal q and average q: A neoclassical interpretation. Econometrica, 50(1), 213-224.

Heathcote, J., Storesletten, K., \& Violante, G. L. (2009). Quantitative macroeconomics with heterogeneous households. Annual Review of Economics, 1(1), 319-354.

Hristov, N. (2016). The Ifo DSGE Model for the German Economy (ifo Working Paper Series No. 210). ifo Institute - Leibniz Institute for Economic Research at the University of Munich. Retrieved from https://ideas.repec.org/p/ces/ifowps/_210.html

Hubbard, R. G., Skinner, J., \& Zeldes, S. P. (1995). Precautionary saving and social insurance. Journal of political Economy, 103(2), 360-399.

Huggett, M. (1993). The risk-free rate in heterogeneous-agent incomplete-insurance economies. Journal of economic Dynamics and Control, 17(5-6), 953-969.

Huggett, M., Ventura, G., \& Yaron, A. (2011). Sources of lifetime inequality. American Economic Review, 101 (7), 2923-2954. 
Huynh, B. T. (2016). Macroeconomic effects of energy price shocks on the business cycle. Macroeconomic Dynamics, $20(3), 623-642$.

Imrohoroğlu, A. (1989). Cost of business cycles with indivisibilities and liquidity constraints. Journal of political Economy, 97(6), 1364-1383.

Judd, K. L. (1992). Projection methods for solving aggregate growth models. Journal of Economic Theory, 58(2), 410-452.

Kanbur, S. M. (1979). Impatience, Information and Risk Taking in a General Equilibrium Model of Occupational Choice. Review of Economic Studies, 46(4).

Kemfert, C., \& Welsch, H. (2000). Energy-capital-labor substitution and the economic effects of CO2 abatement: evidence for Germany. Journal of Policy Modeling, 22(6), $641-660$.

Kim, H., Kim, J., \& Kollmann, R. (2005). Applying Perturbation Methods to Incomplete Market Models with Exogenous Borrowing Constraints (Discussion Papers Series No. 0504). Department of Economics, Tufts University. Retrieved from https://ideas. repec.org/p/tuf/tuftec/0504.html

Kim, I.-M., \& Loungani, P. (1992). The role of energy in real business cycle models. Journal of Monetary Economics, 29(2), 173-189.

Krusell, P., \& Smith, A. A., Jr. (1998). Income and wealth heterogeneity in the macroeconomy. Journal of political Economy, 106(5), 867-896.

Kydland, F. E., \& Prescott, E. C. (1982). Time to build and aggregate fluctuations. Econometrica: Journal of the Econometric Society, 50(6), 1345-1370.

Lee, Y., \& Mukoyama, T. (2015). Productivity and employment dynamics of US manufacturing plants. Economics Letters, 136 , 190-193. doi: 10.1016/j.econlet.2015.09.018

Lopez, J. I. (2010). Consumption and labor income risk, aggregation and business cycles (Tech. Rep.). UCLA.

Lucas Jr, R. E. (1978). On the size distribution of business firms. The Bell Journal of Economics, 9(2), 508-523.

Mankiw, N. G. (2000). The savers-spenders theory of fiscal policy. American Economic Review, 90(2), 120-125.

Marto, R. (2014). Assessing the impacts of non-ricardian households in an estimated new keynesian dsge model. Swiss Journal of Economics and Statistics, 150(4), 353-398. 
Maußner, A. (1994). Gegenstand und Entwicklungslinien der Konjunkturtheorie. Springer.

Mayer, E., \& Stähler, N. (2013). The debt brake: business cycle and welfare consequences of Germany's new fiscal policy rule. Empirica, 40(1), 39-74.

Muscatelli, V. A., Tirelli, P., \& Trecroci, C. (2004). Fiscal and monetary policy interactions: Empirical evidence and optimal policy using a structural New-Keynesian model. Journal of Macroeconomics, 26(2), 257-280.

Neckerman, K. M., \& Torche, F. (2007). Inequality: Causes and consequences. Annual Review of Sociology, 33, 335-357. doi: 10.1146/annurev.soc.33.040406.131755

Nordhaus, W. D. (1975). The political business cycle. The review of economic studies, 42(2), 169-190.

OECD. (2019a). Data warehouse. Database. Retrieved from https://www. oecd-ilibrary.org/content/data/data-00900-en doi: https://doi.org/https:// doi.org/10.1787/data-00900-en

OECD. (2019b). Inequality. Database. Retrieved from http://www.oecd.org/social/ inequality.htm\#tax

Ogaki, M., \& Reinhart, C. M. (1998). Measuring intertemporal substitution: The role of durable goods. Journal of political Economy, 106(5), 1078-1098.

Persson, T., \& Tabellini, G. (1994). Is inequality harmful for growth? American Economic Review, 84(3), 600-621.

Piketty, T., \& Saez, E. (2003). Income inequality in the united states, 1913-1998. The Quarterly journal of economics, 118(1), 1-41.

Preston, B., \& Roca, M. (2007, July). Incomplete Markets, Heterogeneity and Macroeconomic Dynamics (Vol. 13260; NBER Working Papers No. 13260). National Bureau of Economic Research. Retrieved from https://ideas.repec.org/p/nbr/nberwo/ 13260.html

Rotemberg, J. J., \& Woodford, M. (1996). Imperfect competition and the effects of energy price increases on economic activity. Journal of Money, Credit and Banking, 28(4), 549-577.

Schmalwasser, O., \& Schidlowski, M. (2006). Measuring capital stock in germany. Wirtschaft und Statistik, 11, 1-15. 
Shimer, R. (2010). Labor markets and business cycles (NBER Working Papers No. 2008-3). National Bureau of Economic Research.

Stähler, N., \& Thomas, C. (2012). FiMod - A DSGE model for fiscal policy simulations. Economic Modelling, 29(2), 239-261.

Storesletten, K., Telmer, C. I., \& Yaron, A. (2004). Cyclical dynamics in idiosyncratic labor market risk. Journal of political Economy, 112(3), 695-717.

The World Bank. (2014). Introduction to poverty analysis. World Bank Group. Retrieved from http://documents.worldbank.org/curated/en/775871468331250546/ Introduction-to-poverty-analysis

The World Bank. (2019). World Development Indicators. Retrieved from https://data. worldbank.org/indicator

Troch, T. (2014). Wealth inequality in dynamic stochastic general equilibrium models (Master thesis). Charles University in Prague. 


\section{A Additional Figures and Tables}

Figure A.1: Model overview.

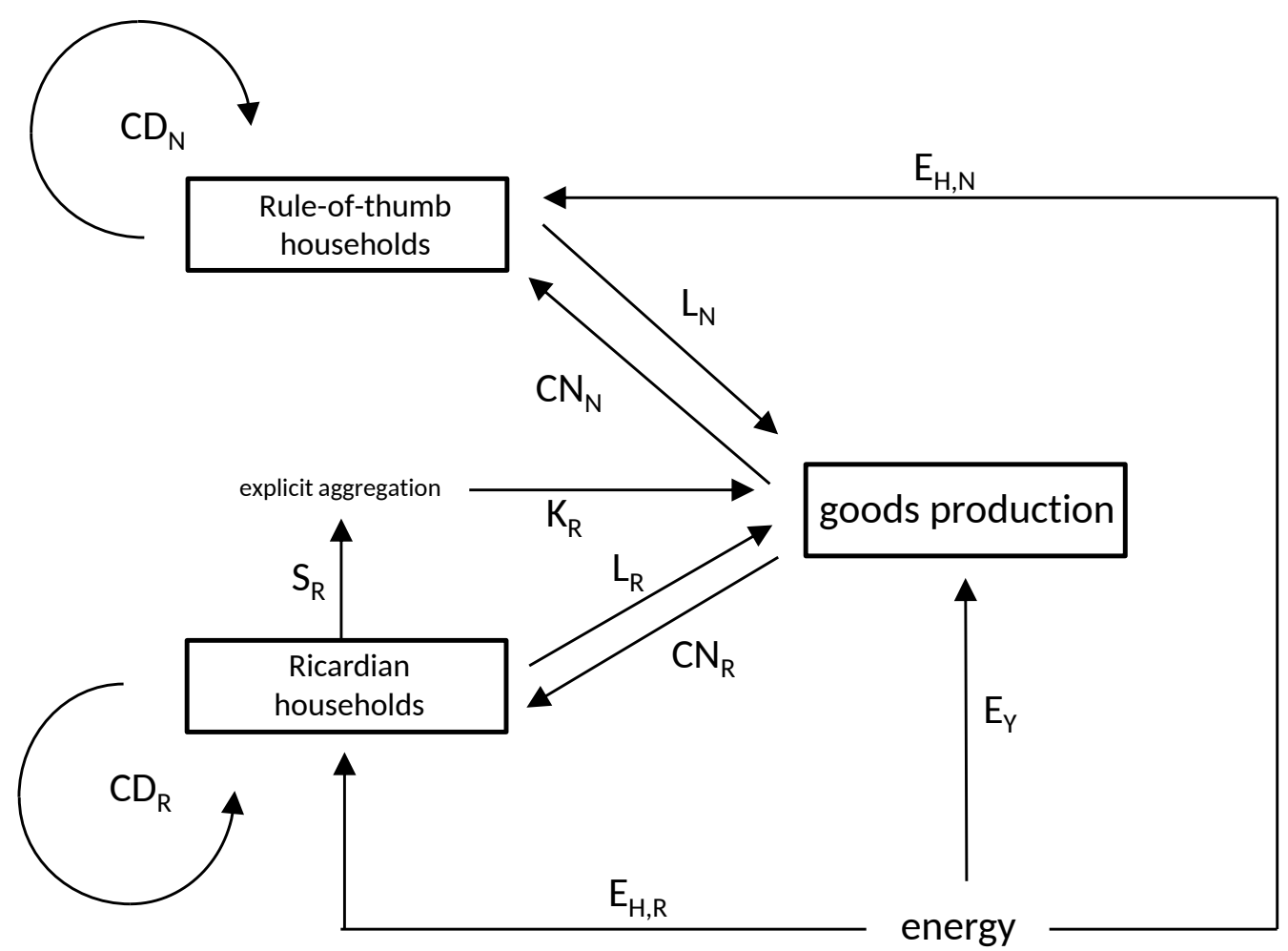

Figure A.2: Comparison of Lorenz curves with taxation

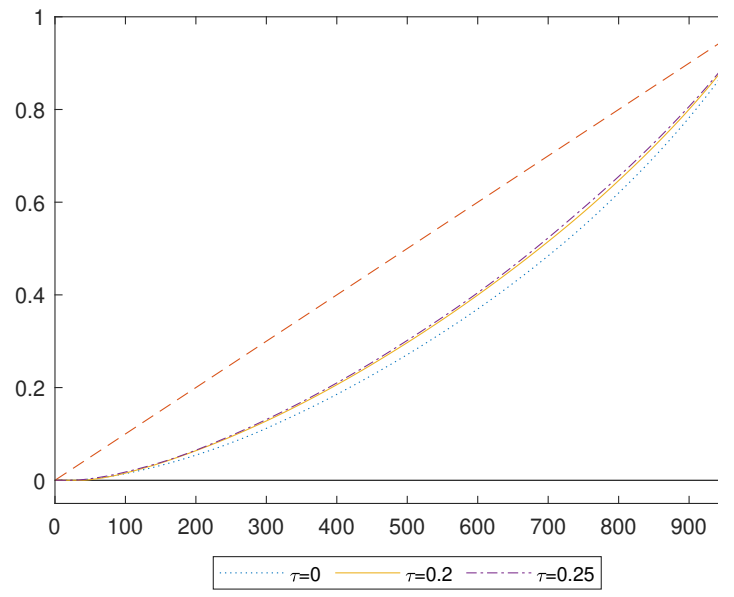

(a) Income

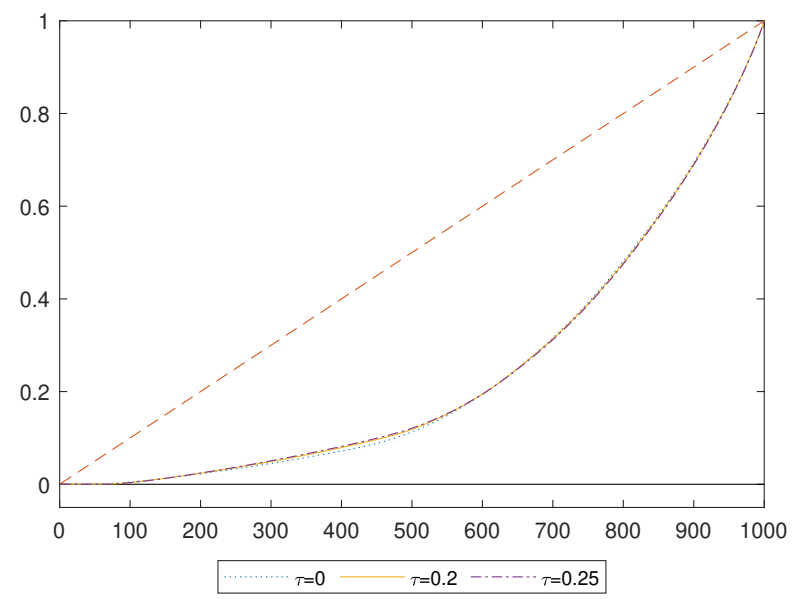

(b) Wealth

The dashed (dotted) curve denotes the $45^{\circ}$-line description line of equity while the remaining curves depict the Lorenz curves described by the legends. 
Table A.1: Decomposition of Theil index with taxation

\begin{tabular}{|c|c|c|c|c|c|}
\hline & \multicolumn{2}{|c|}{ Theil index within } & \multirow{2}{*}{$\begin{array}{l}\text { between group } \\
\text { inequality }\left(T_{B}\right)\end{array}$} & \multirow{2}{*}{$\begin{array}{c}\text { total } \\
\text { Theil }\left(T_{T}\right)\end{array}$} \\
\hline & & $T_{R}^{\mathrm{a}}$ & $T_{N}^{\mathrm{b}}$ & & \\
\hline \multirow{3}{*}{ Income } & $\tau=0$ (baseline model) & 0.1486 & 0.1483 & 0.0300 & 0.1761 \\
\hline & $\tau=0.2$ & 0.1547 & 0.1003 & 0.0028 & 0.1403 \\
\hline & $\tau=0.25$ & 0.1566 & 0.0935 & 0.0004 & 0.1357 \\
\hline \multirow{3}{*}{ Wealth } & no energy price shocks & 0.1542 & 0.1450 & 0.0308 & 0.1827 \\
\hline & baseline model & $0 . \overline{2} 6 \overline{8} \overline{6}$ & $\overline{0} . \overline{0} \overline{4} \overline{0}$ & $0 . \overline{20} \overline{2} 3$ & $0 . \overline{4} \overline{5} \overline{2} 8$ \\
\hline & no energy price shocks & 0.2776 & 0.0430 & 0.2034 & 0.4625 \\
\hline & & \multicolumn{2}{|c|}{ share of } & & total \\
\hline & & $S_{R}^{\mathrm{c}}$ & $S_{N}^{\mathrm{d}}$ & & share \\
\hline \multirow{3}{*}{ Income } & $\tau=0$ & $76.30 \%$ & $23.70 \%$ & - & $100 \%$ \\
\hline & $\tau=0.2$ & $68.48 \%$ & $31.52 \%$ & - & $100 \%$ \\
\hline & $\tau=0.25$ & $66.22 \%$ & $33.78 \%$ & - & $100 \%$ \\
\hline
\end{tabular}

Theil index is calculated according to (41).

a $T_{R}$ is Theil index of Ricardian agent class.

b $T_{N}$ is Theil index of rule-of-thumb agent class.

${ }^{c} S_{R}$ is share of Ricardian agents.

d $S_{N}$ is share index of rule-of-thumb agents.

\section{B Accuracy Checks}

In general, it is difficult to find analytical solutions of stochastic general equilibrium models with rational expectations. Hence, simulations are helpful instruments to solve those models numerically. However, as a downside, simulations can also be inefficient numerical tools as they vanish sampling uncertainty as well as white noise which might arise along with approximation methods. Nevertheless, they are helpful to analyze complex models but need to be checked for accuracy. For instance, in our model, inaccuracies can appear in the process of explicit aggregation to determine the law of motion of aggregate capital as we look at first moments only. But also approximating the policy rules of each individual can contribute to inaccurate results.

A simple accuracy test proposed is the $R^{2}$ along with the standard error by Krusell \& Smith (1998) who estimate the aggregate law of motion of capital with least-square regression. However, Den Haan (2010) has shown that this test is inadequate as it scales the errors which runs the risk of underestimating large errors. Therefore, we will perform two alternative accuracy tests to evaluate the accuracy of our solution method. ${ }^{21}$ We concentrate on the $\chi^{2}$-test by Den Haan \& Marcet (1994) and the Euler equation error test originally based on Judd (1992). ${ }^{22}$

\footnotetext{
${ }^{21}$ See Algan et al. (2014) for a discussion of the weakness of the $R^{2}$ accuracy test and an overview about several alternative accuracy tests.

${ }^{22}$ We refer to Fernández-Villaverde et al. (2016) for a detailed technical discussion of both accuracy tests.
} 
Table B.1: DHM-statistics with different simulation lengths

\begin{tabular}{ccccc}
\hline & $\mathbf{t}=\mathbf{2 0 0}$ & $\mathbf{t}=\mathbf{5 0 0}$ & $\mathbf{t}=\mathbf{1 0 0 0}$ & $\mathbf{t}=\mathbf{1 0 0 0 0}$ \\
\hline DHM-statistics & 0.85769 & 0.26129 & 0.13564 & 1.05466 \\
\hline
\end{tabular}

Values present $\chi^{2}$-distribution with simulation length $\mathrm{t}$.

Lower $5 \%$ critical value of $\chi^{2}$ is 0.0039 , upper $5 \%$ critical values. of $\chi^{2}$ is 3.8415

The DHM test considers the accumulated error residuals of the Euler equation along the simulated path. By theory, the residual that expresses the deviation of the Euler equation should be zero at all points in state space. Hence, it holds that:

$$
\begin{gathered}
f(\cdot) \equiv \mathbb{E}\left\{C N_{R, i, t}^{-1}-\beta C N_{R, i, t+1}^{-1}\left(1+r_{R, i, t+1}-\delta^{Y}\right)+2 \frac{\phi}{\gamma} S_{t}^{-3}\right\} \\
\mathbb{E}\left\{f(\cdot) h\left(x_{t}\right) \mid I_{t}\right\}=0 .
\end{gathered}
$$

where $I_{t}$ is the information set of information available in the period $t$ and $h(\cdot)$ is an arbitrary function. We compute the residual of the model which has been simulated for $T$ periods to obtain an empirical distribution according to:

$$
B_{T}=\frac{1}{T} \sum_{t=1}^{T} f(\cdot) \otimes h\left(x_{t}\right)
$$

which converges to a $\chi^{2}$-distribution. ${ }^{23}$ Subsequently, we check the closeness of this distribution to the $\chi^{2}$ distribution of the true policy function. However, according to Den Haan (2008), the DHM statistic is also limited in its accuracy power. On the one hand, the computational time for this test can be very high depending on the simulation length. On the other hand, this test is sensible to the simulation length as accurate solutions can be rejected more often than $5 \%$ for a high enough time range. Therefore, we compare the results of the DHM test with a different length of simulations. The results are summarized in Table B.1. According to the outcomes, (43) is satisfied for all observed simulation lengths.

Due to the limitations of the DHM statistics, we do a second accuracy test by testing for one-period ahead forecast errors according to Den Haan (2010). It is similar to the definition of the normalized Euler equation error proposed by Judd (1992). To be more specific, we compute the Euler equation errors (EEE) by comparing the numerical approximation with the result of the optimal decision (equation 42) such as:

$$
\operatorname{EEE}\left(S_{t}\right)=1-\frac{u_{C N, t}^{\prime}\left(\left(\beta \mathbb{E}\left\{u_{C N, t+1}^{\prime}\left(1+r_{t+1}\right)\right\}-\delta_{Y}\right)+2 \frac{\phi}{\gamma} S_{t}^{-3}\right)}{\hat{c}_{t}}
$$

\footnotetext{
${ }^{23}$ Note that if $T \rightarrow \infty$ than $B_{T} \rightarrow 0$.
} 
where $\hat{c_{t}}$ is the optimal decision under assumed calibration and $S_{t}$ denotes the set of states. In other words, we check the degree of irrationality of an agent to use the approximation rule. To do so we compute the Euler equation error at many points in the state space defined by Gauss-Hermite nodes in the numerical integration. Den Haan \& Ocaktan (2009) note that increasing the number of nodes has only negligible effects, hence we limit its amount to 10 for each state variable. The bounds of the grid defining the 8-D state space are obtained by the simulation to get reasonable values. The test statistics shows that agents make an average $1.233 \%$ error in their decision about consumption with a maximum of $3.263 \%$. These values are higher than in standard homogeneous DSGE models. However, this is not surprising with respect to the higher amount of state variables as well as more shocks which increase the degree of uncertainty. In sum, the model seems to be an effective framework to consider incomplete markets, heterogeneous agents, and different consumption goods.

\section{Mathematical Appendix}

\section{C.1 Optimization}

Under the assumption that prices for final energy are equal for households and final goods-producing firms $p_{\mathrm{E}}=p_{\mathrm{H}}=p_{\mathrm{Y}}$, the households' problems of Ricardian and rule-ofthumb agents, the decision making of firms, and the corresponding first order conditions with respect to the decision variables are:

\section{Household sector (Ricardian agents)}

$$
\begin{aligned}
\mathcal{L}_{R, i}^{H}= & \mathbb{E}_{0} \sum_{t=0}^{\infty} \beta^{t}\left\{\log \left[C N_{R, i, t}^{\gamma}\left(\theta C D_{R, i, t-1}^{\zeta}+(1-\theta)\left(E_{\mathrm{H}}\right)_{R, i, t}^{\zeta}\right)^{\frac{1-\gamma}{\zeta}}\right]-\phi \frac{1}{\left(S_{R, i, t}+b\right)^{2}}\right. \\
+ & \lambda_{R, i, t}^{H}\left[w_{t} L_{R, i, t}+r_{t} S_{R, i, t-1}+\pi_{t}-C N_{R, i, t}-\left(p_{\mathrm{E}}\right)_{t}\left(E_{\mathrm{H}}\right)_{R, i, t}\right. \\
& -C D_{R, i, t}+\left(1-\delta^{C D}\right) C D_{R, i, t-1}-\frac{\omega_{1 c d}}{1+\omega_{2 c d}}\left(\frac{C D_{R, i, t}-C D_{R, i, t-1}}{C D_{R, i, t-1}}\right)^{1+\omega_{2 c d}} \\
& \left.\left.-S_{R, i, t}+\left(1-\delta^{Y}\right) S_{R, i, t-1}\right]\right\}
\end{aligned}
$$

- Non-durable goods:

$$
\begin{gathered}
\frac{\partial \mathcal{L}_{R, i}^{H}}{\partial C N_{R, i, t}}=\beta^{t} \vartheta \gamma \frac{C N_{R, i, t}^{\gamma-1}\left(\theta C D_{R, i, t-1}^{\zeta}+(1-\theta)\left(E_{\mathrm{H}}\right)_{R, i, t}^{\zeta}\right)^{\frac{1-\gamma}{\zeta}}}{C N_{R, i, t}^{\gamma}\left(\theta C D_{R, i, t-1}^{\zeta}+(1-\theta)\left(E_{\mathrm{H}}\right)_{R, i, t}^{\zeta}\right)^{\frac{1-\gamma}{\zeta}}}-\beta^{t} \vartheta \gamma \frac{1}{C N_{R, i, t}}-\beta^{t} \lambda_{R, i, t}^{H} \stackrel{!}{=} 0 \\
\Leftrightarrow \quad \vartheta \gamma \frac{1}{C N_{R, i, t}}-\lambda_{R, i, t}^{H} \stackrel{!}{=} 0 \Leftrightarrow \quad \Leftrightarrow \quad \lambda_{R, i, t}^{H}=\vartheta \gamma \frac{1}{C N_{R, i, t}}
\end{gathered}
$$


- Durable goods:

$$
\begin{aligned}
& \frac{\partial \mathcal{L}_{R, i}^{H}}{\partial C D_{R, i, t}}=\beta^{t+1} \mathbb{E}\left\{\frac{\vartheta(1-\gamma) \zeta \theta}{\zeta} \frac{C N_{R, i, t+1}^{\gamma}\left(\theta C D_{R, i, t}^{\zeta}+(1-\theta)\left(E_{\mathrm{H}}\right)_{t+1}^{\zeta}\right)^{\frac{1-\gamma}{\zeta}} C D_{R, i, t}^{\zeta-1}}{C N_{R, i, t+1}^{\gamma}\left(\theta C D_{R, i, t}^{\zeta}+(1-\theta)\left(E_{\mathrm{H}}\right)_{t+1}^{\zeta}\right)^{\frac{1-\gamma}{\zeta}}}\right\} \\
& +\beta^{t+1} \mathbb{E}\left\{\lambda_{R, i, t+1}^{H}\left[1-\delta^{\mathrm{CD}}+\omega_{1 c d} \frac{C D_{R, i, t+1}}{C D_{R, i, t}^{2}}\left(\frac{C D_{R, i, t+1}-C D_{R, i, t}}{C D_{R, i, t}}\right)^{\omega_{2 c d}}\right]\right\} \\
& -\beta^{t} \lambda_{R, i, t}^{H}\left[1+\frac{\omega_{1 c d}}{C D_{R, i, t-1}}\left(\frac{C D_{R, i, t}-C D_{R, i, t-1}}{C D_{R, i, t-1}}\right)^{\omega_{2 c d}}\right] \stackrel{!}{=} 0 \\
& \Leftrightarrow \quad \lambda_{R, i, t}^{H}\left[1+\frac{\omega_{1 c d}}{C D_{R, i, t-1}}\left(\frac{C D_{R, i, t}-C D_{R, i, t-1}}{C D_{R, i, t-1}}\right)^{\omega_{2 c d}}\right] \\
& =\beta \vartheta \theta(1-\gamma) \mathbb{E}\left\{\frac{C D_{R, i, t}^{\zeta-1}}{\theta C D_{R, i, t}^{\zeta}+(1-\theta)\left(E_{\mathrm{H}}\right)_{t+1}^{\zeta}}\right\} \\
& +\beta \mathbb{E}\left\{\lambda_{R, i, t+1}^{H}\left[1-\delta^{\mathrm{CD}}+\omega_{1 c d} \frac{C D_{R, i, t+1}}{C D_{R, i, t}^{2}}\left(\frac{C D_{R, i, t+1}-C D_{R, i, t}}{C D_{R, i, t}}\right)^{\omega_{2 c d}}\right]\right\}
\end{aligned}
$$

- Energy consumption of households:

$$
\begin{gathered}
\frac{\partial \mathcal{L}_{R, i}^{H}}{\partial\left(E_{\mathrm{H}}\right)_{R, i, t}}=\beta^{t} \vartheta(1-\gamma) \frac{C N_{R, i, t}^{\gamma}\left(\theta C D_{R, i, t-1}^{\zeta}+(1-\theta)\left(E_{\mathrm{H}}\right)_{R, i, t}^{\zeta}\right)^{\frac{1-\gamma}{\zeta}}}{C N_{R, i, t}^{\gamma}\left(\theta C D_{R, i, t-1}^{\zeta}+(1-\theta)\left(E_{\mathrm{H}}\right)_{R, i, t}^{\zeta}\right)^{\frac{1-\gamma}{\zeta}}}(1-\theta)\left(E_{\mathrm{H}}\right)_{t-1}^{\zeta-1}-\beta^{t} \lambda_{R, i, t}^{H}\left(p_{\mathrm{E}}\right)_{t} \\
=\beta^{t} \vartheta(1-\gamma)(1-\theta) \frac{(1-\theta)\left(E_{\mathrm{H}}\right)_{R, i, t}^{\zeta-1}}{\theta C D_{R, i, t-1}^{\zeta}+(1-\theta)\left(E_{\mathrm{H}}\right)_{R, i, t}^{\zeta}-\beta^{t} \lambda_{R, i, t}^{H}\left(p_{\mathrm{E}}\right)_{t} \stackrel{!}{=} 0} \\
\Leftrightarrow \quad \lambda_{R, i, t}^{H}\left(p_{\mathrm{E}}\right)_{t}=\vartheta(1-\gamma)(1-\theta) \frac{(1-\theta)\left(E_{\mathrm{H}}\right)_{R, i, t}^{\zeta-1}}{\theta C D_{R, i, t-1}^{\zeta}+(1-\theta)\left(E_{\mathrm{H}}\right)_{R, i, t}^{\zeta}}
\end{gathered}
$$

- Euler equations for asset stock:

$$
\frac{\partial \mathcal{L}_{R, i}^{H}}{\partial S_{R, i, t}}=\beta^{t+1} \mathbb{E}\left\{\lambda_{R, i, t+1}^{H}\left(1+r_{t+1}-\delta^{Y}\right)\right\}-\beta^{t} \lambda_{R, i, t}^{H}+\beta^{t} \frac{\phi}{\gamma} \frac{2}{\left(S_{R, i, t}+b\right)^{3}} \stackrel{!}{=} 0
$$




\section{Household sector (Rule-of-thumb agents)}

$$
\begin{aligned}
\mathcal{L}_{N, i}^{H}= & \mathbb{E}_{0} \sum_{t=0}^{\infty} \beta^{t}\left\{\log \left[C N_{N, i, t}^{\gamma}\left(\theta C D_{N, i, t-1}^{\zeta}+(1-\theta)\left(E_{\mathrm{H}}\right)_{N, i, t}^{\zeta}\right)^{\frac{1-\gamma}{\zeta}}\right]\right. \\
& +\lambda_{N, i, t}^{H}\left[w_{t} L_{N, i, t}-C N_{N, i, t}-\left(p_{\mathrm{E}}\right)_{t}\left(E_{\mathrm{H}}\right)_{N, i, t}\right. \\
& \left.\left.-C D_{N, i, t}+\left(1-\delta^{C D}\right) C D_{N, i, t-1}-\frac{\omega_{1 c d}}{1+\omega_{2 c d}}\left(\frac{C D_{N, i, t}-C D_{N, i, t-1}}{C D_{N, i, t-1}}\right)^{1+\omega_{2 c d}}\right]\right\}
\end{aligned}
$$

- Non-durable goods:

$$
\begin{gathered}
\frac{\partial \mathcal{L}_{N, i}^{H}}{\partial C N_{N, i, t}}=\beta^{t} \vartheta \gamma \frac{C N_{N, i, t}^{\gamma-1}\left(\theta C D_{N, i, t-1}^{\zeta}+(1-\theta)\left(E_{\mathrm{H}}\right)_{N, i, t}^{\zeta}\right)^{\frac{1-\gamma}{\zeta}}}{C N_{N, i, t}^{\gamma}\left(\theta C D_{N, i, t-1}^{\zeta}+(1-\theta)\left(E_{\mathrm{H}}\right)_{N, i, t}^{\zeta}\right)^{\frac{1-\gamma}{\zeta}}}-\beta^{t} \vartheta \gamma \frac{1}{C N_{N, i, t}}-\beta^{t} \lambda_{N, i, t}^{H} \stackrel{!}{=} 0 \\
\Leftrightarrow \quad \vartheta \gamma \frac{1}{C N_{N, i, t}}-\lambda_{N, i, t}^{H} \stackrel{!}{=} 0 \quad \Leftrightarrow \quad \lambda_{N, i, t}^{H}=\vartheta \gamma \frac{1}{C N_{N, i, t}}
\end{gathered}
$$

- Durable goods:

$$
\begin{gathered}
\frac{\partial \mathcal{L}_{N, i}^{H}}{\partial C D_{N, i, t}}=\beta^{t+1} \mathbb{E}\left\{\frac{\vartheta(1-\gamma) \zeta \theta}{\zeta} \frac{C N_{N, i, t+1}^{\gamma}\left(\theta C D_{N, i, t}^{\zeta}+(1-\theta)\left(E_{\mathrm{H}}\right)_{t+1}^{\zeta}\right)^{\frac{1-\gamma}{\zeta}} C D_{N, i, t}^{\zeta-1}}{\left.C N_{N, i, t+1}^{\gamma}\left(\theta C D_{N, i, t}^{\zeta}+(1-\theta)\left(E_{\mathrm{H}}\right)_{t+1}^{\zeta}\right)^{\frac{1-\gamma}{\zeta}}\right\}}\right. \\
+\beta^{t+1} \mathbb{E}\left\{\lambda_{N, i, t+1}^{H}\left[1-\delta^{\mathrm{CD}}+\omega_{1 c d} \frac{C D_{N, i, t+1}}{C D_{N, i, t}^{2}}\left(\frac{C D_{N, i, t+1}-C D_{N, i, t}}{C D_{N, i, t}}\right)^{\omega_{2 c d}}\right]\right\} \\
\quad-\beta^{t} \lambda_{N, i, t}^{H}\left[1+\frac{\omega_{1 c d}}{C D_{N, i, t-1}}\left(\frac{C D_{N, i, t}-C D_{N, i, t-1}}{C D_{N, i, t-1}}\right)^{\omega_{2 c d}}\right] \stackrel{!}{=} 0 \\
\Leftrightarrow \quad \lambda_{N, i, t}^{H}\left[1+\frac{\omega_{1 c d}}{C D_{N, i, t-1}}\left(\frac{C D_{N, i, t}-C D_{N, i, t-1}}{C D_{N, i, t-1}}\right)^{\omega_{2 c d}}\right] \\
\quad=\beta \vartheta \theta(1-\gamma) \mathbb{E}\left\{\frac{C D_{N, i, t}^{\zeta-1}}{\theta C D_{N, i, t}^{\zeta}+(1-\theta)\left(E_{\mathrm{H}}\right)_{t+1}^{\zeta}}\right\} \\
+\beta \mathbb{E}\left\{\lambda_{N, i, t+1}^{H}\left[1-\delta^{\mathrm{CD}}+\omega_{1 c d} \frac{C D_{N, i, t+1}}{C D_{N, i, t}^{2}}\left(\frac{C D_{N, i, t+1}-C D_{N, i, t}}{C D_{N, i, t}}\right)^{\omega_{2 c d}}\right]\right\}
\end{gathered}
$$


- Energy consumption of households:

$$
\begin{gathered}
\frac{\partial \mathcal{L}_{N, i}^{H}}{\partial\left(E_{\mathrm{H}}\right)_{N, i, t}}=\beta^{t} \vartheta(1-\gamma) \frac{C N_{N, i, t}^{\gamma}\left(\theta C D_{N, i, t-1}^{\zeta}+(1-\theta)\left(E_{\mathrm{H}}\right)_{N, i, t}^{\zeta}\right)^{\frac{1-\gamma}{\zeta}}}{C N_{N, i, t}^{\gamma}\left(\theta C D_{N, i, t-1}^{\zeta}+(1-\theta)\left(E_{\mathrm{H}}\right)_{N, i, t}^{\zeta}\right)^{\frac{1-\gamma}{\zeta}}}(1-\theta)\left(E_{\mathrm{H}}\right)_{t-1}^{\zeta-1}-\beta^{t} \lambda_{N, i, t}^{H}\left(p_{\mathrm{E}}\right)_{t} \\
=\beta^{t} \vartheta(1-\gamma)(1-\theta) \frac{(1-\theta)\left(E_{\mathrm{H}}\right)_{N, i, t}^{\zeta-1}}{\theta C D_{N, i, t-1}^{\zeta}+(1-\theta)\left(E_{\mathrm{H}}\right)_{N, i, t}^{\zeta}}-\beta^{t} \lambda_{N, i, t}^{H}\left(p_{\mathrm{E}}\right)_{t} \stackrel{!}{=} 0 \\
\Leftrightarrow \quad \lambda_{N, i, t}^{H}\left(p_{\mathrm{E}}\right)_{t}=\vartheta(1-\gamma)(1-\theta) \frac{(1-\theta)\left(E_{\mathrm{H}}\right)_{N, i, t}^{\zeta-1}}{\theta C D_{N, i, t-1}^{\zeta}+(1-\theta)\left(E_{\mathrm{H}}\right)_{N, i, t}^{\zeta}}
\end{gathered}
$$

\section{Goods production sector}

$$
\pi_{0}=\mathbb{E}_{0} \sum_{t=0}^{\infty} \beta^{t}\left\{A_{t}\left[\eta K_{t-1}^{\nu}+(1-\eta)\left(E_{\mathrm{Y}}\right)_{t}^{\nu}\right]^{\frac{\alpha}{\nu}} L_{t}^{1-\alpha}-r_{t} K_{t-1}-w_{t} L_{t}-\left(p_{\mathrm{E}}\right)_{t}\left(E_{\mathrm{Y}}\right)_{t}\right\}
$$

- Capital demand:

$$
\frac{\partial \pi_{0}}{\partial K_{t-1}}=A_{t} \alpha \eta\left[\eta K_{t-1}^{\nu}+(1-\eta)\left(E_{\mathrm{Y}}\right)_{t}^{\nu}\right]^{\frac{\alpha}{\nu}-1} L_{t}^{1-\alpha} K_{t-1}^{\nu-1}-r_{t} \stackrel{!}{=} 0
$$

- Energy consumption of final goods production:

$$
\frac{\partial \pi_{0}}{\partial\left(E_{\mathrm{Y}}\right)_{t}}=A_{t} \alpha \eta\left[\eta K_{t-1}^{\nu}+(1-\eta)\left(E_{\mathrm{Y}}\right)_{t}^{\nu}\right]^{\frac{\alpha}{\nu}-1} L_{t}^{1-\alpha}\left(E_{\mathrm{Y}}\right)_{t}^{\nu-1}-\left(p_{\mathrm{E}}\right)_{t} \stackrel{!}{=} 0
$$

- Labor demand:

$$
\frac{\partial \pi_{0}}{\partial L_{t}}=A_{t}(1-\alpha)\left[\eta K_{t-1}^{\nu}+(1-\eta)\left(E_{\mathrm{Y}}\right)_{t}^{\nu}\right]^{\frac{\alpha}{\nu}} L_{t}^{-\alpha}-w_{t} \stackrel{!}{=} 0
$$

By rearranging the conditions above, the optimized decisions as well as the market clearing equations are calculated which define the complete model (19 equations).

\section{Household sector (Ricardian agents)}

- Durable Euler equation: combining (47) and (48)

$$
\begin{aligned}
& 1+\frac{\omega_{1 c d}}{C D_{R, i, t-1}}\left(\frac{C D_{R, i, t}-C D_{R, i, t-1}}{C D_{R, i, t-1}}\right)^{\omega_{2 c d}}=\beta \mathbb{E}\left\{\theta \frac{(1-\gamma)}{\gamma} \frac{C N_{R, i, t} C D_{R, i, t}^{\zeta-1}}{\theta C D_{R, i, t}^{\zeta}+(1-\theta)\left(E_{\mathrm{H}}\right)_{R, i, t+1}^{\zeta}}\right\} \\
& +\beta \mathbb{E}\left\{\frac{C N_{R, i, t}}{C N_{R, i, t+1}}\left[1-\delta^{\mathrm{CD}}+\omega_{1 c d} \frac{C D_{R, i, t+1}}{C D_{R, i, t}^{2}}\left(\frac{C D_{R, i, t+1}-C D_{R, i, t}}{C D_{R, i, t}}\right)^{\omega_{2 c d}}\right]\right\}
\end{aligned}
$$


- Non-durables vs. energy: combining (48) and (49)

$$
\begin{aligned}
& \beta^{t} \vartheta \gamma \frac{\left(p_{\mathrm{E}}\right)_{t}}{C N_{R, i, t}}=\beta^{t} \vartheta(1-\gamma)(1-\theta) \frac{\left(E_{\mathrm{H}}\right)_{R, i, t}^{\zeta-1}}{\theta C D_{R, i, t-1}^{\zeta}+(1-\theta)\left(E_{\mathrm{H}}\right)_{R, i, t}^{\zeta}} \\
& \Leftrightarrow \quad\left(p_{\mathrm{E}}\right)_{t}=\frac{(1-\gamma)(1-\theta)}{\gamma} \frac{C N_{R, i, t}\left(E_{\mathrm{H}}\right)_{R, i, t}^{\zeta-1}}{\left(\theta C D_{R, i, t-1}^{\zeta}+(1-\theta)\left(E_{\mathrm{H}}\right)_{R, i, t}^{\zeta}\right)}
\end{aligned}
$$

- Labor supply: Ricardian agents

$$
L_{R, i, t}=\left(1-\rho_{L}\right) \bar{L}_{R}+\rho_{L} L_{R, i, t-1}+\varepsilon_{L, R, i, t}
$$

- Euler equation of capital in final production: combining (47) and (50)

$$
\begin{aligned}
\beta^{t} \vartheta \gamma \frac{1}{C N_{R, i, t}} & =\beta^{t+1} \mathbb{E}\left\{\vartheta \gamma \frac{1}{C N_{R, i, t+1}}\left(1+r_{t+1}-\delta^{Y}\right)\right\}+\beta^{t} \frac{\phi}{\gamma} \frac{2}{\left(S_{R, i, t}+b\right)^{3}} \\
\Leftrightarrow \quad \frac{1}{C N_{R, i, t}} & =\beta \mathbb{E}\left\{\frac{1}{C N_{R, i, t+1}}\left(1+r_{t+1}-\delta^{Y}\right)\right\}+\frac{\phi}{\gamma} \frac{2}{\left(S_{R, i, t}+b\right)^{3}}
\end{aligned}
$$

\section{Household sector (Rule-of-thumb agents)}

- Durable Euler equation: combining (52) and (53)

$$
\begin{aligned}
& 1+\frac{\omega_{1 c d}}{C D_{N, i, t-1}}\left(\frac{C D_{N, i, t}-C D_{N, i, t-1}}{C D_{N, i, t-1}}\right)^{\omega_{2 c d}}=\beta \mathbb{E}\left\{\theta \frac{(1-\gamma)}{\gamma} \frac{C N_{N, i, t} C D_{N, i, t}^{\zeta-1}}{\theta C D_{N, i, t}^{\zeta}+(1-\theta)\left(E_{\mathrm{H}}\right)_{N, i, t+1}^{\zeta}}\right\} \\
& +\beta \mathbb{E}\left\{\frac{C N_{N, i, t}}{C N_{N, i, t+1}}\left[1-\delta^{\mathrm{CD}}+\omega_{1 c d} \frac{C D_{N, i, t+1}}{C D_{N, i, t}^{2}}\left(\frac{C D_{N, i, t+1}-C D_{N, i, t}}{C D_{N, i, t}}\right)^{\omega_{2 c d}}\right]\right\}
\end{aligned}
$$

- Non-durables vs. energy: combining (53) and (54)

$$
\begin{aligned}
& \beta^{t} \vartheta \gamma \frac{\left(p_{\mathrm{E}}\right)_{t}}{C N_{N, i, t}}=\beta^{t} \vartheta(1-\gamma)(1-\theta) \frac{\left(E_{\mathrm{H}}\right)_{N, i, t}^{\zeta-1}}{\theta C D_{N, i, t-1}^{\zeta}+(1-\theta)\left(E_{\mathrm{H}}\right)_{N, i, t}^{\zeta}} \\
& \Leftrightarrow \quad\left(p_{\mathrm{E}}\right)_{t}=\frac{(1-\gamma)(1-\theta)}{\gamma} \frac{C N_{N, i, t}\left(E_{\mathrm{H}}\right)_{N, i, t}^{\zeta-1}}{\left(\theta C D_{N, i, t-1}^{\zeta}+(1-\theta)\left(E_{\mathrm{H}}\right)_{N, i, t}^{\zeta}\right)}
\end{aligned}
$$

- Labor supply: rule-of-thumb agents

$$
L_{N, i, t}=\left(1-\rho_{L}\right) \bar{L}_{N}+\rho_{L} L_{N, i, t-1}+\rho_{L, A}\left(A_{t}^{Y}-\bar{A}^{Y}\right)+\varepsilon_{L, N, i, t}
$$




\section{Goods production sector}

- Final goods production output (= non-durable goods)

$$
Y_{t}=A_{t}\left[\eta K_{t-1}^{\nu}+(1-\eta)\left(E_{\mathrm{Y}}\right)_{t}^{\nu}\right]^{\frac{\alpha}{\nu}} L_{t}^{1-\alpha}
$$

- Capital demand of final goods production: rearranging (56)

$$
r_{t}=A_{t} \alpha \eta\left[\eta K_{t-1}^{\nu}+(1-\eta)\left(E_{\mathrm{Y}}\right)_{t}^{\nu}\right]^{\frac{\alpha}{\nu}-1} L_{t}^{1-\alpha} K_{t-1}^{\nu-1}
$$

- Energy demand of final goods production: rearranging (57)

$$
\left(p_{\mathrm{E}}\right)_{t}=A_{t} \alpha \eta\left[\eta K_{t-1}^{\nu}+(1-\eta)\left(E_{\mathrm{Y}}\right)_{t}^{\nu}\right]^{\frac{\alpha}{\nu}-1} L_{t}^{1-\alpha}\left(E_{\mathrm{Y}}\right)_{t}^{\nu-1}
$$

- Labor demand of final goods production: rearranging (58)

$$
w_{t}=A_{t}(1-\alpha)\left[\eta K_{t-1}^{\nu}+(1-\eta)\left(E_{\mathrm{Y}}\right)_{t}^{\nu}\right]^{\frac{\alpha}{\nu}} L_{t}^{-\alpha}
$$

\section{Market Clearing}

- Aggregate market constraint:

$$
Y_{t}-\left(p_{\mathrm{E}}\right)_{t}\left(E_{\mathrm{Y}}\right)_{t}=C N_{t}+\left(p_{\mathrm{E}}\right)_{t}\left(E_{\mathrm{H}}\right)_{t}+C D_{t}-\left(1-\delta^{C D}\right) C D_{t-1}+K_{t}-\left(1-\delta^{Y}\right) K_{t-1}
$$

- Aggregate non-durable goods:

$$
C N_{t}=\int_{0}^{\lambda} C N_{R, i, t}+\int_{\lambda}^{1} C N_{N, i, t}
$$

- Aggregate durable goods:

$$
C D_{t}=\int_{0}^{\lambda} C D_{R, i, t}+\int_{\lambda}^{1} C D_{N, i, t} .
$$

- Aggregate capital market:

$$
K_{t}=\int_{0}^{\lambda} S_{R, i, t}
$$

- Aggregate labor market:

$$
L_{t}=\int_{0}^{\lambda} L_{R, i, t}+\int_{\lambda}^{1} L_{N, i, t}
$$


with (61) and (65), the law of large numbers hold for $\vee t: \int_{0}^{\lambda} \varepsilon_{L, R, i, t} d i \simeq \int_{\lambda}^{1} \varepsilon_{L, N, i, t} d i \simeq 0$

$$
\begin{aligned}
L_{t} & =\int_{0}^{\lambda} \frac{\left(1-\rho_{L}\right) \bar{L}_{N}}{1-\rho_{L}}+\int_{\lambda}^{1}\left(\frac{\left(1-\rho_{L}\right) \bar{L}_{N}}{1-\rho_{L}}+\frac{\rho_{L, A}\left(A_{t}^{Y}-\bar{A}^{Y}\right)}{\left(1-\rho_{L}\right)}\right) \\
& =\lambda \bar{L}+(1-\lambda)\left(\bar{L}+\frac{\rho_{L, A}\left(A_{t}^{Y}-\bar{A}^{Y}\right)}{\left(1-\rho_{L}\right)}\right) \\
& =\bar{L}+\frac{(1-\lambda)}{\left(1-\rho_{L}\right)} \rho_{L, A}\left(A_{t}^{Y}-\bar{A}^{Y}\right)
\end{aligned}
$$

- Aggregate energy market:

$$
E_{t}=\int_{0}^{\lambda}\left(E_{\mathrm{H}}\right)_{R, i, t}+\int_{\lambda}^{1}\left(E_{\mathrm{H}}\right)_{N, i, t}+\left(E_{\mathrm{Y}}\right)_{t}
$$

\section{Formation of shocks}

- Productivity shock in final goods production:

$$
\ln A_{t}=\rho_{\mathrm{A}} \ln A_{t-1}+\varepsilon_{\mathrm{A}, t}
$$

- Productivity shock in final energy generation:

$$
\ln \left(p_{\mathrm{E}}\right)_{t}=\rho_{\mathrm{P}} \ln \left(p_{\mathrm{E}}\right)_{t-1}+\varepsilon_{\mathrm{P}, t}
$$

\section{C.2 Steady states}

In the following, we can construct the steady state conditions from the model.

\section{Household sector}

- Durable Euler equation (59) and (63) (same for both types of agents):

$$
1=\beta \theta \frac{(1-\gamma)}{\gamma} \frac{C N C D^{\zeta-1}}{\theta C D^{\zeta}+(1-\theta)\left(E_{\mathrm{H}}\right)^{\zeta}}+\beta\left(1-\delta^{C D}\right)
$$

- Non-durables vs. energy (60) and (64) (same for both types of agents):

$$
p_{\mathrm{E}}=\frac{(1-\gamma)(1-\theta)}{\gamma} \frac{C N\left(E_{\mathrm{H}}\right)^{\zeta-1}}{\left(\theta C D^{\zeta}+(1-\theta)\left(E_{\mathrm{H}}\right)^{\zeta}\right)}
$$

- Labor supply (75)

$$
L_{t}=\bar{L}+\frac{(1-\lambda)}{\left(1-\rho_{L}\right)} \rho_{L, A}\left(A_{t}-\bar{A}\right)
$$


- Euler equation for capital of final production (62)

$$
1=\beta\left(1+r-\delta^{Y}\right)+\frac{\phi}{\gamma} \frac{2}{(S+b)^{3}} C N
$$

consequently

$$
r=\frac{1}{\beta}-1+\delta^{Y}-\frac{\phi}{\beta \gamma} \frac{2}{(S+b)^{3}} C N
$$

\section{Goods production sector}

- Final goods production output (= non-durable goods) (66)

$$
Y=A\left[\eta K^{\nu}+(1-\eta)\left(E_{\mathrm{Y}}\right)^{\nu}\right]^{\frac{\alpha}{\nu}} L^{1-\alpha}
$$

- Capital demand of final goods production (67)

$$
r=A \alpha \eta\left[\eta K^{\nu}+(1-\eta)\left(E_{\mathrm{Y}}\right)^{\nu}\right]^{\frac{\alpha}{\nu}-1} L^{1-\alpha} K^{\nu-1}
$$

- Energy demand of final goods production (68)

$$
p_{\mathrm{E}}=A \alpha \eta\left[\eta K^{\nu}+(1-\eta)\left(E_{\mathrm{Y}}\right)^{\nu}\right]^{\frac{\alpha}{\nu}-1} L^{1-\alpha}\left(E_{\mathrm{Y}}\right)^{\nu-1}
$$

- Labor demand of final goods production (69)

$$
w=(1-\alpha) \frac{Y}{L}
$$

\section{Market Clearing}

- Aggregate market constraint (70)

$$
Y-p_{\mathrm{E}} E_{\mathrm{Y}}=C N+p_{\mathrm{E}} E_{\mathrm{H}}+\delta^{C D} C D+\delta^{Y} K
$$

- Aggregate non-durable goods market (71)

$$
C N=\lambda C N_{R}+(1-\lambda) C N_{N}
$$

- Aggregate durable goods market (72)

$$
C D=\lambda C D_{R}+(1-\lambda) C D_{N}
$$


- Aggregate asset market (73)

$$
K=\lambda S_{R}
$$

- Aggregate energy market (76)

$$
E=\lambda E_{\mathrm{H}}+(1-\lambda) E_{\mathrm{H}}+\left(E_{\mathrm{Y}}\right)
$$

\section{C.3 Log-linearized equations}

In contrast to Chapter 3, we feed Dynare with the numerical steady state values of all endogenous variables derived in Section C.2, which makes the calculation of log-linearized equations obsolete.

\section{C.4 Calibration}

The calibration of parameters is carried out analogously to Bergmann (2018), except for the parameter $\delta_{Y}$.

Given $r$ and, we can rearrange (62.SS) to get:

$$
\delta_{Y}=1+r-\frac{1}{\beta}+\frac{\phi}{\beta \gamma} \frac{2}{(S+b)^{3}} C N
$$

